\title{
New records of Agromyzidae (Diptera) from Portugal, with an updated checklist
}

\author{
Miloš Černý, Rui Andrade, Ana Rita Gonçalves \& Michael von Tschirnhaus
}

\begin{abstract}
New records of Agromyzidae (Diptera) from Portugal, with an updated checklist. - Acta Mus. Siles. Sci. Natur., 67: 7-57, 2018.

Abstract: New records of 110 species of the acalyptrate Diptera family Agromyzidae are given from Portugal, including Madeira, Porto Santo and the Azores. A quarantine plant pest, Nemorimyza maculosa (Malloch, 1913), was detected in the Old World for the first time. Details on Phytobia xylemminers and a parthenogenetic Phytomyza species are recorded together with new distribution data. For certain species morphological and taxonomic notes and discussions on known or new host plants are added. A complete checklist of Agromyzidae of Portugal is presented.
\end{abstract}

Key words: Diptera, Agromyzidae, new records, new host plants, distribution, biology, parthenogenesis, quarantine species, checklist, Argentina, Azores, Canary Islands, Chile, Italy, Madeira, Portuguese mainland, Sahara, Turkey.

\section{Introduction}

The Agromyzidae belong to families of Diptera Acalyptratae hitherto insufficiently studied on the Iberian Peninsula and Balearic Islands. The first concrete records on leaf miner flies from Portugal were published by Tavares (1901) including the description of the new species Agromyza kiefferi Tavares, 1901 from the locality "Castello Branco ate a Covilhan". The first records on the fauna of Agromyzidae from Madeira are by Buhr (1908). Our knowledge of the Agromyzidae of the Portuguese mainland has in the past firstly been based on brief articles by Buhr (1941), Godinho et al. (1994), Griffiths (1967), Hendel (1931-36, 1957), Nowakowski (1973), Spencer (1954, 1965a, b, 1990, 1992). Phytomyza smyrnii Spencer, 1954 was described from the continental territory of Portugal but only based on one female. Records of Agromyzidae from the Azores and Madeira have been summarised by Frey $(1945,1949)$. Also from the Azores are described two new species, namely Cerodontha bistrigata Frey, 1945 from localities on Terceira (Angra do Heró́smo, Bagacina), São Jorge (Ribeira do Salto), Pico (Silveira, Lagoa do Caiado), Faial (Caldeira), Corvo (Caldeirão) and Liriomyza subartemisicola Frey, 1945 from localities on São Miguel, Terceira, São Jorge, Pico, Faial, and Flores. The latter one was synonymized by Spencer (1965b) with L. umbilici Hering, 1927 known from the Canary Islands. These works have been used by Martinez \& Báez (2002), who record 46 species for Portugal (namely 16 for the Portuguese mainland, 19 for the Azores and 24 for Madeira) in the „Catálogo de los Diptera de España, Portugal y Andorra“. Subsequently Bella (2013), Černý (2005, 2009, 2013), Cerný \& Merz (2006), Gil-Ortiz et al. 2011 and Zlobin (2003, 2005) updated the number of species of the agromyzid fauna of Portugal.

This study is mainly aimed at the presentation of new data on the species of the family Agromyzidae based on material acquired between the years 2009 and 2017 in which fieldwork in various parts of continental Portugal mainland and on Madeira has been done. Some older data were taken from the Michael von Tschirnhaus Insect Collection diaries and re-identified by him if necessary. 


\section{Material and methods}

The majority of the material examined from the continental territory of Portugal was collected by Rui Andrade and Ana Rita Gonçalves during their study in 2009-2017 (512 specimens). Material examined from the Azores and Madeira (1164 specimens) were determined by M. von Tschirnhaus and belong to his collection. As far as not otherwise noted above, material examined was identified by the first author and specimens are deposited in the private collection of the first author.

Macrophotographs of living adults were taken by digital cameras Fujifilm FinePix S5500 and Fujifilm FinePix HS10 HS11 both with macro lens Raynox DCR-250 (R. Andrade). Also habitats of some species in their Portuguese localities were documented by photography during the fieldwork. Specimens were mostly collected by sweeping over vegetation in various habitats. When necessary male terminalia were studied after detachment, softening and mazerating the terminalia in hot $10 \% \mathrm{KOH}$, washing in water and dissecting the whole abdomen in a droplet of glycerine under a binocular microscope MBS 10-100 (M. Černý). After examination all dissected parts were placed into a droplet of the medium ,glycerin plus gum resin“ on a card which was pinned below the relevant specimen. M. von Tschirnhaus fundamentally used the same method but with washing in $10 \%$ acetic acid and transferring the genitalia into glycerin in open micro-craters on $9 \mathrm{~mm} \times 36 \mathrm{~mm}$ glass slides, those stored in small vials (von Tschirnhaus 1981: 27).

The material examined is deposited in the following collections: CMBP - collection of Miroslav Barták, Praha, Czech Republic; CMCH - collection of Miloš Černý, Halenkovice, Czech Republic; CMTB - collection of Michael von Tschirnhaus, Bielefeld, Germany, later to be stored in the „Zoologische Staatssammlung München“.

Genera and species are arranged alphabetically in the two subfamilies Agromyzinae and Phytomyzinae. The distribution of species in Europe is well documented in the database Fauna Europaea which is available online (Martinez 2011). Therefore records which are not listed in that database are accompanied by citing the papers in which they were published.

\section{Localities}

[1a] Azores, Island São Miguel: From João Bom, path in SSE direction to crater edge of "Caldeira das Sete Cidades", also path along crater edge, way down to Remédios, $37^{\circ} 53^{\prime} \mathrm{N}, 25^{\circ} 46^{\prime}$ to $25^{\circ} 47^{\prime} \mathrm{W}$, M. von Tschirnhaus leg. et det. (CMTB).

[1b] Azores, Island São Miguel: João Bom, private vegetable and flower garden, M. von Tschirnhaus leg. et det. (CMTB).

[1c] Azores, Island São Miguel: Village João Bom at western end of island, repeatedly swept on young leaves of Arundo donax, M. von Tschirnhaus leg. et det. (CMTB).

[1d] Azores, Island São Miguel: Lagoa Verde, crater lake in Caldeira das Sete Cidades, M. von Tschirnhaus leg. et det. (CMTB).

[1e] Azores, Island São Miguel: Atlantic coast north of Mosteiros, 2549'N, 3754'W, M. von Tschirnhaus leg. et det. (CMTB).

[1f] Azores, Island São Miguel: $25^{\circ} 49^{\prime} \mathrm{N}, 37^{\circ} 54^{\prime} \mathrm{W}$, western lower mountain slope of Pico dos Gatos, M. von Tschirnhaus leg. et det. (CMTB).

[1g] Azores, Island São Miguel: Miradouro de Santa Iria above steep coast, E Ribeira Grande, $3 \mathrm{~km}$ ESE

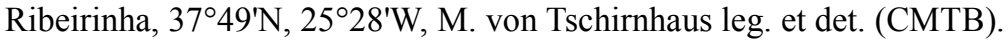

[1h] Azores, Island São Miguel: Lagoa do Carvão (W of crater lake), 3749'N, $25^{\circ} 45^{\prime} \mathrm{W}$, M. von Tschirnhaus leg. et det. (CMTB).

[1i] Azores, Island São Miguel: Near road $1.5 \mathrm{~km} \mathrm{~W}$ Covoada, $37^{\circ} 47^{\prime} \mathrm{N}, 25^{\circ} 45^{\prime} \mathrm{W}$, M. von Tschirnhaus leg. et det. (CMTB).

[1j] Azores, Island São Miguel: Lagoa do Canário, SE Caldeira das Sete Cidades, $37^{\circ} 50^{\prime} \mathrm{N}, 25^{\circ} 46^{\prime} \mathrm{W}$, M. von Tschirnhaus leg. et det. (CMTB).

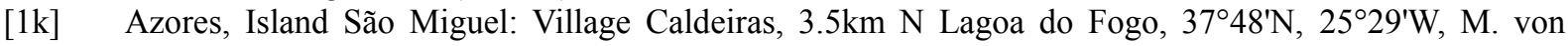
Tschirnhaus leg. et det. (CMTB).

$25^{\circ} 29^{\prime} \mathrm{W}$, pasture at lake bank, between hot springs and church, M. von Tschirnhaus leg. et det. (CMTB).

[11] Azores, Island São Miguel: „Lombadas“ locality above waterfall, $45^{\circ} 38^{\prime} 30^{\prime \prime} \mathrm{N}, 25^{\circ} 28^{\prime} \mathrm{W}$, M. von Tschirnhaus leg. et det. (CMTB).

[1m] Azores, Island São Miguel: Mountain road and irrigation channel at $37^{\circ} 47^{\prime} \mathrm{N}, 25^{\circ} 29^{\prime} \mathrm{W}$, M. von Tschirnhaus leg. et det. (CMTB).

[1n] Azores, Island São Miguel: Western part of Island São Miguel, country lane between Pico de Mafra and João Bom, $37^{\circ} 53^{\prime} \mathrm{N}, 25^{\circ} 48^{\prime} \mathrm{W}$, path between cattle pastures, M. von Tschirnhaus leg. et det. (CMTB).

[1o] Azores, Island São Miguel: Village João Bom at western end of island, cattle pasture, swept on flowering Coleostephus myconis (Asteraceae), M. von Tschirnhaus leg. et det. (CMTB). 
[1p] Azores, Island São Miguel: $37^{\circ} 43^{\prime} \mathrm{N}, 25^{\circ} 28^{\prime} \mathrm{W}$, southern coast, beach $3 \mathrm{~km}$ W Vila Franca do Campo, M. von Tschirnhaus leg. et det. (CMTB).

[1r] Azores, Island São Miguel: Ponta Delgada, city park and botanical garden „Jardim António Borges“, M. von Tschirnhaus leg. et det. (CMTB).

[1s] Azores, Island São Miguel: $37^{\circ} 52^{\prime} \mathrm{N}, 25^{\circ} 51^{\prime} \mathrm{W}$, most western point of the island, black lava above breakwater coast at base of Pico das Camarinhas, swept on tussocks of Festuca petraea, M. von Tschirnhaus leg. et det. (CMTB).

[1t] Azores: Island São Miguel: N' Pico das Camarinhas, $37^{\circ} 52^{\prime} \mathrm{N}, 25^{\circ} 51^{\prime} \mathrm{W}$, cattle pastures, forest edge, M. von Tschirnhaus leg. et det. (CMTB).

[2a] Madeira: Caniço, 32 $2^{\circ} 39^{\prime} \mathrm{N}, 16^{\circ} 50^{\prime} \mathrm{W}, \mathrm{M}$. Lehnert leg., M. von Tschirnhaus det. (CMTB).

[2b] Madeira: Camacha, 32 40'50"N, 1651'00"W, M. Lehnert leg., M. von Tschirnhaus det. (CMTB).

[2c] Madeira: Coastal road W of Seixal, P. Ohm leg., M. von Tschirnhaus det. (CMTB).

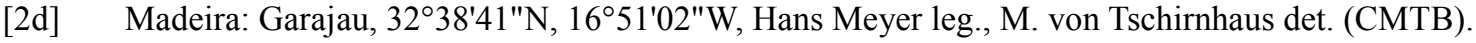

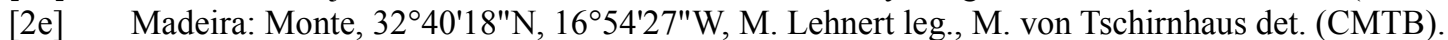

[2f] Madeira: Paul da Serra, Campo Grande near „Cristo Rei“, 5.5km N Canhas, 1350m a.s.1., edge of aqueduct, W. Barkemeyer leg., M. von Tschirnhaus det. (CMTB).

[2g] Madeira: $1 \mathrm{~km}$ SW Poiso, 6.5km N Funchal, 1350m a.s.l., conifer forest, W. Barkemeyer leg., M. von Tschirnhaus det. (CMTB).

[2h] Madeira: Porto da Cruz, salt marshes, G. Weigmann leg., M. von Tschirnhaus det. (CMTB).

[2i] Madeira: Rabaçal, meadow, G. Weigmann leg., M. von Tschirnhaus det. (CMTB).

[2j] Madeira: Ribeiro Frio, 850m a.s.1., about 10km N Funchal, Lauraceae forest, W. Barkemeyer leg., M. von Tschirnhaus det. (CMTB).

[2k] Madeira: Ribeiro Frio, aqueduct Levada do Furado, 32 44'06"N, 1653'10"W, 895m a.s.1., W. Barkemeyer leg., M. von Tschirnhaus det. (CMTB).

[21] Madeira: Santana, meadow along a steep, G. Weigmann leg., M. von Tschirnhaus det. (CMTB).

[2m] Madeira: São Vicente, meadow above shore, G. Weigmann leg., M. von Tschirnhaus det. (CMTB).

[2n] Madeira: forest 2.5km WNW Santo da Serra, 800m a.s.1., aqueduct „Levada da Serra - Lamaceiros“, W. Barkemeyer leg., M. von Tschirnhaus det. (CMTB).

[2o] Madeira: Trail between Boca da Encumeada and Boca dos Corgos, south of Ribeiro de Poço, close to a spring, 1000m a.s.1., W. Barkemeyer leg., M. von Tschirnhaus det. (CMTB).

[2p] Madeira: Trail between Boca da Encumeada and Boca dos Corgos, $1 \mathrm{~km}$ W Fenda do Ferreiro, 1200$1250 \mathrm{~m}$ a.s.1., W. Barkemeyer leg., M. von Tschirnhaus det. (CMTB).

[2r] Madeira: Calheta Beach, 32 $43^{\prime} \mathrm{N}, 17^{\circ} 10^{\prime} \mathrm{W}, \mathrm{V}$. Vrabec leg., M. Černý det. (CMBP, CMCH).

[3] Madeira: Island of Porto Santo: 50km NE Madeira, 3304'55"N, $16^{\circ} 20^{\prime} 45^{\prime \prime} \mathrm{W}, 0.5 \mathrm{~km}$ SW Camacha, dry stream bed, W. Barkemeyer leg., M. von Tschirnhaus det. (CMTB).

[4] Algarve, Faro, dry grassland, close to Puccinellia saltmarshes, sweeping vegetation, G. Weigmann leg., M. von Tschirnhaus det. (CMTB).

[5a] Aveiro, Estarreja, Canelas e Fermelã, 4043'22.7"N, 8³4'20.6"W, 4m a.s.l., sweeping vegetation, R. Andrade leg., M. Černý det. (CMCH). (Fig. 17)

[5b] Aveiro, Estarreja, Canelas e Fermelã, 4042'49.6"N, 8³5'09.3"W, $1 \mathrm{~m}$ a.s.l., sweeping vegetation, R. Andrade leg., M. Černý det. (CMCH).

[5c] Aveiro, Estarreja, Salreu, 4044'04.4"N, 8³4'51.9"W, 5m a.s.1., sweeping vegetation, R. Andrade leg., M. Černý det. (CMCH).

[6a] Beja, Barrancos, Barrancos (Noudar), 3809'46.8"N, $7^{\circ} 03^{\prime} 08.7^{\prime \prime} \mathrm{W}, 165 \mathrm{~m}$ a.s.l., sweeping vegetation, R. Andrade leg., M. Černý det. (CMCH).

[6b] Beja, Moura, Safara e Santo Aleixo da Restauração, 3804'40.1"N, 7014'21.3"W, 207m a.s.1., sweeping vegetation, R. Andrade leg., M. Černý det. (CMCH).

[6c] Beja, Moura, Sobral da Adiça, 3802'34.7"N, 7¹5'52.7"W, 173m a.s.1., sweeping vegetation, R. Andrade leg., M. Černý det. (CMCH).

[6d] Beja, Odemira, Longueira/Almograve (Parque Natural do Sudoeste Alentejano e Costa Vicentina), 3743'33"N, 846'08"W, 3m a.s.1., estuary Rio Mira, sweeping vegetation, M. Barták leg., M. Černý det. (CMBP).

[6e] Beja, Ourique, Garvão e Santa Luzia, 3743'50.3"N, 8²5'27.2"W, 200m a.s.1., sweeping vegetation, R. Andrade leg., M. Černý det. (CMCH).

[6f] Beja, Serpa, Serpa (Salvador e Santa Maria), 3758'46.5"N, 7³8'53.4"W, 73m a.s.1., sweeping vegetation, R. Andrade leg., M. Černý det. (CMCH).

[6g] Beja, Serpa, Vila Verde de Ficalho, 3757'46.5"N, $7^{\circ} 17^{\prime} 58.5^{\prime \prime} \mathrm{W}, 280 \mathrm{~m}$ a.s.l., sweeping vegetation, R. Andrade leg., M. Černý det. (CMCH).

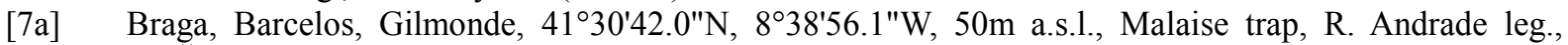
M. Černý det. (CMCH). 


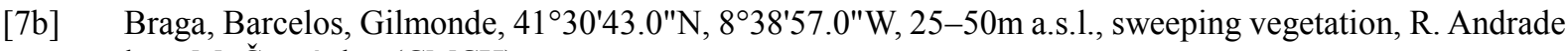
leg., M. Černý det. (CMCH).

[7c] Braga, Celorico de Basto, Veade, Gagos e Molares, $41^{\circ} 25^{\prime} 07.5^{\prime \prime} \mathrm{N}, 7^{\circ} 58^{\prime} 54.0^{\prime \prime} \mathrm{W}, 175 \mathrm{~m}$ a.s.1., sweeping vegetation, R. Andrade leg., M. Černý det. $(\mathrm{CMCH})$.

[7d] Braga, Esposende, Apúlia e Fão (Parque Natural do Litoral Norte), 41²8'16.4"N, $8^{\circ} 46^{\prime} 27.2^{\prime \prime W}, 2 \mathrm{~m}$ a.s.l., sweeping vegetation, R. Andrade leg., M. Černý det. (CMCH). (Fig. 16)

[7e] Braga, Esposende, Fonte Boa e Rio Tinto (Marachão), 41 ${ }^{\circ} 30^{\prime} 16.9^{\prime \prime} \mathrm{N}, 8^{\circ} 43^{\prime} 10.6^{\prime \prime} \mathrm{W}, 23 \mathrm{~m}$ a.s.1., sweeping vegetation, R. Andrade leg., M. Černý det. $(\mathrm{CMCH})$.

[7f] Braga, Fafe, Travassós, 4130'06.4"N, $8^{\circ} 10^{\prime} 55.6^{\prime \prime W}, 386 \mathrm{~m}$ a.s.l., sweeping vegetation, R. Andrade leg, M. Černý det. (CMCH).

[7g] Braga, Terras de Bouro, Campo do Gerês (Parque Nacional da Peneda-Gerês), 41 ${ }^{\circ} 48^{\prime} 28.5^{\prime \prime} \mathrm{N}$, $8^{\circ} 07^{\prime} 55.5^{\prime \prime W}, 500-800 \mathrm{~m}$ a.s.l., sweeping vegetation, R. Andrade leg., M. Černý det. (CMCH).

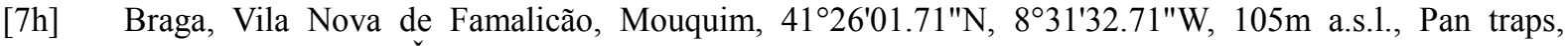
R. Andrade leg., M. Černý det. (CMCH).

[7i] Braga, Vila Nova de Famalicão, Novais, $41^{\circ} 23^{\prime} 26.34 " \mathrm{~N}, 8^{\circ} 26^{\prime} 06.06^{\prime \prime} \mathrm{W}, 150 \mathrm{~m}$ a.s.l., sweeping vegetation, R. Andrade leg., M. Černý det. (CMCH).

[8a] Bragança, Bragança, Castrelos e Carrazedo, 41 ${ }^{\circ} 45^{\prime} 56.9^{\prime \prime} \mathrm{N}, 6^{\circ} 54^{\prime} 43.5^{\prime \prime} \mathrm{W}$, 980m a.s.l., sweeping vegetation, R. Andrade leg., M. Černý det. $(\mathrm{CMCH})$.

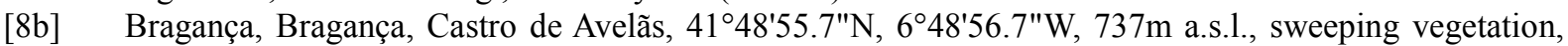
R. Andrade leg., M. Černý det. (CMCH).

[8c] Bragança, Bragança, Espinhosela (Parque Natural de Montesinho), 41 ${ }^{\circ} 53^{\prime} 08.2^{\prime \prime N}, 6^{\circ} 49^{\prime} 37.4^{\prime \prime} \mathrm{W}, 793 \mathrm{~m}$ a.s.l., sweeping vegetation, R. Andrade \& A. Gonçalves leg., M. Černý det. (CMCH). (Fig. 20)

[8d] Bragança, Bragança, França (Parque Natural de Montesinho), 41 ${ }^{\circ} 56^{\prime} 33.0^{\prime \prime} \mathrm{N}, 6^{\circ} 45^{\prime} 51.0^{\prime \prime} \mathrm{W}, 1049 \mathrm{~m}$ a.s.1., sweeping vegetation, R. Andrade leg., M. Černý det. $(\mathrm{CMCH})$.

[8e] Bragança, Bragança, Gondesende (Parque Natural de Montesinho), 41 ${ }^{\circ} 50^{\prime} 47.1^{\prime \prime} \mathrm{N}, 6^{\circ} 52^{\prime} 45.9^{\prime \prime} \mathrm{W}, 635 \mathrm{~m}$ a.s.l., sweeping vegetation, R. Andrade leg., M. Černý det. (CMCH).

[8f] Bragança, Bragança, Parâmio (Parque Natural de Montesinho), 41 ${ }^{\circ} 53^{\prime} 54.0^{\prime \prime N}, 6^{\circ} 51^{\prime} 16.3^{\prime \prime} \mathrm{W}, 780 \mathrm{~m}$ a.s.1., sweeping vegetation, R. Andrade leg., M. Černý det. (CMCH).

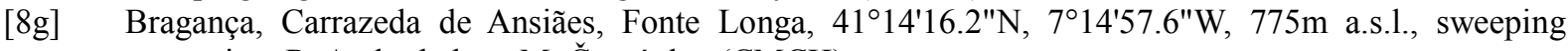
vegetation, R. Andrade leg., M. Černý det. (CMCH).

[8h] Bragança, Miranda do Douro, Vila Chã de Braciosa (Parque Natural do Douro Internacional), $41^{\circ} 25^{\prime} 29.8^{\prime \prime} \mathrm{N}, 6^{\circ} 18^{\prime} 29.4^{\prime \prime} \mathrm{W}, 602 \mathrm{~m}$ a.s.l., sweeping vegetation, R. Andrade leg., M. Černý det. (CMCH).

[8i] Bragança, Vimioso, Algoso, Campo de Víboras e Uva, 4127'17.6"N, 6³5'35.2"W, 340m a.s.l., sweeping vegetation, R. Andrade leg., M. Černý det. $(\mathrm{CMCH})$.

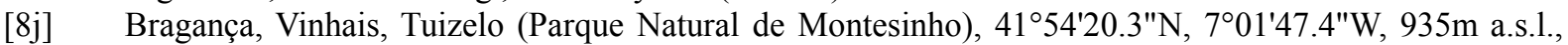
sweeping vegetation, R. Andrade leg., M. Černý det. (CMCH).

[8k] Bragança, Vinhais, Quirás e Pinheiro Novo (Parque Natural de Montesinho), 4157'29.7"N, $7^{\circ} 09^{\prime 2} 29.9^{\prime \prime} \mathrm{W}$, $588 \mathrm{~m}$ a.s.l., sweeping vegetation, R. Andrade leg., M. Černý det. (CMCH).

[9a] Castelo Branco, Castelo Branco, Monforte da Beira (Monte Barata, Parque Natural do Tejo Internacional), $39^{\circ} 42^{\prime} 33.5^{\prime \prime} \mathrm{N}, 7^{\circ} 18^{\prime} 59.3^{\prime \prime} \mathrm{W}, 250 \mathrm{~m}$ a.s.l., sweeping vegetation, A. Gonçalves leg., M. Černý det. (CMCH). (Fig. 19)

[9b] Castelo Branco, Covilhã, Cortes do Meio (Parque Natural da Serra da Estrela), 40 $18^{\prime} 38.83^{\prime \prime N}$, 7³4'35.14"W, 1645m a.s.l., sweeping vegetation, A. Gonçalves leg., M. Černý det. (CMCH).

[9c] Castelo Branco, Vila Velha de Ródão, Vila Velha de Ródão, 39³8'51.3"N, 7²40'41.6"W, 110m a.s.1., sweeping vegetation, R. Andrade leg., M. Černý det. (CMCH).

[10] Coimbra, Coimbra, Taveiro, Ameal e Arzila (Reserva Natural do Paul de Arzila), $40^{\circ} 10^{\prime} 45.0^{\prime \prime} \mathrm{N}$, 8³3'18.7"W, 25 m a.s.l, sweeping vegetation, A. Gonçalves leg., M. Černý det. (CMCH).

[11] Évora, Évora, São Manços e São Vicente do Pigeiro, 38²7'32.0"N, $7^{\circ} 40^{\prime} 44.9^{\prime \prime W}, 170 \mathrm{~m}$ a.s.l., sweeping vegetation, R. Andrade \& A. Gonçalves leg., M. Černý det. (CMCH).

[12a] Faro, Loulé, Querença, Tôr e Benafim (Paisagem Protegida Local da Fonte Benémola), 37²12'29.2"N,

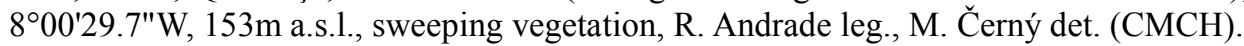

[12b] Faro, Silves, São Marcos da Serra, 37²0'01.16"N, 8²4'20.63"W, 100m a.s.l., Pan traps, Pedro Andrade leg., M. Černý det. (CMCH).

[12c] Faro, Vila do Bispo, Budens (Parque Natural do Sudoeste Alentejano e Costa Vicentina), 3704'28.7"N, $8^{\circ} 48^{\prime} 10.7^{\prime \prime} \mathrm{W}, 6 \mathrm{~m}$ a.s.l., sweeping vegetation, R. Andrade leg. (CMCH).

[12d] Faro, 10km W Lagos, Luz env., pasture, 4-5.vi.1997, B. Mocek leg., M. Černý det. (CMCH).

[13a] Guarda, Estrela Mts., Manteigas env., valey of Mondego river, 1000m a.s.l., B. Mocek leg., M. Černý det. $(\mathrm{CMCH})$.

[13b] Guarda, Figueira de Castelo Rodrigo, Algodres, Vale de Afonsinho e Vilar de Amargo, 40 57'36.5"N, $7^{\circ} 02^{\prime} 09.6^{\prime \prime W}, 525 \mathrm{~m}$ a.s.1., sweeping vegetation, R. Andrade leg., M. Černý det. (CMCH). 
[13c] Guarda, Gouveia, Aldeias e Mangualde da Serra (Parque Natural da Serra da Estrela), 40²4'13"N, $7^{\circ} 35^{\prime} 10^{\prime \prime} \mathrm{W}, 1450 \mathrm{~m}$ a.s.1., forest, sweeping vegetation, M. Barták leg., M. Černý det. (CMBP).

[13d] Guarda, Gouveia, Folgosinho (Parque Natural da Serra da Estrela), 40³0'32.92"N, 7³1'56.48"W, 784m a.s.1., sweeping vegetation, A. Gonçalves leg., M. Černý det. (CMCH).

[13e] Guarda, Gouveia, Melo e Nabais (Parque Natural da Serra da Estrela), 40³0'21.70"N, 7³2'17.82"W, $735 \mathrm{~m}$ a.s.1., sweeping vegetation, A. Gonçalves leg., M. Černý det. (CMCH).

[13f] Guarda, Guarda, Fernão Joanes (Parque Natural da Serra da Estrela), 40²8'31"N, 7²1'32"W, 930m a.s.1., Castanea wood, sweeping vegetation, M. Barták leg., M. Černý det. (CMBP).

[13g] Guarda, Guarda, Valhelhas (Parque Natural da Serra da Estrela), 40²4'10"N, 7²4'16"W, 500m a.s.1., near river, sweeping vegetation and Pan traps, M. Barták leg., M. Černý det. (CMBP).

[13h] Guarda, Manteigas, Sameiro (Parque Natural da Serra da Estrela), 40²4'42"N, 7²8'04"W, 580m a.s.1., near river, sweeping vegetation, M. Barták leg., M. Černý det. (CMBP).

[13i] Guarda, Manteigas, São Pedro (Poço do Inferno, Parque Natural da Serra da Estrela), 40²2'21.7"N, $7^{\circ} 31^{\prime} 00.1 " \mathrm{~W}, 1100 \mathrm{~m}$ a.s.1., sweeping vegetation, A. Gonçalves leg., M. Černý det. (CMCH).

[13j] Guarda, Seia, Alvoco da Serra (Parque Natural da Serra da Estrela), 40¹7'59.60"N, 741'17.45"W, 855m a.s.l., sweeping vegetation, A. Gonçalves leg., M. Černý det. (CMCH).

[13k] Guarda, Seia, Loriga (Parque Natural da Serra da Estrela), 40¹9'41.26"N, 740'36.71"W, 901m a.s.1., sweeping vegetation, A. Gonçalves leg., M. Černý det. (CMCH).

[131]1 Guarda, Seia, Loriga (Parque Natural da Serra da Estrela), 40¹9'43.71"N, 742'53.22"W, 832m a.s.1., sweeping vegetation, A. Gonçalves leg., M. Černý det. (CMCH).

[13m] Guarda, Seia, Seia, São Romão e Lapa dos Dinheiros (Parque Natural da Serra da Estrela), 40²3'04.19"N, $7^{\circ} 42^{\prime} 18.40^{\prime \prime}$ W, 587m a.s.l., sweeping vegetation, A. Gonçalves leg., M. Černý det. (CMCH).

[14a] Leiria, Alcobaça, Cela, 39³0'21.3"N, 901'37.2"W, 70m a.s.1., Pan traps, R. Andrade leg., M. Černý det. $(\mathrm{CMCH})$.

[14b] Leiria, Alvaiázere, Almoster, 3950'49.8"N, 8²5'53.3"W, 280m a.s.l., sweeping vegetation, R. Andrade leg., M. Černý det. (CMCH).

[14c] Leiria, Caldas da Rainha, Tornada e Salir do Porto (Reserva Natural Local do Paul de Tornada), 39²6'53.1"N, 908'04.3"W, 25m a.s.l., sweeping vegetation, R. Andrade leg., M. Černý det. (CMCH).

[14d] Leiria, Caldas da Rainha, Tornada e Salir do Porto, 39²8'28.06"N, 909'25.76"W, 25m a.s.1., sweeping vegetation, R. Andrade leg., M. Černý det. (CMCH).

[15a] Lisboa, Torres Vedras, A dos Cunhados (Casal da Serra), 3909'56.20"N, 9²0'31.53"W, sweeping vegetation, R. Andrade leg., M. Černý det. (CMCH).

[15b] Lisboa, Sintra, Almargem do Bispo, Pero Pinheiro e Montelavar, 3850'31.43"N, 9¹5'36.34"W, 275m a.s.l., sweeping vegetation, R. Andrade leg., M. Černý det. (CMCH).

[15c] Lisboa, Torres Vedras, A dos Cunhados e Maceira, 3908'41.82"N, 9¹6'16.62"W, 23m a.s.1., sweeping vegetation, R. Andrade leg., M. Černý det. (CMCH).

[16] Portalegre, Portalegre, Ribeira de Nisa e Carreiras, 39²19'53.5"N, $7^{\circ} 25^{\prime} 23.4^{\prime \prime} \mathrm{W}, 590 \mathrm{~m}$ a.s.1., sweeping vegetation, R. Andrade leg., M. Černý det. (CMCH).

[17a] Porto, Porto, Lordelo do Ouro e Massarelos (Jardim Botânico do Porto), 4109'10.0"N, 8³8'35.1"W, 66m a.s.l., collected with a vial, R. Andrade leg., M. Černý det. (CMCH).

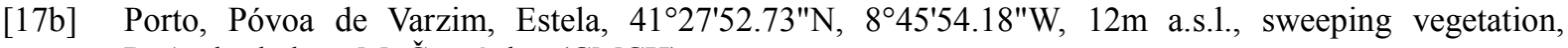
R. Andrade leg., M. Černý det. (CMCH).

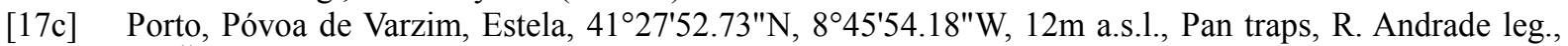
M. Černý det. (CMCH).

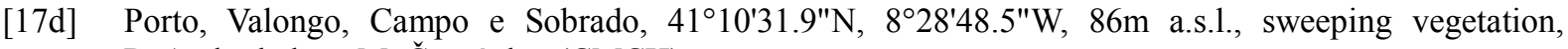
R. Andrade leg., M. Černý det. (CMCH).

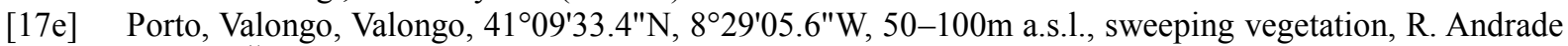
leg., M. Černý det. (CMCH). (Fig. 21)

[17f] Porto, Vila do Conde, Malta e Canidelo, 41 ${ }^{\circ} 18^{\prime} 17.25^{\prime \prime} \mathrm{N}, 8^{\circ} 39^{\prime} 38.10^{\prime \prime} \mathrm{W}, 65 \mathrm{~m}$ a.s.1., collected with a vial, R. Andrade leg., M. Černý det. (CMCH).

[17g] Porto, Vila do Conde, Mindelo (Paisagem Protegida Regional do Litoral de Vila do Conde e Reserva Ornitológica de Mindelo), 41 ${ }^{\circ} 19^{\prime} 13.9^{\prime \prime} \mathrm{N}, 8^{\circ} 44^{\prime} 07.5^{\prime \prime} \mathrm{W}, 5-20 \mathrm{~m}$ a.s.1., sweeping vegetation, R. Andrade leg., M. Černý det. (CMCH). (Fig. 18)

[17h] Porto, Vila Nova de Gaia, Arcozelo (Parque de Dunas da Aguda), 4103'12.3"N , 8³9'18.0"W, 10m a.s.1, sweeping vegetation, R. Andrade leg., M. Černý det. (CMCH).

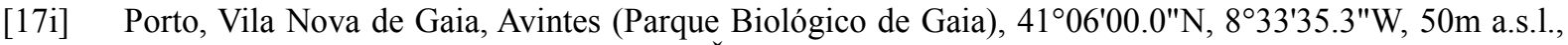
sweeping vegetation, R. Andrade leg., M. Černý det. (CMCH).

[17j] Porto, Vila Nova de Gaia, Canidelo (Reserva Natural Local do Estuário do Douro), 41 ${ }^{\circ} 08^{\prime} 20.7^{\prime \prime} \mathrm{N}$, $8^{\circ} 39^{\prime} 55.2^{\prime \prime} \mathrm{W}, 10 \mathrm{~m}$ a.s.1., sweeping vegetation, R. Andrade leg., M. Černý det. (CMCH). 
[17k] Porto, Vila Nova de Gaia, Mafamude e Vilar do Paraíso, 41ํ0'22.99"N, 8³6'42.78"W, 125m a.s.1., sweeping vegetation, R. Andrade leg., M. Černý det. $(\mathrm{CMCH})$.

[18] Santarém, Abrantes, Mouriscas, 39²8'02.0"N, $8^{\circ} 04^{\prime} 41.0^{\prime \prime} \mathrm{W}, 50 \mathrm{~m}$ a.s.1., sweeping vegetation, R. Andrade leg., M. Černý det. (CMCH).

[19] Setúbal, Grândola, Carvalhal, 38²3'38.1"N, 848'13.6"W, 0m a.s.1., sweeping vegetation, R. Andrade leg., M. Černý det. (CMCH).

[20] Viana do Castelo, Melgaço, Castro Laboreiro e Lamas de Mouro (Parque Nacional da Peneda-Gerês), 41 ${ }^{\circ} 59^{\prime} 39.4^{\prime \prime} \mathrm{N}, 8^{\circ} 10^{\prime} 03.7^{\prime \prime} \mathrm{W}, 805 \mathrm{~m}$ a.s.1., sweeping vegetation, R. Andrade leg., M. Černý det. (CMCH).

[21] Viana do Castelo, Viana do Castelo, Vila Nova de Anha, 41 ${ }^{\circ} 40^{\prime} 08.9^{\prime \prime} \mathrm{N}, 8^{\circ} 49^{\prime} 25.7^{\prime \prime} \mathrm{W}, 10 \mathrm{~m}$ a.s.1., sweeping vegetation, R. Andrade leg., M. Černý det. (CMCH).

[22a] Vila Real, Mondim de Basto, Bilhó, 41²5'15.5"N, 751'53.6"W, 610m a.s.l., sweeping vegetation, R. Andrade leg., M. Černý det. (CMCH).

[22b] Vila Real, Mondim de Basto, Ermelo e Pardelhas (Varzigueto, Parque Natural do Alvão), 41 ${ }^{\circ} 22^{\prime} 44.0^{\prime \prime} \mathrm{N}$, 751'14.4"W, 750m a.s.l., sweeping vegetation, R. Andrade leg., M. Černý det. (CMCH).

[22c] Vila Real, Mondim de Basto, Ermelo e Pardelhas (Fisgas de Ermelo, Parque Natural do Alvão), $4^{\circ} 22^{\prime} 48.9^{\prime \prime} \mathrm{N}, 7^{\circ} 52^{\prime} 38.6^{\prime \prime} \mathrm{W}, 525 \mathrm{~m}$ a.s.l., sweeping vegetation, R. Andrade leg., M. Černý det. (CMCH).

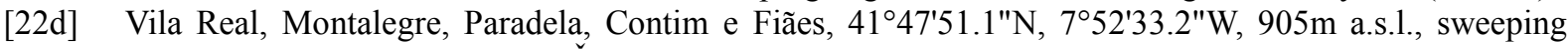
vegetation, R. Andrade leg., M. Černý det. $(\mathrm{CMCH})$.

[22e] Vila Real, Vila Real, Borbela e Lamas de Olo (Parque Natural do Alvão), 41²2'27.6"N, 748'23.7"W, $975 \mathrm{~m}$ a.s.l., sweeping vegetation, R. Andrade leg., M. Černý det. (CMCH).

[23a] Viseu, Moimenta da Beira, Leomil, 41 ${ }^{\circ} 00^{\prime} 16.1^{\prime \prime N}, 7^{\circ} 40^{\prime} 13.4^{\prime \prime W}, 830 \mathrm{~m}$ a.s.1., Pan traps, R. Andrade leg., M. Černý det. (CMCH).

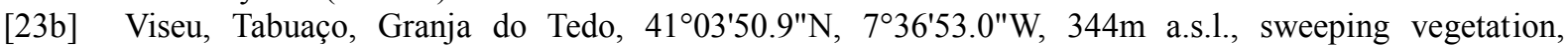
R. Andrade leg., M. Černý det. (CMCH).

\section{Results}

\section{List of species}

\section{SUbFAMILY AGROMYZINAE}

Agromyza abiens Zetterstedt, 1848 (Fig. 1)

Material examined: Portugal: [8j] 1, 21.vi.2015; [17d] 10^, 9.iv.2012.

Distribution: Widespread in the Holarctic Region. In Europe known from the following countries: Andorra (Černý 2007a), Austria, Bulgaria (Beiger 1979), Czech Republic, Denmark, Finland, France, Germany, Great Britain, Greece incl. Crete (Černý 2011a), Hungary, Lithuania, Ireland, Italy incl. Sicily (Černý 2006), Maltese Islands, Montenegro (Spasić 1996), Netherlands, Norway, Poland, Portugal (Černý \& Merz 2006), Romania, Russia (Nartshuk \& von Tschirnhaus 2017), Slovakia, Spain, Sweden, Switzerland and Ukraine (Guglya 2016). Also known from Azerbaijan, Cyprus, Japan, Morocco, Turkey and Turkmenistan (Çıkman \& Civelek 2005, Černý \& Vála, 2006, Nartshuk \& von Tschirnhaus 2017),

Biology: The larva forms leaf mine on host plants Anchusa, Asperugo, Cerinthe, Cynoglossum, Echium, Lappula, Lycopsis, Myosotis, Nonea, Omphalodes, Podonosma, Pulmonaria and Symphytum.

Agromyza albipennis Meigen, 1830

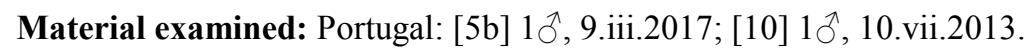

Distribution: Widespread in the Holarctic Region. In Europe known from the following countries: Austria, Belarus, Belgium, Czech Republic, Denmark, Estonia, Finland, France incl. Corsica, Germany, Great Britain, Greece (Černý 2011a), Hungary, Latvia, Lithuania, Ireland, Italy, Montenegro (Spasić 1996), Netherlands, Norway, Poland, Russia (Nartshuk \& von Tschirnhaus 2017), Slovakia, Spain, Sweden, Switzerland and Ukraine (Guglya 2012). Also known from China, Iraq, Japan, Kamchatka, Kazakhstan, Mongolia, South Korea, Tajikistan, Turkey, Yakutia, Canada and United States (Nartshuk \& Bagachanova 2010, Nartshuk \& von Tschirnhaus 2017, Spencer 1981, Suh \& Kwon 1998). First record from Portugal. 

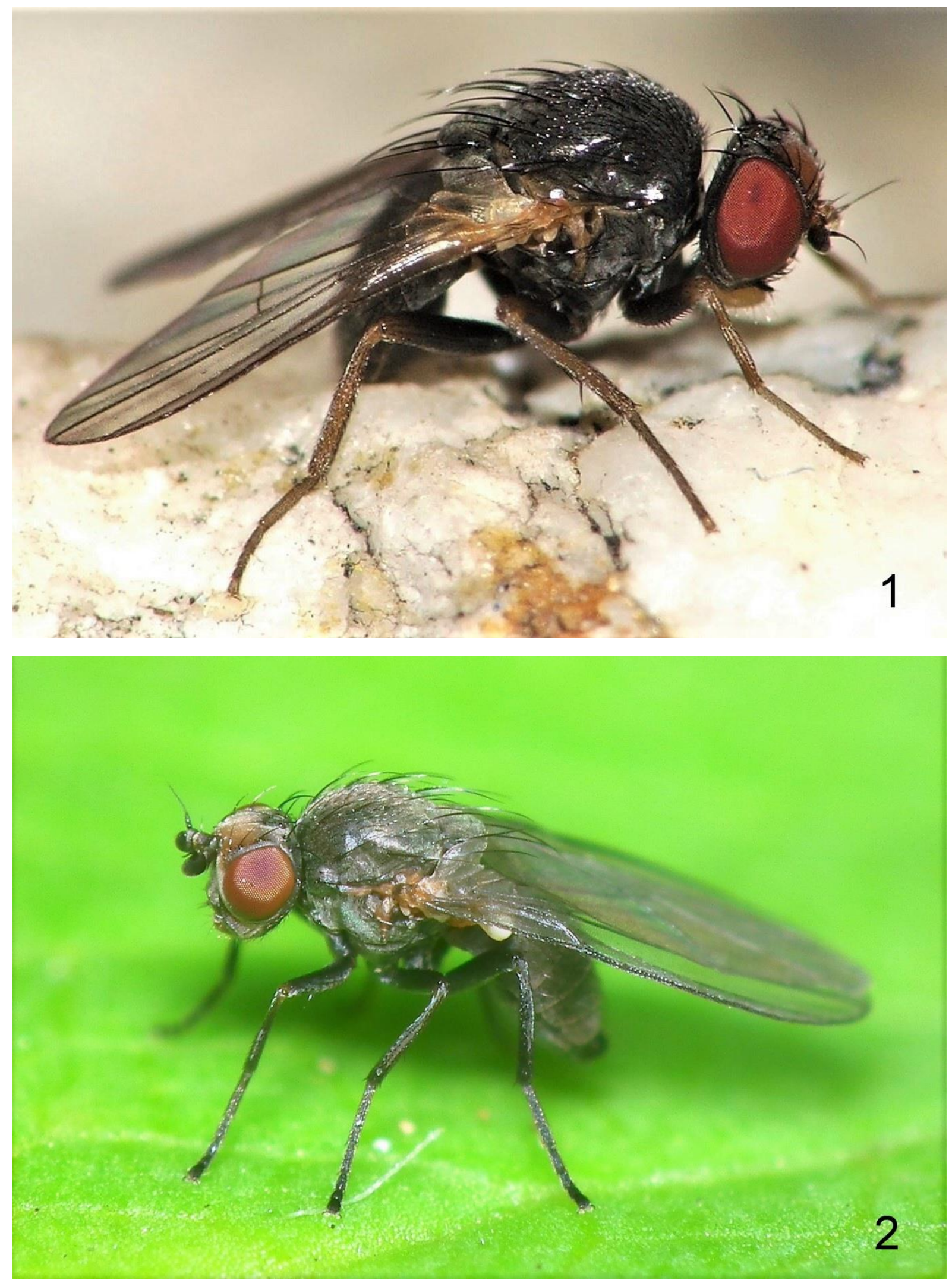

Figs 1-2: Agromyzidae species. 1 - Agromyza abiens Zetterstedt, male, laterally; 2 - Agromyza nana Meigen, female, laterally. Photo by R. Andrade. 
Biology: The larva forms an upper surface leaf mine on host plants Agrostis stolonifera, Arrhenatherum elatius, Brachypodium sylvaticum, Bromus, Calamagrostis arundinacea, Dactylis, Deschampsia cespitosa, Festuca, Glyceria, Hordeum murinum, H. vulgare, Milium, Phalaris arundinacea, Phleum pratense, Poa trivialis, Secale cereale, Setaria viridis and Triticum.

Agromyza conjuncta Spencer, 1966

Material examined: Portugal: [9a] 2ో4ㅇ, 12.iv.2014; [10] 1§, 10.vii.2013; [16] 1ㅇ, 14.iii.2015.

Distribution: This European species is recorded from Belgium, Czech Republic, France, Germany, Great Britain, Greece incl. Crete, Hungary (Papp \& Černý 2015), Italy incl. Sicily, Poland, Serbia (Spasić 1991), Slovakia, Spain and Sweden (Zlobin 2005). First record from Portugal.

Biology: Host and early stages unknown.

Agromyza hiemalis Becker, 1908

Material examined: Portugal: [17d] 1q, 26.i.2015; [17i] 1ð, 29.iii.2014.

Distribution: Species firstly described from Canary Islands - Tenerife, is known mainly from the Mediterranean, hitherto recorded from France, Greece, Italy incl. Sicily (Süss 1999), Spain incl. Balearic and Canary Islands (Gil-Ortiz et al. 2011), Maltese Islands, Morocco, Israel and Turkey. First record from Portugal.

Biology: Host plants are Urtica membranacea and U. urens.

Agromyza idaeiana Hardy, 1853

Material examined: Portugal: [18] 10, 29.iii.2011.

Distribution: Widespread species in Europe known from Austria, Belgium, Czech Republic, Denmark, Estonia, Finland, France, Germany, Great Britain, Hungary, Ireland, Latvia (Karpa 2008), Lithuania, Montenegro (Spasić 1996), Netherlands, Norway, Poland, Romania, Russia, Sardinia, Slovakia, Spain, Sweden, Switzerland (Černý \& Merz 2006). Also known from China, Turkey (Civelek et al. 2007), Kuril Islands (Iwasaki 2000), Uzbekistan, Japan, Canada and United States. First record from Portugal.

Biology: The larva forms a linear mine which later widens to a conspicuous blotch on host plants Acaena, Agrimonia, Alchemilla, Aremonia, Filipendula, Fragaria, Geum, Potentilla, Ribes, Rosa, Rubus, Sanguisorba and Sibbaldia.

Agromyza luteifrons Strobl, 1906

Material examined: Portugal: $[6 \mathrm{~g}] 2 \hat{\jmath}, 16 . x i .2014$.

Distribution: European species recorded from southern France, Hungary, Sicily, Slovenia, Spain incl. Canary Islands. First record from Portugal.

Biology: The larva forms leaf mine on host plant Spartium junceum.

Agromyza mobilis Meigen, 1830

Material examined: Portugal: [5a] 10, 29.iii.2012; [5b] 1ठ, 7.v.2017; [7b] 1ð, 17.iv.2015; [7e] 1ð, 2.vi.2015. Distribution: Palaearctic species known in Europe from Andorra, Austria, Belgium, Czech Republic, Denmark, Estonia, Finland, France, Germany, Great Britain, Greece, Hungary, Italy, Latvia, Lithuania, Netherlands, Norway, Poland, Portugal (Černý 2013), Russia (Nartshuk \& von Tschirnhaus 2017), Slovakia, Spain, Sweden, Switzerland, Ukraine (Guglya 2011) and former Yugoslavia. Also known from China, Japan and Turkey (Dursun et al. 2015).

Biology: The larva form leaf mine on Agropyron, Brachypodium, Bromus, Echinochloa, Holcus, Hordeum, Secale and Triticum. 
Agromyza nana Meigen, 1830 (Fig. 2)

Material examined: Portugal: [5a] 1q, 25.ii.2011, 1ð, 13.iii.2016; [5b] 1ㅇ, 9.iii.2017, 1ð, 7.v.2017; [6a] 1ㅇ,

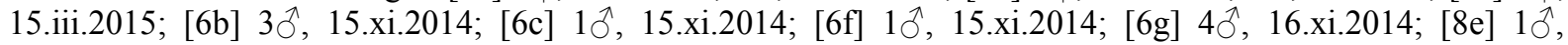
10.v.2015; [9a] 1ठ, 13.iv.2014; [13c] 1ठ, 16-17.vii.2009; [17d] 1ठ, 26.xi.2010.

Distribution: Generally common in the Palaearctic region including North Africa and eastern Siberia, also recorded in northern India. Spencer (1954) recorded it from mines on Trifolium sp. near the Parque Florestal, 10 miles west of Lisbon. Hitherto no adult specimens have been collected in Portugal. First record from Portugal.

Biology: The larva form leaf mine on Anthyllis, Medicago, Melilotus, Onobrychis, Oxalis, Trifolium, Trigonella and Vicia.

Agromyza nigrociliata Hendel, 1931

Material examined: Portugal: [7e] 10, 2.vi.2015.

Distribution: This Palaearctic species is known in Europe from Austria, Belarus, Czech Republic, Denmark, Estonia, Faroe Isl., Finland (Kahanpää 2014), France, Germany, Great Britain, Hungary, Italy (Černý 2006), Lithuania, Poland, Russia (Černý \& Merz 2006), Slovakia, Spain, Sweden (Zlobin 2005), Switzerland, Kuril Islands (Iwasaki 2000) and Yakutia (Nartshuk \& Bagachanova 2010). First record from Portugal.

Biology: The larva forming upper surface greenish leaf mine on host plants Apera spica-venti, Arrhenatherum elatius, Avena, Avenula vesicolor, Dactylis glomerata, Elymus repens, E. caninus, Hordeum murinum, Phalaris arundinacea, Secale cereale and Triticum aestivum.

Agromyza pseudoreptans Nowakowski, 1967

Material examined: Portugal: $[17 \mathrm{~g}] 1$ ô, 30.x.2016.

Distribution: Holarctic species known in Europe from Austria, Belgium, Canary Islands, Czech Republic, Denmark, Estonia, France, Germany, Great Britain, Greece, Hungary, Ireland, Italy, Lithuania, Netherlands, Norway, Poland, Portugal (Černý 2009), Russia, Slovakia, Sweden, Switzerland and Ukraine (Guglya 2016). Also known from Georgia, Kazakhstan, North Korea, Uzbekistan (Černý 2007b, Černý \& Merz 2006, Nartshuk \& von Tschirnhaus 2017), in North America known from Canada and United States.

Biology: The larva form leaf mine on Humulus, Laportea, Loasa, Parietaria and Urtica.

Agromyza rondensis Strobl, 1900

Material examined: Portugal: [14d] $6 \AA 2$ \%, $1 . x i .2013$.

Distribution: Palaearctic species in Europe known from Austria, Belgium, Czech Republic, Estonia, France, Germany, Great Britain, Greece incl. Crete, Croatia, Hungary, Italy incl. Sicily, Lithuania, Norway, Poland, Romania, Russia (Nartshuk \& von Tschirnhaus 2017), Slovakia, Spain incl. Balearic and Canary Islands, Sweden, Switzerland (Černý 2005), Ukraine (Guglya 2011) and former Yugoslavia. Also recorded from Cyprus (Černý \& Vála 2006), Egypt (Černý \& Merz 2006), Iran, Israel, Saudi Arabia (Deeming 2006), South Korea, Tunisia, Turkey, Yakutia (Narthusk \& Bagachanova 2010). First record from Portugal.

Biology: The larva form leaf mine on Arrhenatherum, Avena, Brachypodium, Bromus, Calamagrostis, Dactylis, Hordeum, Oryzopsis, Poa, Secale, Sorghum and Triticum.

Agromyza spenceri Griffiths, 1963

Material examined: Portugal: [12c] 1 ô, $2 . x .2016 .^{2}$

Distribution: West Palaearctic species, recorded in Europe from Bulgaria (Beiger 1979), Czech Republic, France, Hungary (Papp \& Černý 2015), Italy (Černý 2006), Maltese Islands (Černý 2005a), Lithuania, Poland, Spain and known from Morocco (Černý \& Merz 2006), Turkey (Černý 2013) and Uzbekistan (Černý \& Merz 2006). First record from Portugal. 
Biology: This is one of the species which develops in leaves of reed (Phragmites australis). Its mines are not differentiated from those of its congeners.

Hexomyza cecidogena (Hering, 1927)

Material examined: Portugal: [9a] 1 ${ }^{\lambda}, 13 . i v .2014$.

Distribution: Palaearctic species known in Europe from Austria, Belgium, Czech Republic, Denmark, France, Germany, Hungary (Papp \& Černý 2015) Italy, Lithuania, Slovakia and also recorded from China. First record from Portugal.

Biology: The larva forms a small, cylindrical twig-gall on Salix aurita and S. repens.

Hexomyza sarothamni (Hendel, 1923)

Material examined: Portugal: [8c] 10ึ, 16.v.2015.

Distribution: West Palaearctic species in Europe known from Austria, Czech Republic, France, Germany, Great Britain, Greece, Hungary (Papp \& Černý 2015), Netherlands, Portugal (Černý \& Merz 2006), Sicily, Spain, but also recorded from Cyprus and Israel. M. v. Tschirnhaus collected it also on the island of Rhodes (Greece), 4.6km SW Laerma, 36 $07^{\circ} 58^{\prime \prime} \mathrm{N}, 27^{\circ} 53^{\prime} 35^{\prime \prime} \mathrm{E}$, $1 \precsim 1$, 1. iv.1997).

Biology: The larva forms oval stem galls on Cytisus scoparius.

Melanagromyza aenea (Meigen, 1830)

Material examined: Portugal: [8i] 10, 16.vi.2015.

Distribution: Widespread species in Europe, recorded from Austria, Belgium, Czech Republic, Denmark, Estonia, Finland, France, Germany, Great Britain, Greece (Černý 2011a), Hungary, Italy, Latvia (Karpa 2008), Poland, Slovakia, Spain, Sweden, Switzerland and Ukraine (Guglya 2011). First record from Portugal.

Biology: The larvae bore in stems of Urtica spp., only a single generation.

Melanagromyza aeneoventris (Fallén, 1823)

Material examined: Portugal: [5b] 1ㅇ, 31.v.2017.

Distribution: Species known from Palaearctic region and it has been found also in Taiwan (Sasakawa 2008). In Europe recorded from Austria, Belgium, Bulgaria (Černý \& Merz 2006), Czech Republic, Dalmatia (Spasić \& Spencer 1992), Denmark, Estonia, Finland, France, Germany, Great Britain, Greece (Černý 2011a), Hungary, Ireland, Italy, Lithuania, Netherlands, Poland, Slovakia, Spain, Sweden, Switzerland, Ukraine (Guglya 2011) and former Yugoslavia. Also known from Iran (Ranji et al. 2015), Turkey (Çıkman \& Sasakawa 2006), Pakistan, Asian Russia and Japan. First record from Portugal.

Biology: The larva is oligophagous, feeding as an internal stem-borer on Cirsium arvense, C. palustre, C. vulgare, more rarely recorded on Carduus acanthoides, C. crispus, Inula sp. and Senecio jacobaea.

Melanagromyza cunctans (Meigen, 1830)

Material examined: Portugal: [5b] 2へ, 1.x.2017; [13e] 1ㅇ, 28.vii.2014.

Distribution: A species known from the Palaearctic, Afrotropical and Oriental Regions. Indeed, it is widespread throughout Europe, hitherto recorded from Albania, Andorra, Austria, Belgium, Bulgaria, Croatia, Czech Republic, Dalmatia, Denmark, France incl. Corsica, Germany, Great Britain, Greece incl. Crete, Hungary, Italy incl. Sicily, Lithuania, Maltese Islands, Netherlands, Poland, Romania, Slovakia, Spain, Sweden, Switzerland, Ukraine and former Yugoslavia. First record from Portugal.

Biology: Host plants are Lotus corniculatus, L. ornithopodioides and L. rectus. The larva feeds in the upper part of the stem, forms a slender, cylindrical gall immediately below inflorescence. 
Melanagromyza pubescens Hendel, 1923

Material examined: Portugal: [9a] 1ㅇ, 12.iv.2014; [10] 1ð, 10.vii.2013; [12c] 1§, 2.x.2016.

Distribution: A Palaearctic species in Europe known from Austria, Belgium, Czech Republic, Denmark, Estonia, Finland, Germany, Great Britain, Greece (Černý 2011a), Hungary, Italy, Lithuania, Poland, Romania, Russia, Spain (Černý \& Merz 2007), Sweden and Ukraine (Guglya 2011), as well as from China, Japan, Mongolia, Nepal, North Korea, Kuril Islands, Asian Russia and Turkey. First record from Portugal.

Biology: The larva feeds in the lower part of Artemisia vulgaris.

Melanagromyza siciliensis Spencer, 1966

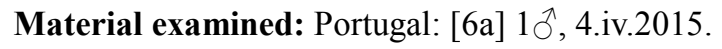

Distribution: West Palaearctic species described from Sicily and later recorded from Czech Republic, Israel, Slovakia and Spain (Papp \& Černý 2015). First record for Portugal.

Biology: Host and early stages unknown.

Ophiomyia alliariae Hering, 1954

Material examined: Portugal: [7b] 1へ̂, 16.iv.2015.

Distribution: European species described from Germany and recorded from Andorra, Austria, Czech Republic, France, Great Britain, Greece, Hungary, Italy incl. Sardinia, Latvia, Lithuania, Maltese Islands, Slovakia, Spain and Ukraine (Guglya 2012). First record from Portugal.

Biology: The larva forms external stem mine on host plants Alliaria officinalis, Bertorea, Brassica napus, Capsella bursa-pastoris, Cardamine bulbifera, Erysimum cheiranthoides, Raphanus raphanistrum, $R$. sativum, Sinapis alba, S. arvensis, Sisymbrium altissimum and $S$. officinale.

Ophiomyia beckeri (Hendel, 1923)

Material examined: Portugal: [7d] 1ㅇ, 16.vi.2017.

Distribution: Palaearctic species in Europe known from Albania (Černý \& Merz 2006), Andorra (Černý 2007a), Austria, Belgium, Czech Republic, Denmark, Finland, France, Germany, Great Britain, Greece incl. Crete, Ireland, Lithuania, Hungary (Papp \& Černý 2015), Maltese Islands, Poland, Portugal incl. Madeira (Černý \& Merz 2006), Sicily, Slovakia, Spain incl. Balearic and Canary Islands, Sweden (Zlobin 2005), Switzerland (Černý \& Merz 2005), Ukraine (Guglya 2011). Also recorded from Egypt, Israel, Iran, Morocco, Oman, Saudi Arabia, South Africa, Tanzania, Tunisia, Turkey, Yemen, Zimbabwe and India (Çıkman \& Sasakawa 2005, Černý \& von Tschirnhaus 2014, Deeming 2006, Ranji et al. 2015).

Biology: Host plants are Coreopsis, Crepis, Hypochoeris, Launaea, Leontodon, Picris, Sonchus and Taraxacum.

Ophiomyia curvipalpis (Zetterstedt, 1848)

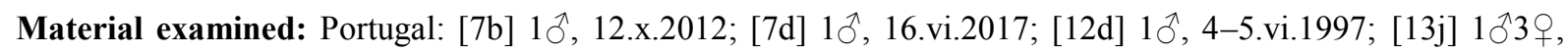
30.vii.2014.

Distribution: Palaearctic species widespread in Europe and also recorded from Cyprus, Egypt, Iran (Ranji et al. 2015), Israel, Japan, Morocco and Turkey. In Europe known from the following countries: Andorra (Černý 2007a), Austria, Belgium, Bulgaria (Černý \& Merz 2006), Czech Republic, Estonia, France, Germany, Great Britain, Greece (Černý \& Merz 2006), Hungary, Italy incl. Sardinia and Sicily (Černý 2006), Lithuania, Macedonia, Maltese Islands (Černý 2005a), Poland, Romania (Černý \& Merz 2006), Russia, Slovakia, Spain, Sweden, Switzerland, former Yugoslavia and Ukraine (Guglya 2011). First record from Portugal.

Biology: The larva forms narrow stem mine on Achillea millefolium, A. ptarmica, Anthemis tinctoria, Artemisia absinthium, A. campestris, A. vulgaris, Centaurea cyanus, C. stoebe, Matricaria inodora, Medicago sativa and Tanacetum vulgare. 
Ophiomyia galii Hering, 1937

Material examined: Portugal: [12c] 10ึ, 2.x.2016.

Distribution: Palaearctic species described from Germany and known from Andorra (Černý 2007a), Bulgaria (Černý \& Merz 2006), Czech Republic, France incl. Corsica, Greece (Černý 2011), Hungary (Papp \& Černý 2015), Italy (Černý 2006), Lithuania, Poland, Slovakia, Spain, Sweden (Černý \& Merz 2006), Switzerland (Černý 2005b), recorded also from Turkey (Černý \& Merz 2007) and North Korea (Černý 2007b). First record from Portugal.

Biology: The larva forms an external stem mine, with frass in large, widely-spaced grains on Asperula, Galium mollugo and G. verum.

Ophiomyia heringi Starý, 1930

Material examined: Portugal: [7b] 10, 17.iv.2015.

Distribution: European species described from Czech Republic and known from Austria, Finland, France, Germany, Great Britain, Hungary, Italy (Süss 1999), Latvia (Karpa 2008), Lithuania, Poland, Slovakia, Sweden and Switzerland (Černý \& Merz 2007). First record from Portugal.

Biology: The larva forms an external stem mine with frass in two rows of disconnected strips on host plants Campanula patella, C. persicifolia, Crepis paludosa, Hieracium sylvaticum, Hypochaeris radicata, Jasione montana, Lapsana communis, Leontodon autumnalis, L. hispidus, Matricaria, Mycelis muralis, Phyteuma, Prenanthes, Reichardia, Scorzonera humilis, Sonchus and Tragopogon.

Ophiomyia labiatarum Hering, 1937

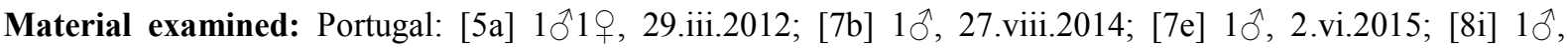
16.vi.2015.

Distribution: Holarctic species, described from Germany, in Europe recorded from Andorra (Černý 2007a), Austria, Belgium, Bulgaria, Croatia (Černý 2009), Czech Republic, Finland, France, Germany, Great Britain, Greece (Černý 2011a), Hungary, Latvia (Karpa 2008), Lithuania, Norway, Slovakia, Spain (Gil-Ortiz et al 2010a), Sweden (Černý \& Merz 2006), Switzerland (Černý 2009), Ukraine (Guglya 2016). Also recorded from Cyprus (Černý 2013), Israel and Turkey (Černý \& Merz 2016), in North America recorded from Canada and United States. First record from Portugal.

Biology: The larva forms an external stem mine on Clinopodium vulgare, Galeopsis, Lamium album, L. galeobdolon, L. maculatum, Leonurus, Nepeta, Prunella, Salvia, Satureja, Scutellaria galericulata, Stachys officinalis, S. palustris, S. recta and S. sylvatica.

Ophiomyia melandryi de Meijere, 1924

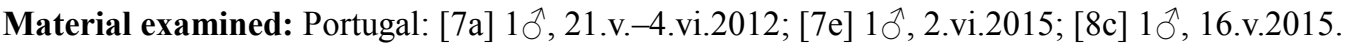

Distribution: Palaearctic species in Europe known from Andorra, Austria, Czech Republic, France, Germany, Great Britain, Greece, Italy, Lithuania, Netherlands, Poland, Slovakia, Sweden, Switzerland, Ukraine (Guglya 2011) and also recorded from Cyprus and Japan. First record from Portugal.

Biology: The larva forms a shallow mine inside the hollow stem on Lychnis and Silene.

\section{Ophiomyia moravica Černý, 1994}

Material examined: Portugal: [17d] 1ð, 27.viii.2011.

Distribution: This species described from Czech Republic and hitherto only recorded from Hungary (Papp \& Černý 2015), Slovakia, Switzerland and Ukraine (Guglya 2016). First record from Portugal.

Biology: Host and early stages unknown. 
Ophiomyia orbiculata (Hendel, 1931)

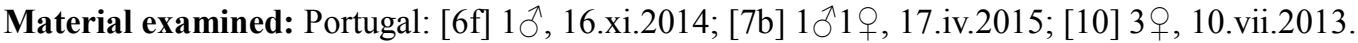

Distribution: Palaearctic species widespread in Europe known from Austria, Belarus, Bulgaria, Czech Republic, Denmark, Estonia, Finland, France, Germany, Great Britain, Greece, Hungary, Italy incl. Sicily, Latvia, Lithuania, Norway, Poland, Portugal, Romania, Russia, Slovakia, Spain, Sweden, Switzerland, Ukraine, former Yugoslavia, and also recorded from Cyprus, Iran, Turkey and Uzbekistan (Papp \& Černý 2015, Ranji et al. 2015).

Biology: Host plants are Lathyrus, Pisum and probably Vicia.

Ophiomyia pulicaria (Meigen, 1830)

Material examined: Portugal: [10] 19, 10.vii.2013.

Distribution: Palaearctic and Afrotropical species in Europe known from Andorra, Austria, Belarus, Belgium, Bulgaria, Croatia, Czech Republic, Dalmatia, Denmark, Estonia, Finland, France, Germany, Great Britain, Greece, Hungary, Italy, Latvia, Lithuania, Netherlands, Norway, Portugal, Russia, Slovakia, Spain incl. Canary Islands, Sweden, Switzerland, Ukraine, former Yugoslavia and also recorded from China, Turkey, Japan and Kenya (Černý \& von Tschirnhaus 2014, Papp \& Černý 2015).

Biology: The larva forms leaf mine on Andryala, Chondrilla, Crepis, Hieracium, Hypochoeris, Lapsana, Leontodon, Picris, Reichardia, Sonchus and Taraxacum.

Ophiomyia vimmeri Černý, 1994

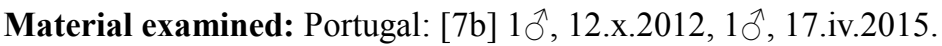

Distribution: West Palaearctic species, described from Czech Republic and Slovakia, also recorded from Andorra (Černý 2007a), France, Greece, Hungary (Papp \& Černý 2015), Italy, Morocco, Spain, Switzerland and Ukraine (Guglya 2011). First record from Portugal.

Biology: Host and early stages unknown.

\section{Subfamily Phytomyzinae}

Amauromyza (Cephalomyza) flavifrons (Meigen, 1830)

Material examined: Portugal: [7i] 10, 16.viii.2013.

Distribution: It is a Holarctic species, widespread in Europe known from Albania, Belgium, Czech Republic, Denmark, Finland, France incl. Corsica, Germany, Great Britain, Hungary, Italy, Lithuania, Montenegro (Spasić 1996), Netherlands, Norway, Poland, Romania, Spain, Sweden and Switzerland, also recorded from Kyrgyzstan, North Korea (Černý 2007b) and Turkey. From North America recorded in Canada and United States (Boucher 2012). First record from Portugal.

Biology: It is a polyphagous miner, the larva forms a white blotch mine on many genera of Amaranthaceaea and Capryophyllaceae, namely on Agrostemma, Beta, Cerastium, Dianthus, Gypsophila, Moehringia, Saponaria, Silene, Spinacia, Stellaria and Vaccaria (Benavent-Corai et al. 2005, Spencer 1990).

Amauromyza (Cephalomyza) luteiceps (Hendel, 1920)

Material examined: Portugal: [10] 3 $\hat{\alpha}$, 10.vii.2013; [21] 1ㅇ, 28.viii.2010.

Distribution: It is an uncommon Holarctic species, in Europe known from the following countries: Czech Republic, Great Britain, Greece (Černý \& Merz 2006), Denmark, Finland, France, Germany, Hungary (Papp \& Černý 2016), Lithuania (Ostrauskas et al. 2005), Maltese Islands (Černý 2005b), Netherlands, Norway, Poland, Spain (Černý \& Merz 2006) and Sweden, also known from Iran (Ranji et al. 2015) and Turkey. Later recorded in North America from Eastern Canada (Boucher 2012). First record from Portugal.

Biology: The larvae develop as stem borer in Atriplex (von Tschirnhaus 1981; Spencer 1990). 
Aulagromyza discrepans (van der Wulp, 1871)

Material examined: Portugal: [6c] 1 $\lesssim 2$ ㅇ, 15.xi.2014.

Distribution: European species known from Belgium, Czech Republic, Finland (Thuneberg 1960), France, Germany, Great Britain, Greece incl. Crete (Černý 2011a) and Kos (von Tschirnhaus 1994), Hungary (Papp 2004), Netherlands, Poland, Portugal (Černý 2009), Slovakia, Spain incl. Balearic Islands and Switzerland (Černý \& Merz 2007).

Biology: Flies emerged from puparia obtained together with Aulagromyza orphana from stems of Galium aparine, the belonging larva was described and figured by Dempewolf (2001). A record of reared flies from Artemisia vulgare by Bland (1983) was corrected by von Tschirnhaus (1992: 520).

Aulagromyza orphana (Hendel, 1920)

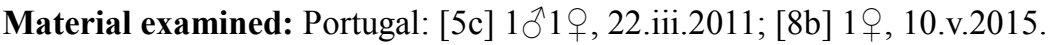

Distribution: West Palaearctic species recorded from Andorra (Černý 2007a), Austria, Belgium, Bulgaria (Černý \& Merz 2006), Czech Republic, Denmark, France, Germany, Great Britain, Greece (Černý \& Merz 2006), Hungary, Ireland, Netherlands, Poland, Slovakia, Spain, Sweden (Zlobin 2005) and Switzerland (Černý 2005b), it has been reported also from Turkey. First record from Portugal.

Biology: The larva forming an external stem mine on Galium aparine and G. palustre.

Cerodontha (Butomomyza) angulata (Loew, 1869)

Material examined: Portugal: [17d] 10, 26.iv.2016.

Distribution: A Holarctic species widespread and locally common over the better part of Europe. Recorded from Andorra (Černý 2007a), Austria, Belgium, Czech Republic, Denmark, Estonia, France, Great Britain, Germany, Greece (Černý 2011a), Hungary, Ireland, Italy, Latvia (Karpa 2008), Lithuania, Netherlands, Norway, Poland, Romania, Slovakia, Sweden, Switzerland (Černý 2005b). Also recorded in Israel (Černý 2011b), Japan, Turkey, North and South Korea (Černý 2007b), Kuril Islands and Yakutia, Canada, United States and Guiana (Spencer 1990). First record from Portugal.

Biology: The larva forms a long greenish mine in its host plants Carex spp. and rarely Scirpus sylvaticus.

Cerodontha (Butomomyza) mellita Spencer, 1971

Material examined: Portugal: [8c] 5^, 16.v.2015.

Distribution: A rare European species recorded from Belgium, Czech Republic (Černý \& Heřman 2015), Great Britain, Poland and Slovakia (Vála \& Černý 2009). First record from Portugal.

Biology: The larva mines on the middle part of leaf in host plants of Carex spp.

Cerodontha (Cerodontha) ? bistrigata Frey, 1945

Material examined: Azores: [1s] 1ठ1ㅜ, 9.iv.1994.

Note. Between and above the coastal black lava rocks and within permanent salt influence these predominantly yellow specimens have been captured on scattered tussocks of the endemic coastal grass "Bracel-da-rocha, Bracéu", Festuca petraea Guthn. ex Seub. The only other plants on the rocky shore, interrupted by black sand below a steep lava cliff belonged to the genus Limonium (Plumbaginaceae) which is not yet known to be host genus of any world agromyzid and not being a monocot to which all Cerodontha hosts belong worldwide. The natural colouration of these specimens was protocolled short time after collecting and does not fit exactly to the description of Frey (1945), the phallus is very similar to the figure of Spencer $(1965 b)$. In the São Miguel material, the slightly elongate third antennal segment with a long 
pubescence is only light brown on its outer side, arista black with first two segments yellow, the long black phallapodeme is reaching back until the mid of the first tergite, the ejaculatory apodeme is hyaline, the tips of the male cerci are blackish, the slender oviscape is laterally compressed at its end and bicoloured, black dorsally, reddish ventrally, all bristles and hairs of the fly are black. For a final determination it is necessary to compare the type series of C. bistrigata which was collected on other islands of the archipel. May be that this endemic species already developed slight differences on the nine volcanic islands with different geological age.

\section{Cerodontha (Cerodontha) denticornis (Panzer, 1806)}

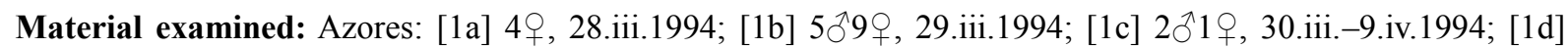

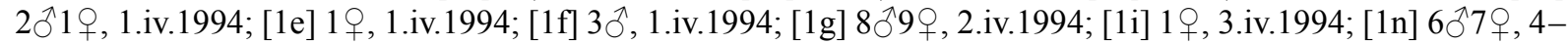

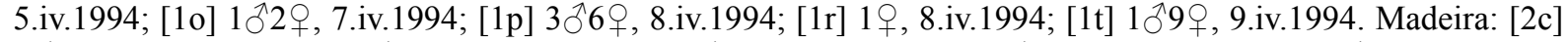

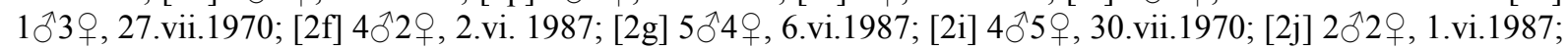

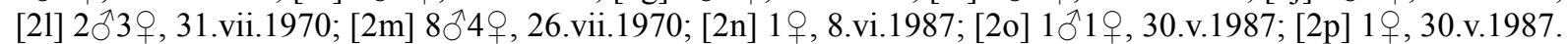

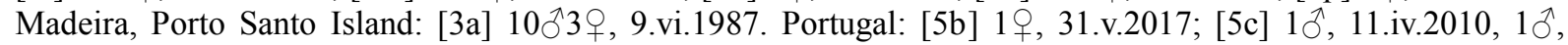

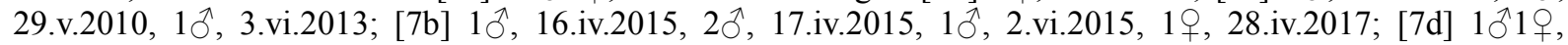

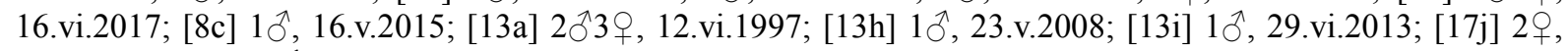
22.ix.2009; [22e] 1§, 30.iv.2017.

Distribution: In Europe known from Albania, Andorra, Austria, Belgium, Bulgaria, Czech Republic, Dalmatia, Denmark, Estonia, Finland, France incl. Corsica, Germany, Great Britain, Greece, Hungary, Ireland, Italy incl. Sicily, Latvia, Lithuania, Maltese Islands, Montenegro, Netherlands, Norway, Poland, Portugal incl. Azores and Madeira, Romania, Slovakia, Spain incl. Canary Islands, Sweden, Switzerland and Ukraine, also known from North Africa, Central and East Asia.

Biology: Host plants are Agropyron, Alopecurus, Avena, Calamagrostis, Dactylis, Festuca, Holcus, Hordeum, Phalaris, Phleum, Poa and Triticum.

\section{Cerodontha (Cerodontha) fulvipes (Meigen, 1830)}

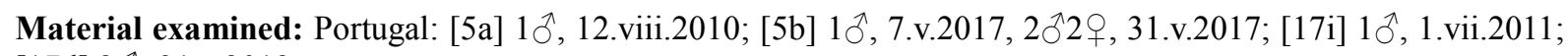
[17d] 2へ, 31.v.2012.

Distribution: Palaearctic species widespread in Europe recorded from Austria, Belgium, Czech Republic, Denmark, Estonia, Finland, France, Germany, Great Britain, Greece (Černý 2011a), Hungary, Ireland, Italy, Latvia, Lithuania, Montenegro (Spasić 1996), Netherlands, Norway (Andersen 2012), Poland, Romania, Russia (Zlobin 1979b), Slovakia, Spain, Sweden, Ukraine, and also recorded from China, Japan, Tajikistan, Turkey and Yakutia (Nartshuk \& Bagachanova 2010). First record from Portugal.

Biology: The larva forms leaf mine in Poa trivialis but probably feeding on other grasses (Nowakowski 1973), too.

\section{Cerodontha (Cerodontha) phragmitophila Hering, 1935 (Fig. 3)}

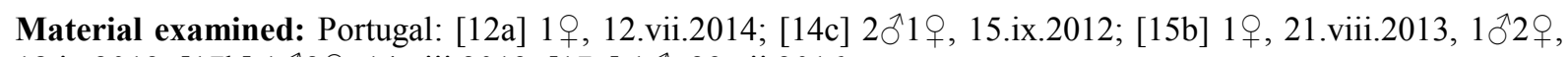

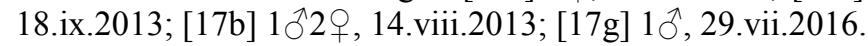

Distribution: A Palaearctic species known in Europe and recorded from Belgium, Bulgaria, Croatia, Czech Republic, France incl. Corsica, Great Britain (Gibbs 2006), Greece (Č́erný 2011a), Hungary, Italy, Poland, Spain incl. Canary Islands and former Yugoslavia, also recorded from Cyprus, Egypt, Israel, Kazakhstan, Pakistan and Uzbekistan. The potential for long dispersion and the attractivity of isolated host plants could be stated in an only $100 \mathrm{~m}^{2}$ small reed bed of Phragmites australis around a leaky water pipeline within the endless Egyptian Sahara desert, $55 \mathrm{~km}$ SSW Bawiti and $213 \mathrm{~km} \mathrm{~W}$ of the Nile valley, $27^{\circ} 54^{\prime} \mathrm{N}, 28^{\circ} 34^{\prime} \mathrm{E}$, 16.iii.1992, R. Mannesmann leg., M. von Tschirnhaus det.). First record from Portugal.

Biology: The larva mines in the leaf sheath of Arundo donax L. and Phragmites australis. 
Cerodontha (Cerodontha) vandalitiensis Spencer, 1965

Material examined: Portugal: [9a] 1 ${ }^{\lambda}, 12$. iv.2014, 1ð, 13.iv.2014.

Distribution: A European species known from Czech Republic, France, Hungary (Papp \& Černý 2016), Portugal (Černý 2009), Russia and Spain.

Biology: Host and early stages unknown.

Cerodontha (Dizygomyza) bimaculata (Meigen, 1830)

Material examined: Portugal: [8e] 10, 10.v.2015; [8g] 10, 30.v.2016.

Distribution: This Palaearctic species is widespread in Europe, known from Andorra (Černý 2007a), Austria, Belgium, Bosnia and Herzegovina, Czech Republic, Dalmatia, Denmark, Estonia, Finland, France, Germany, Great Britain, Greece (Černý 2011a), Hungary, Italy, Latvia, Lithuania, Montenegro (Spasić 1996), Netherlands, Norway, Poland, Romania, Russia, Slovakia, Slovenia, Spain, Sweden, Switzerland (Černý 2005b), Ukraine, Vatican City, also recorded in Turkey (Civelek et al. 2009), Japan and the Kuril Islands. First record from Portugal.

Biology: The larva forms a narrow leaf mine in its host plants Luzula campestris, L. multiflora, L. pilosa and L. sylvatica.

Cerodontha (Dizygomyza) iraeos (Robineau-Desvoidy, 1851)

Material examined: Portugal: [5c] 10̂, 31.v.2010.

Distribution: This Palaearctic species is widespread in Europe and it has been recorded from Albania (Černý \& Merz 2006), Austria, Belarus, Belgium, Czech Republic, Denmark, Estonia, Finland, France incl. Corsica, Germany, Great Britain, Hungary, Ireland, Italy, Latvia, Lithuania, Moldavia, Netherlands, Norway (Andersen \& Jonassen 1994), Poland, Romania, Russia, Slovakia, Spain, Switzerland, also known from Japan (Sasakawa 2005) and South Korea. First record from Portugal.

Biology: The larva forms a short white leaf mine in its host plants Iris pseudacorus and I. sibirica.

Cerodontha (Dizygomyza) luctuosa (Meigen, 1830) (Fig. 4)

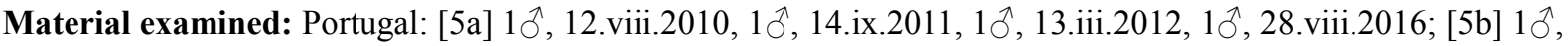

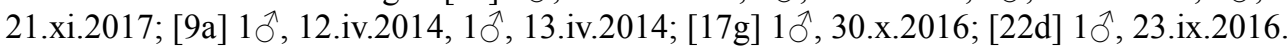

Distribution: Holarctic species known in Europe from Albania, Austria, Belgium, Belarus, Czech Republic, Denmark, Finland, France, Germany, Greece, Hungary, Ireland, Italy incl. Sicily, Latvia, Lithuania, Netherlands, Norway, Poland, Portugal, Russia, Slovakia, Spain, Sweden, Switzerland and former Yugoslavia, but also recorded from Iraq, Israel, Tunisia, China, Japan and Uzbekistan. In North America recorded from Canada and United States incl. Alaska. Biology: The larva form leaf mine on Juncus effusus.

Cerodontha (Dizygomyza) luzulae (Groschke, 1957)

Material examined: Portugal: [20] 10, 8.ix.2016.

Distribution: This European species was recorded from the Czech Republic, Germany, Great Britain, Greece (Černý 2011a), Hungary, Montenegro (Spasić 1996), Poland, Slovakia, Slovenia and Switzerland (Černý 2005b). First record from Portugal.

Biology: The larva forms leaf mine in its host plants Luzula sylvatica and L. pilosa. 

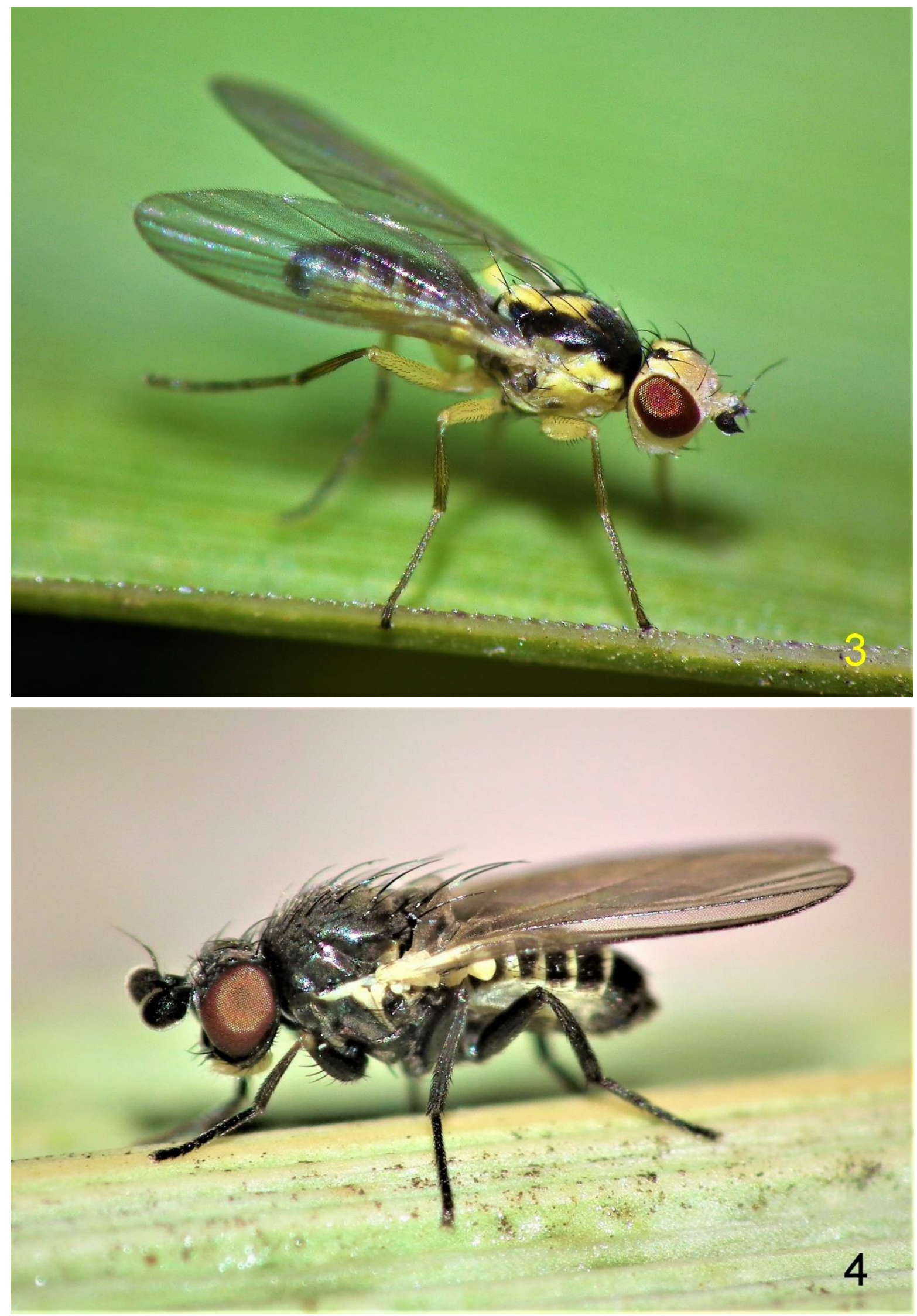

Figs 3-4: Agromyzidae species. 3 - Cerodontha (Cerodontha) phragmitophila Hering, male, dorsolaterally; 4 - Cerodontha (Dizygomyza) luctuosa (Meigen), male, laterally. Photo by R. Andrade. 
Cerodontha (Dizygomyza) morosa (Meigen, 1830)

Material examined: Portugal: [22d] 10, 23.ix.2016.

Distribution: This Holarctic species is common in Europe: Andorra (Černý 2007a), Azores, Austria, Belarus, Czech Republic, Denmark, Estonia, Finland, France, Germany, Great Britain, Greece (Černý 2011a), Hungary, Iceland, Ireland, Italy, Latvia, Lithuania, Madeira Islands, Netherlands, Norway, Poland, Russia, Slovakia, Spain incl. Canary Islands, Sweden, Switzerland, former Yugoslavia, and known to occur also in the East Palaearctic: China, Japan, North Korea (Černý 2007b), Yakutia (Nartshuk \& Bagachanova 2010), and the Oriental region: India, Philippines. Also recorded from Canada and the United States. From Portugal hitherto only known from Azores and Madeira (Hendel 1931-36), this is first record from Portuguese mainland.

Biology: The larva forms a relatively short and broad leaf mine in its host plants Carex spp.

Cerodontha (Dizygomyza) suturalis (Hendel, 1931)

Material examined: Madeira: [2e] 1ð, 1.viii.1959; [2i] 1ㅇ, 30.vii.1970; [2k] 1§1ㅇ, 3.vi.1987; [21] 1ð, 31.vii.1970.

Distribution: This Palaearctic species is widespread in Europe, known from Albania (Černý \& Merz 2006), Austria, Belgium, Bulgaria, Czech Republic, Denmark, France (Černý \& Merz 2006), Germany, Great Britain, Greece (Černý 2011a), Hungary, Latvia (Karpa 2008), Lithuania, Montenegro (Spasić 1996), Poland, Slovakia, Sweden (Zlobin 2005), Switzerland (Černý 2009) and also recorded from Cyprus (Černý \& Vála 2006), Israel (Černý 2011b), China, Japan and Yakutia (Nartshuk \& Bagachanova 2010). First record from Madeira.

Biology: The larva forms leaf mine in its host plant Carex hirta.

Cerodontha (Icteromyza) capitata (Zetterstedt, 1848) (Fig. 5)

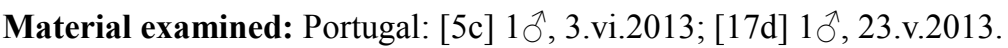

Distribution: It is a Holarctic species, known from nearly 20 European countries from Ireland and Great Britain to Hungary and Serbia and from Spain to Sweden. Known also from Morocco, Kyrgyzstan, Canada and the United States incl. Alaska. First record from Portugal.

Biology: Repeatedly speculations have been published about the host plant of this peculiarly large species, so often caught on stands of Juncus effusus. All searches for puparia in the seeds, stems and roots by M. von Tschirnhaus were successless also in localities where the flies were abundantly on the wing (von Tschirnhaus 1991: 295). Spencer (1976a) recorded this rush as host and the base of the stems as the larval substrate, but not based on any real observation. In his book 1990 he changed his mind and expressed the information of Nowakowski (1973: 34). Later authors took over this unconfirmed information (Benavent-Corai et al. 2005, Gil-Ortiz et al. 2011). But to date it was overlooked that already Fahringer (1937: 342-346) obtained Microgaster globatus (L.) var. rufipes Nees from "Dizygomyza capitata" and other hosts. But details on the rearing were not described. C. van Achterberg (Leiden) informed M. von Tschirnhaus that this braconid parasitoid was a misidentification of Microgaster rufipes Nees, 1834 (van Achterberg 2014: 207). Finally, parts of a letter of G.C.D. Griffiths (dated 3.ii. 1992) to von Tschirnhaus should be cited here serving as the most informative observation: "The failure of so many workers to find the immature stages of this common species suggests that development may occur at an unusual time of the year, perhaps in winter or early spring. On 16.vii.1966 I colleted two large emty Cerodontha puparia [at Woodwalton Fen] of presumably capitata from inside stem bases of Juncus effusus from which the flies had emerged". Those puparia were sent by Griffiths to J.T. Nowakowski in Warsaw. 
Cerodontha (Icteromyza) geniculata (Fallén, 1823) (Fig. 6)

Material examined: Portugal: [5c] 10, 20.vii.2010; [17a] 10, 16.iii.2017.

Distribution: It is a widespread Palaearctic species (known also from North Africa) and it has some doubtful records also from the Oriental Region. In Europe known from the following countries: Austria, Belgium, Bulgaria, Czech Republic, Estonia, Finland, France, Germany, Great Britain, Greece (Černý 2011a), Hungary, Italy, Latvia (Karpa 2008), Netherlands, Poland, Romania, Russia, Slovakia, Spain, Sweden, Switzerland and Ukraine. First record from Portugal.

Biology: The larvae form linear mines in the leaves of Eriophorum latifolium.

Cerodontha (Icteromyza) rozkosnyi Černý, 2007

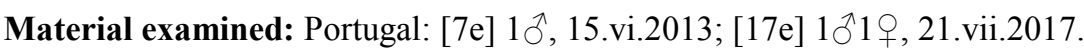

Distribution: This species was described from the type series from the Czech Republic, Romania and Morocco. Rather recently, it has been confirmed from Greece (Černý 2011a), Israel (Černý 2011b) and Hungary (Papp \& Černý 2016). First record from Portugal.

Biology: Host and early stages unknown.

Cerodontha (Poemyza) melicae Nowakowski, 1973

Material examined: Madeira: [2m] 1 ${ }^{\Uparrow} 2$, 26. vii.1970.

Distribution: This European species has been known from the Czech Republic, Germany, Ireland, Poland and Slovakia. First record from Madeira.

Biology: The larva forms leaf mine in its host plants Poa chaixii, Melica uniflora, M. nutans, Molinia caerulea and Calamagrostis arundinacea.

Cerodontha (Poemyza) muscina (Meigen, 1830)

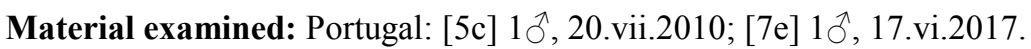

Distribution: This Holarctic species which is widely distributed in much of Europe also recorded in Russia (Yakutia), Canada, and the United States including Alaska. First record from Portugal.

Biology: The larva forms a long mine on the lower surface of the leaf in many genera of Poaceae, confirmed genera are Bromus, Dactylis, Festuca, Hierochloe, Holcus, Lolium, Milium and Poa.

Cerodontha (Poemyza) pygmaea (Meigen, 1830)

Material examined: Madeira: [2j] 1ㅇ, 1.vi.1987; [2k] 2ㅇ, 3.vi.1987.

Distribution: A Holarctic species is widespread and frequently common over the greatest part of Europe, but recorded also from Iran, Japan, Turkey, Canada and the United States.

Biology: Leaf mines in a multitude of grass species, 20 genera are listed by Benavent-Corai et al. (2005).

Cerodontha (Xenophytomyza) atronitens (Hendel, 1920)

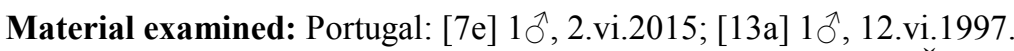

Distribution: European species known from Albania (Černý \& Merz 2006), Austria, Belgium, Czech Republic, Denmark, Estonia, Finland, France, Germany, Great Britain, Hungary (Papp 2009), Ireland, Latvia (Karpa 2008), Lithuania, Netherlands, Norway, Portugal (Černý \& Merz 2006), Russia, Slovakia, Spain, Sweden and Switzerland (Černý 2005b).

Biology: Larval development in the culm of Poa nemoralis (von Tschirnhaus 1991: 294) and possibly other grasses. Xenophytomyza is the only group of Agromyzidae tunneling in grass stems. 
Chromatomyia aprilina (Goureau, 1851)

Material examined: Portugal: [17d] 10, 9.iv.2012.

Distribution: European species known from Austria (Franz 1989), France incl. Corsica, Germany, Great Britain, Italy, Norway, Poland, Portugal and Spain.

Biology: The larva forms leaf mine on Lonicera.

Chromatomyia farfarella (Hendel, 1935)

Material examined: Portugal: [4] 2ð1 1 , 1-5.v.1971.

Distribution: This European species was described after a female holotype which was found near Bleder See (Slovenia), later recorded from Denmark, Faroe Islands, Ireland, Finland, France, Germany, Iceland, Latvia (Karpa 2008), Lithuania, Norway, Poland and Sweden. First record from Portugal.

Biology: The larva forms a narrow, whitish linear mine on Taraxacum officinale and Leontodon autumnalis.

Note. Details of the phallus, arista and morphometry were figured and compared with the two closely related global polyphagous pest species C. horticola (Goureau, 1851) and C. syngenesiae Hardy, 1849 by von Tschirnhaus (1969).

Chromatomyia horticola (Goureau, 1851)

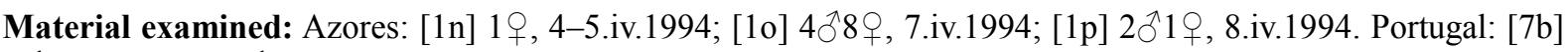
10, 14.iv.2013, 30 , 17.iv.2015.

Distribution: This is a semi-cosmopolitan species common throughout Europe, North Africa, East and West Africa, Madagascar, India, China (incl. Taiwan) and Japan. This species appears to have dispersed naturally across temperate areas of Africa to South Africa, it is common in parts of India and by natural spreading it has reached eastern Asia. Hitherto it has not been reported from Australia, New Zealand, North and South America.

Biology: It is an exceptionally polyphagous species: it has been recorded from host plant species of 60 families and some 230 genera (Benavent-Corai et al. 2005, Spencer 1990).

Chromatomyia lindbergi (Spencer, 1957)

Material eamined: Madeira: [2g] 1q, 6.vi.1987; [2k] 1, 3.vi.1987.

Distribution: Hitherto only known from the male holotype from La Palma, Canary Islands. First record from Madeira.

Biology: Host plants are not yet known. The fly was captured in a shady and moist conifer forest with ferns, grass and the herbaceous vegetation dominated by two species of Caryophyllaceae, Digitalis, Veronica and two species of yellow flowering Asteraceae in locality [2k]. In a similar biotope of locality [2g] Erigeron karwinskianus and Chrysanthemum spec. were protocolled.

Note. The type specimen has been reinvestigated by Griffiths (1967: 5), who published figures of the male genitalia. Later he transferred it to the genus Chromatomyia Hardy, 1849 (Griffiths 1974: 37). The most similar species $C$. farfarella, $C$. horticola and $C$. syngenesiae were separated by minute characters of the palpi and aristae by von Tschirnhaus (1969) at that time without having seen $C$. lindbergi which belongs to the syngenesiae-group, too. Both descriptions, the original one and that of Griffiths (1967) agree with the first females now available. The tips of the fore coxae are yellow and only 2, 3 or 4 acrostichals are present in each of the two rows, ending short distance behind the 3rd dorsocentral seta (counted from behind). Additional features ease the future identification: All knees are bright yellow in more than the width of the diameter of the distal end of the tibiae, the scapes are ochre, the palpi are yellowish (black in the other three species), outer and inner vertical setae (vte and vti) emerge 

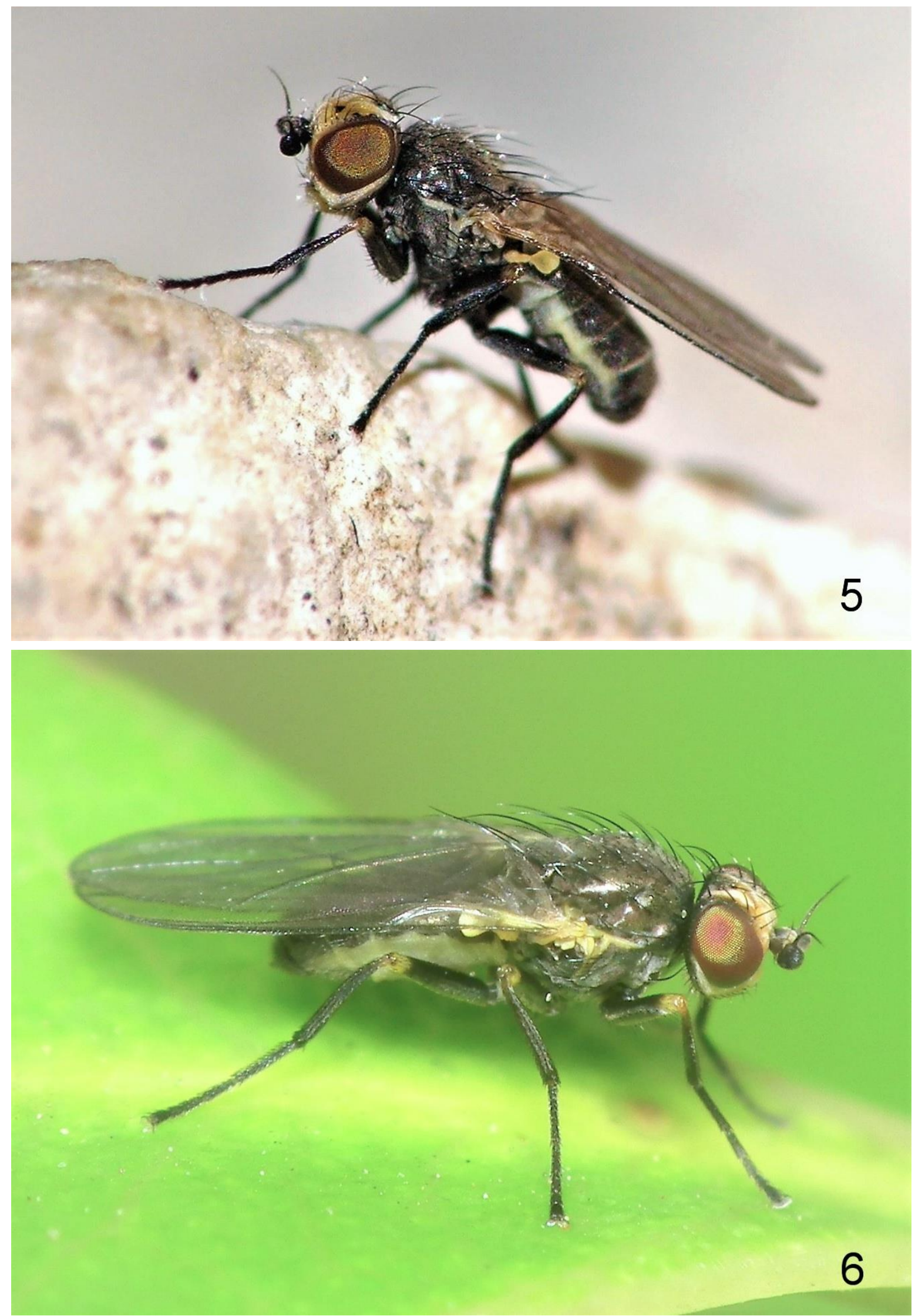

Figs 5-6: Agromyzidae species. 5 - Cerodontha (Icteromyza) capitata (Zetterstedt), male, laterally; 6 - Cerodontha (Icteromyza) geniculata (Fallén), male, laterally. Photo by R. Andrade. 
from yellow ground. The typical interruption within the arista as figured by von Tschirnhaus (1969) for $C$. horticola and $C$. syngenesiae (to date not reported for any other agromyzid) is only very weak and difficult to detect. It divides the arista in two parts of about equal lengths like in C. syngenesiae.

Chromatomyia milii (Kaltenbach, 1864)

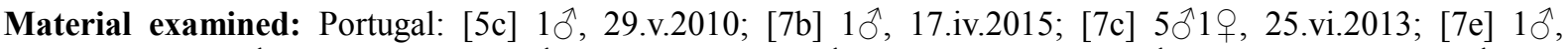

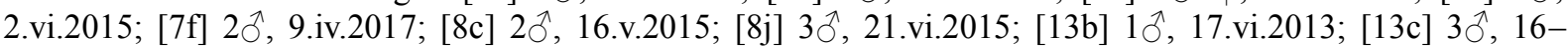

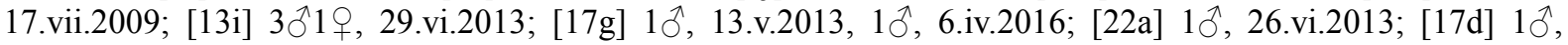

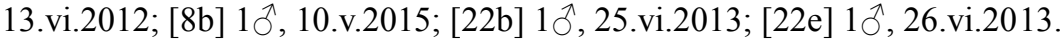

Distribution: This species is known from the Holarctic and Oriental regions, in Europe recorded from Andorra, Austria, Belarus, Belgium, Bulgaria, Czech Republic, Denmark, Estonia, Faroe Islands, Finland, France incl. Corsica, Germany, Great Britain, Greece, Ireland, Italy, Latvia, Lithuania, Poland, Portugal, Montenegro, Norway, Russia, Slovakia, Spain, Sweden and Switzerland (Černý 2007b, Černý \& Merz 2007, Gil-Ortiz et al. 2011, Griffiths 1980). Also widespread from Canada, Morocco, India, Japan (Sasakawa 2005), Taiwan (Sasakawa 2008), Turkey and Yakutia (Nartshuk \& Bagachanova 2010).

Biology: The larva forms leaf mine on Agrostis, Aira, Brachypodium, Catabrosa, Dactylis, Festuca, Hierochloe, Holcus, Hordeum, Lolium, Milium and Poa.

\section{Chromatomyia nigra (Meigen, 1830)}

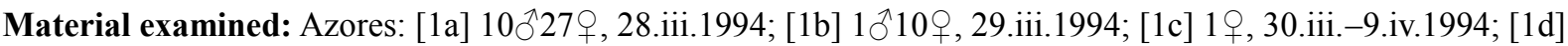

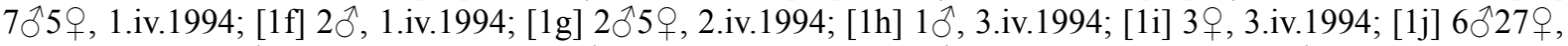

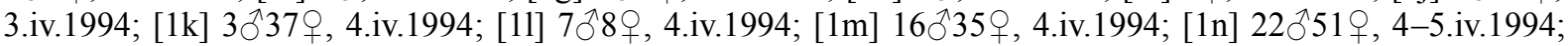

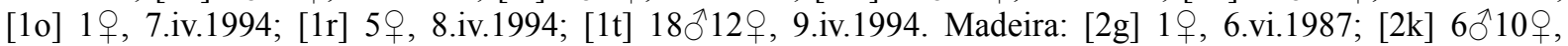

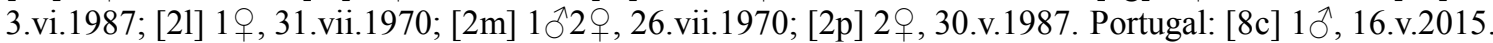

Distribution: This species known from Holarctic and Oriental regions, is widespread and common in much of Europe. From Portugal hitherto only known from Madeira (Spencer 1965b, as Phytomyza nigra Mg.), this is the first record from the Azores and the Portuguese mainland. Biology: $C$. nigra has the widest range of Chromatomyia species on the Poaceae or other monocots with host plant records from 47 genera (Spencer 1990).

Note. All material from the Azores belongs to the species of the C. nigra-group possessing at least a partly yellowish frons. The two pairs of long supporting sclerites of the phallus are of uneven lengths. As in all Chromatomyia species a distinct distiphallus is reduced to a short, hyaline, hook-like and (in rest position of the phallus) upwards curved appendix. After the issue of the revision of the C. nigra-group by Griffiths (1980) it could be clarified in correspondance with Griffiths that the form with equal lengths of those four sclerites and with a dark frons deserves its own species status with the name obscuriceps Hendel, 1935 (see von Tschirnhaus 1981: 32). This darker and on average slightly smaller species is peculiarly abundant along coasts and not conspecific with the similar C. puccinelliae Griffiths, 1980 from North America and as recently recorded from the high north of Greenland (Wirta et al. 2016).

Chromatomyia syngenesiae Hardy, 1849

Material examined: Portugal: [5c] 20, 2.vi.2014.

Distribution: An extremely widespread species in temperate areas, known from Europe, North America (Canada, United States), Colombia, Israel, Japan, Saudi Arabia, Yakutia, Australia, New Zealand and Srí Lanka (Černý 2009, Nartshuk \& Bagachanova 2010, Spencer \& Steyskal 1986). In Europe known from Czech Republic, Dalmatia (Spasić \& Spencer 1992), Denmark, Finland, France, Germany, Great Britain, Greece (Černý 2011b), Ireland, Netherlands, Poland, Portugal, Spain incl. Balearic Islands, Sweden and Switzerland.

Biology: It is a polyphagous species, its host plants are mainly in the Compositae (BenaventCorai et al. 2005, Griffiths 1976, Spencer 1990). 
Liriomyza artemisicola de Meijere, 1924

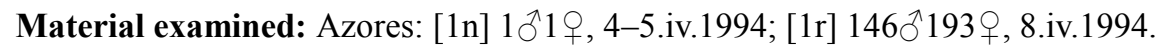

Distribution: A Palaearctic species, in Europe recorded from Andorra (Černý 2007a), Austria, Belgium, Croatia (Černý 2009), Czech Republic, Denmark, Finland, France incl. Corsica, Germany, Great Britain, Greece (Černý 2011a), Hungary (Papp \& Černý 2017), Ireland, Italy (Černý 2006), Lithuania, Netherlands, Norway (Andersen 2016), Poland, Slovakia, Sweden, Switzerland, also recorded from China, North Korea (Černý 2007b), Yakutia (Nartshuk \& Bagachanova 2010), Japan and India. First record from the Azores.

Biology: Host plants are several species in the genus Artemisia. In the botanical garden of Ponta Delgada (Azores) [1r] mass occurrence of flies and leaf mines was observed on flowering Argyranthemum sp. (= Chrysanthemum s.l.). Mines and larvae were collected, and flies and Chalcidoidea parasitoids emerged later. Mymaridae were captured and preserved in numbers, too, they may be egg parasitoids of the leaf miner. First record of this host plant genus.

Liriomyza bryoniae (Kaltenbach, 1858)

Material examined: Azores: $2 q$ of this species were obtained from [1b] and [1c], 29.iii.-9.iv.1994, but

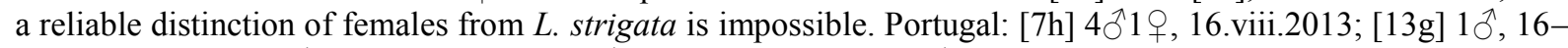

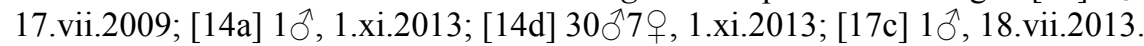

Distribution: A polyphagous species with a Palaearctic and Oriental type of distribution. It has been reported from ca. 36 European countries: known from Albania, Austria, Belgium, Great Britain, Bulgaria, Belarus, Croatia, Czech Republic, Denmark, Estonia, Finland, France incl. Corsica, Germany, Greece incl. Crete, Hungary, Italy incl. Sicily, Latvia (Karpa 2008), Lithuania, Maltese Isles, Moldavia, Netherlands, Norway, Poland, Portugal incl. Azores, Romania, Russia, Slovenia, Spain incl. Canary Isles, Sweden, Switzerland (Černý \& Merz 2006), Ukraine and former Yugoslavia. Also known from China, Egypt, Georgia, India, Iran, Iraq (Spencer 1981), Japan, Morocco, Nepal (Sasakawa 1996), South Korea, Taiwan, Thailand, Turkey, Turkmenistan and Yakutia (Nartshuk \& Bagachanova 2010).

Biology: A highly polyphagous species, recorded from 112 genera in 30 plant families (Benavent-Corai et al. 2005, Spencer 1990).

Liriomyza congesta (Becker, 1903)

Material examined: Portugal: [9c] 4 $\delta$, 11.iv.2014.

Distribution: It is very common throughout most of Europe, known also from Canary Islands, China, Cyprus (Černý \& Vála 2006), Egypt, India, Iran, Iraq (Saleh et al. 2013), Israel, Japan, Oman (Deeming 2006), South Korea, Tunisia, Turkey, Yakutia (Nartshuk \& Bagachanova 2010), Yemen (Deeming 2006) and Uzbekistan.

Biology: The larva forms leaf mine on Anthyllis, Astragalus, Caragana, Cicer, Colutea, Coronilla, Euphorbia, Glycine, Glycyrrhiza, Hippocrepis, Hymenocarpos, Lathyrus, Lens, Lotus, Lupinus, Medicago, Melilotus, Onobrychis, Ononis, Ornithopus, Oxytropis, Trifolium, Trigonella and Vicia.

\section{Liriomyza flaveola (Fallén, 1823)}

Material examined: Portugal: [22b] 1ð^, 25.vi.2013.

Distribution: This Holarctic species is widespread and common in Europe, namely in Andorra (Černý 2007a), Belgium, Belarus, Bulgaria, Czech Republic, Denmark, Estonia, Finland, France, Germany, Great Britain, Greece (Černý 2011a), Hungary, Ireland, Italy, Latvia (Karpa 2008), Monaco, Montenegro (Spasić 1996), Netherlands, Norway, Poland, Portugal (Černý 2013), Russia, Spain incl. Canary Islands, Slovakia, Sweden, and recorded also in Canada and United States (Lonsdale 2017). Also known from Asian Russia, India, Japan, North Korea (Černý 2007b), Kuril Islands (Iwasaki 2000), Turkey and Uzbekistan. 
Biology: The larva forms leaf mine on Avena, Bromus, Dactylis, Holcus, Hordeum, Milium and Poa.

Liriomyza huidobrensis (Blanchard, 1926)

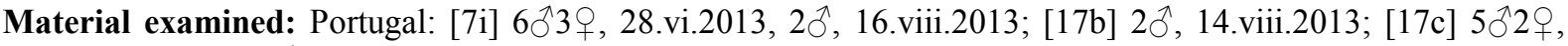
18.vii.2013; [17f] 1ठ, 6.ix.2013.

Distribution: This cosmopolitan species was described from Argentina, known from the Afrotropical, Australian, Oriental, Neotropical regions and from the whole Holarctic region. In Europe known from Austria, Belgium, Czech Republic, Finland, France incl. Corsica, Germany, Great Britain, Greece incl. Crete, Hungary, Italy, Maltese Islands, Netherlands, Norway, Poland, Portugal incl. Madeira Islands, Russia, Spain incl. Canary Islands, Sweden and Switzerland.

Biology: A highly polyphagous species, with confirmed records on 110 genera from 33 families of host plants, especially Chenopodiaceae, Compositae, Cucurbitaceae, Leguminosae, Liliaceae, Linaceae, Solanaceae, Tropaeolaceae, Umbelliferae and Violaceae (Benavent-Corai et al. 2005, Spencer 1973, 1990).

Liriomyza infuscata Hering, 1926

Material examined: Portugal: [5a] 2へ̂1우, 13.iii.2016; [7b] 1우 10.ii.2011.

Distribution: A Palaearctic species, in Europe recorded from Belgium, Bulgaria (Černý 2013), Czech Republic, Denmark, Finland, France, Germany, Great Britain, Hungary (Papp \& Černý 2017), Latvia, Lithuania, Norway (Andersen \& Jonassen 1994), Poland, Russia, Slovakia, Spain, Sweden, Ukraine, also recorded from West and East Siberia, Mongolia (Zlobin 2003). First record from Portugal.

Biology: Host and early stages unknown.

Liriomyza latigenis (Hendel, 1920)

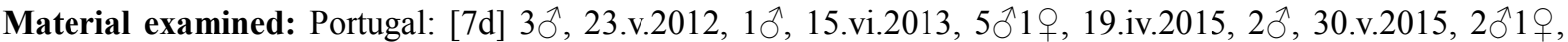

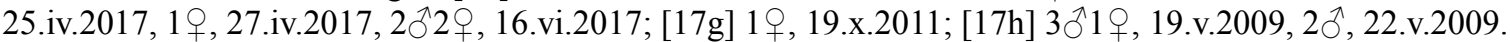

Distribution: Hitherto known from the Czech Republic, France, Greece (Černý 2011a), Spain and Uzbekistan (Černý \& Merz 2006). First record from Portugal.

Biology: The larva forming leaf mine on Senecio jacobaea.

\section{Liriomyza orbona (Meigen, 1830) (Fig. 7)}

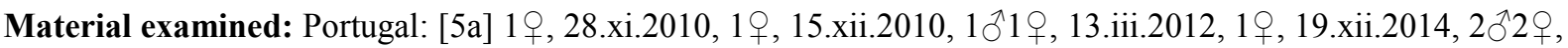

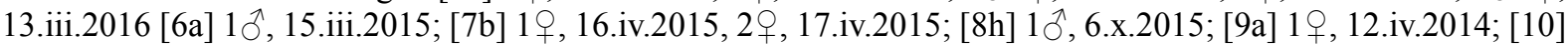
1ㅇ, 24.vii.2013; [14c] 1ڤึ, 15.ix.2012; [17d] 1ڤ, 21.ii.2016; [17f] 1+, 6.ix.2013.

Distribution: Palaearctic species widespread in most parts of Europe and known from Austria, Czech Republic, Dalmatia (Spasić \& Spencer 1992), Denmark, France, Finland, Germany, Great Britain, Greece incl. Crete, Hungary, Ireland, Italy incl. Sicily, Lithuania, Maltese Islands, Netherlands, Norway (Andersen \& Jonassen 1994), Poland, Spain incl. Canary Islands, Sweden, Switzerland and former Yugoslavia. Also recorded from Azerbaijan, Cyprus (Černý \& Vála 2006), Egypt, Iraq, Tunisia and Turkey. From Portugal hitherto only known from Madeira (Zlobin 2003), this is new record from Portuguese mainland.

Biology: Host plants are certainly Poaceae mainly Avena, Deschampsia, Hordeum murinum and Poa. 
Liriomyza pedestris Hendel, 1931 (Fig. 8)

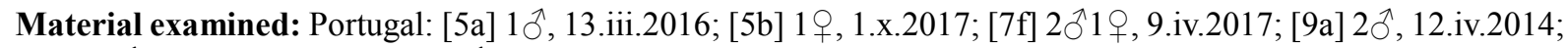

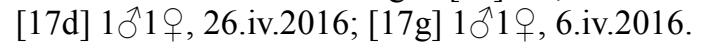

Distribution: This West Palaearctic species was described by Hendel (1931-36) and based on the type series from Hungary, Finland, Germany and Russia (Kamchatka). It is also known from Austria, Corsica (Černý \& Merz 2006), Czech Republic, Denmark, Great Britain, Greece (Zlobin 2003), Italy (Černý 2006) incl. Sicily, Maltese Islands, Norway, Russia (Zlobin 2003), Slovakia (Vála \& Černý 2009), Spain, Sweden, Switzerland (Černý \& Merz 2007) and Ukraine (Zlobin 2003). Also recorded from Cyprus (Černý \& Vála 2006), Iran (Zlobin 2003), Israel (Zlobin 2003), Morocco, Saudi Arabia (Deeming 2006), Turkey (Černý \& Merz 2006) and Uzbekistan (Černý \& Merz 2006). First record from Portugal.

Biology: The larva forming mine on Deschampsia flexuosa, and almost certainly other Poaceae.

Liriomyza ptarmicae de Meijere, 1925

Material examined: Portugal: [6d] 10̂, 19.vii.2009.

Distribution: This Holarctic species is known in Europe from Andorra (Černý 2007a), Belarus, Czech Republic, Estonia, Denmark, Finland, France, Germany, Great Britain, Hungary, Italy (Černý 2006) incl. Sicily, Latvia, Lithuania, Netherlands, Norway, Poland, Portugal (Gil-Ortiz et al. 2011), Slovakia, Sweden, Switzerland (Černý 2009), also recorded from China (Sasakawa 2006), Japan, Yakutia (Nartshuk \& Bagachanova 2010). In North America known from Canada and the United States.

Biology: The larva forms a narrow linear leaf mine on Achillea distans, A. millefolium, A. pannonica, A. ptarmica, Anthemis arvensis and Chrysanthemum coronarium.

Liriomyza taraxaci Hering, 1927

Material examined: Portugal: [17k] 1§, 14.vii.2011.

Distribution: This Holarctic species is known in Europe from Austria, Belarus, Belgium, Bulgaria, Czech Republic, Denmark, Estonia, Finland (Kahanpää 2014), France, Germany, Great Britain, Greece (Černý 2011a), Hungary (Papp \& Černý 2017), Ireland, Italy (Süss 2003), Latvia (Karpa 2008), Lithuania, Netherlands, Norway (Andersen \& Jonassen 1994), Poland, Portugal (Černý 2009), Romania, Russia (Strakhova et al. 2013), Slovakia, Slovenia, Spain, Sweden, Switzerland (Černý 2005b), also recorded from Canada and United States.

Biology: The larva forms leaf mine on Aposeris, Arnoseris, Leontodon, Sonchus and Taraxacum.

Liriomyza umbilici Hering, 1927

Material examined: Azores: [1a] 1ㅇ, 28.iii.1994; [1n] 1ㅇ, 4-5.iv.1994.

Distribution: European species known from Canary Islands, Portugal incl. Azores, Slovenia.

Biology: The larva forms a long, shallow and narrow leaf mine on Umbilicus rupestris.

\section{Liriomyza undescribed species, flaveola Fallén-group}

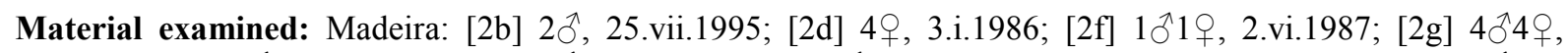

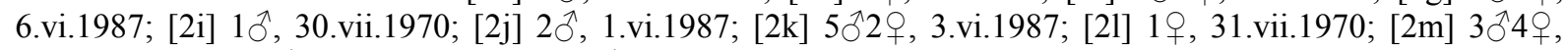
26.vii.1970; [2n] 1ठ1ㅇ, 8.vi.1987; [2o] 10̂, 30.v.1987.

After the publications of Zlobin (2002), Lonsdale (2017) and Papp \& Černý (2017) all former determinations of the grass miners belonging to the $L$. flaveola-group have to be re-identified. Since 48 years M. von Tschirnhaus separated this undescribed species which occurs on Madeira and which he also collected on La Palma (Canary Islands), $28^{\circ} 29^{\prime} 49^{\prime \prime} \mathrm{N}, 1^{\circ} 50^{\prime} 26^{\prime \prime} \mathrm{W}$, Los

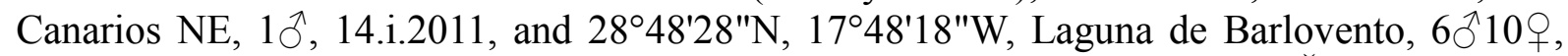
17.i.2011. In Zlobin's Liriomyza key it runs to couplet 12, in the key of Papp \& Černý to couplet 
34. Its male genitalia are very similar to L. phryne Hendel, 1931, but the ejaculatory apodeme is exceptional small, not deeper as the length of the phallus, the epandrium bears not any ,short process“" or „long projection“ (Zlobin 2003), called „bar“" and „elaboration“ (Lonsdale 2017) or „additional laths" or additional "processes" (Papp \& Černý 2017). The so-called surstyli of Liriomyza species (attached to the anterior edge of the epandrium and bent horizontally inwards, are present only as tiny narrow hyaline remnants with a terminal seta, though „considered lost" in the flaveola-group (Lonsdale 2017: 7). The outer vertical seta (vte) is emerging on dark ground, the anepisternum is black in its lower three quarters, the distal third of the fore-femur is yellow dorsally, posterior acrostichals are mostly slightly bent inwards, $1+3$ dorsocentrals, scutum shining, wings slightly brownish. The oviscape is not laterally compressed compared with L. taurica Zlobin, 2003 (this character of taurica first mentioned here).

Metopomyza scutellata (Fallén, 1823) (Fig. 9)

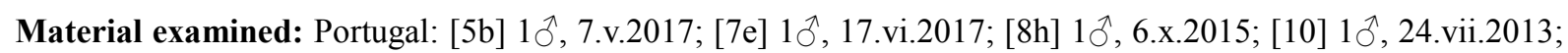

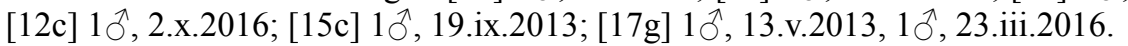

Distribution: Palaearctic species known in Europe from Albania (Černý \& Merz 2006), Andorra (Černý 2007a), Croatia (Černý 2009), Belarus, Czech Republic, Denmark, Estonia, Finland, France, Germany, Great Britain, Greece (Černý 2011a), Hungary, Italy (Černý 2006), Latvia (Karpa 2008), Lithuania, Maltese Islands (Černý 2005a), Norway (Andersen 2012), Poland, Russia (Zlobin 1993), Slovakia, Spain (Černý \& Merz 2006), Sweden and Switzerland (Černý 2005b). First record from Portugal.

Biology: The larva mining on host plants Carex spp.

Napomyza bellidis Griffiths, 1967

Material examined: Portugal: [6e] 1ठ, 17.iv.2011; [23a] 10, 9.x.2013.

Distribution: Palaearctic species known from Europe and recorded from Israel, Japan, Kyrgyzstan, Tajikistan, Turkey and Uzbekistan. In Europe known from the following countries: Andorra, Austria, Belgium, Bulgaria, Czech Republic, Estonia, Finland, France, Germany, Great Britain, Greece, Hungary, Italy, Latvia, Lithuania, Maltese Islands, Russia, Slovakia, Sweden, Switzerland and Ukraine. In Portugal hitherto only known from the Azores (Zlobin 1994a: 62), this is the first record from the Portuguese mainland.

Biology: The larvae are mining in the basal rosette of small plants of Bellis perennis.

Napomyza lateralis (Fallén, 1823)

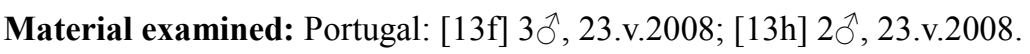

Distribution: Holarctic species, common throughout much of Europe and recorded from Afghanistan (Spencer 1976c), China (Sasakawa 1986), Iraq (Spencer 1981), Israel, Morocco (Černý \& Merz 2006), Kazakhstan, Kyrgyzstan, Tajikistan, Turkmenistan, Uzbekistan, also known from Canada (Spencer 1990).

Biology: The larva mining on host plants Anthemis, Bellis, Bidens, Calendula, Carduus, Centaurea, Cirsium, Crepis, Helichrysum, Hypochaeris, Inula, Lactuca, Linum, Lupinus, Matricaria and Senecio.

Napomyza merita Zlobin, 1993

Material examined: Portugal: [5a] 1§, 13.iii.2012; [7f] $2 \AA 1$ क , 9.iv.2017.

Distribution: This European species is described after a type series from Russia, Finland and Hungary, later the species was recorded from Czech Republic (Černý 2009), France (Černý 2013), Greece (Zlobin 2001), Sweden and Switzerland (Černý \& Merz 2007). First record from Portugal.

Biology: Host and early stages unknown. 

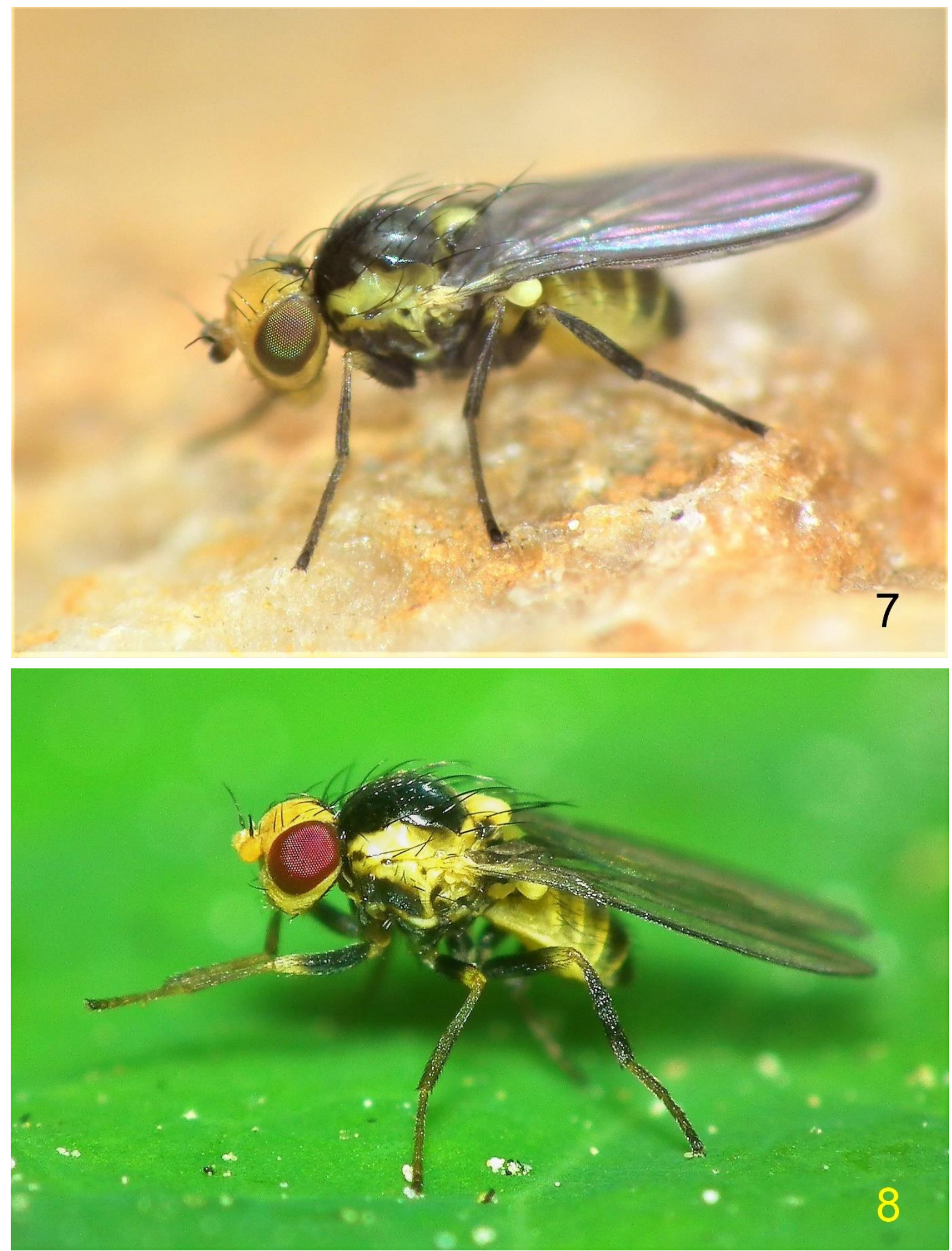

Figs 7-8: Agromyzidae species. 7 - Liriomyza orbona (Meigen) male, dorsolaterally; 8 - Liriomyza pedestris Hendel, male, laterally: Note the distinct stridulation file on the ventral edge of syntergite $1+2$. Photo by R. Andrade. 


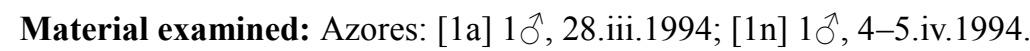

Distribution: Palaearctic species known in Europe from Andorra (2007a), Czech Republic, Denmark, France incl. Corsica, Germany, Great Britain, Greece (Černý \& Merz 2006), Ireland, Lithuania, Norway (Andersen \& Jonassen 1994), Slovakia, Spain, Sweden and Switzerland (Černý \& Merz 2007). Also recorded from Israel, Morocco (Černý \& Merz 2006), Tajikistan and Turkey (Dursun et al. 2015). In Portugal hitherto only known from the Portuguese mainland (Černý 2013: 286), this is the first record from the Azores.

Biology: When the species was described several genera now included in the Plantaginaceae or Orobanchaceae still belonged in the Scrophulariaceae. In German forests, e.g. the Harz mountains, M. von Tschirnhaus repeatedly detected mass occurrence of larvae in the seed capsules and upper stem parts of Digitalis purpurea (Plantaginaceae). Reared specimens can become exceptionally large compared with other Napomyza species. Before Spencer's description the species was already recorded as N. lateralis in seeds of Digitalis (Woodroffe \& Southgate 1952, Erfurth \& Plescher 1983) or as N. annulipes by Neczypor (1962). Zlobin (1994a) in addition to Digitalis also lists Verbascum (Scrophulariaceae) and Mentha (Lamiaceae) as host genera. In Croatia the interior of young stems of Lamium spp. were attacked in spring time, but M. von Tschirnhaus was not successful to rear the flies.

Nemorimyza maculosa (Malloch, 1913), the "burdock leafminer".

Material examined: Madeira: [2r] 14^, 4-11.iv.2016.

Distribution: Species descibed from United States and known from South America, confirmed from Argentina, Bahamas, Barbados, Bermuda, Bolivia, Brazil, Chile, Costa Rica, Cuba, Dominican Republic, Easter Island, Grand Cayman, Hawaii, Jamaica, Peru, Trinidad, Uruguay and Venezuela. An incomplete overview of countries and references is put together by CABI/EPPO (1999). In 177 papers (in the collection of M. von Tschirnhaus) dealing with this pest species under the generic names Agromyza, Amauromyza, Annimyzella, Dizygomyza, Nemorimyza and Phytobia, [as well under the synonym Agromyza guaranatica Brèthes, 1920] not any record for the Old World could be found. But several articles with specific quarantine laws and regulations for the export countries of vegetables and flowers and for imports of those into the European Union and especially to England, Poland, Lithuania, and Finland include this taxon. Here, in addition to Madeira for the first time we report the successful establishment of this neozoon to a further island of the Old World: From 14-17.i.2011 M. von Tschirnhaus collected $20^{\lambda} 5$ ㅇ in three different areas of the Canary Island La Palma $\left(28^{\circ} 48^{\prime} 28^{\prime \prime} \mathrm{N}\right.$, $\left.17^{\circ} 48^{\prime} 18^{\prime \prime W} ; 28^{\circ} 35^{\prime} 50^{\prime \prime} \mathrm{N}, 17^{\circ} 55^{\prime} 32^{\prime \prime} \mathrm{W} ; 28^{\circ} 29^{\prime} 49^{\prime \prime} \mathrm{N}, 17^{\circ} 55^{\prime} 32^{\prime \prime} \mathrm{W}\right)$. During many weeks of collecting by M. von Tschirnhaus in earlier years on Gomera, Tenerife, Fuerteventura and Gran Canaria the species could not yet be obtained! The species became a quarantine pest during the last years, e.g. documented by Commission of the European Communities (2002) and Bell et al. (2014), and it was treated in 99 further publications since the year 1980. Concerning the massive tourism from the Atlantic islands to continental Europe it will be only a question of time until larvae or puparia become transferred; see discussion. First records from Portugal (Madeira) and the Canary Islands.

Biology: An oligophagous species, the larvae form a large blotch leaf mine on host plants, namely Acanthospermum, Ageratum, Artemisia, Aster, Baccharis, Bellis, Bidens, Chrysanthemum, Conyza, Cynara, Dahlia, Emilia, Erechtites, Eupatorium, Gaillardia, Gnaphalium, Helenium, Helianthus, Lactuca, Melanthera, Senecio, Solanum (Sanabria de Arevalo 1994: 72), Solidago, Sonchus, Synedrella, Tagetes, Taraxacum and Zinnia (BenaventCorai et al. 2005, Spencer 1990). 

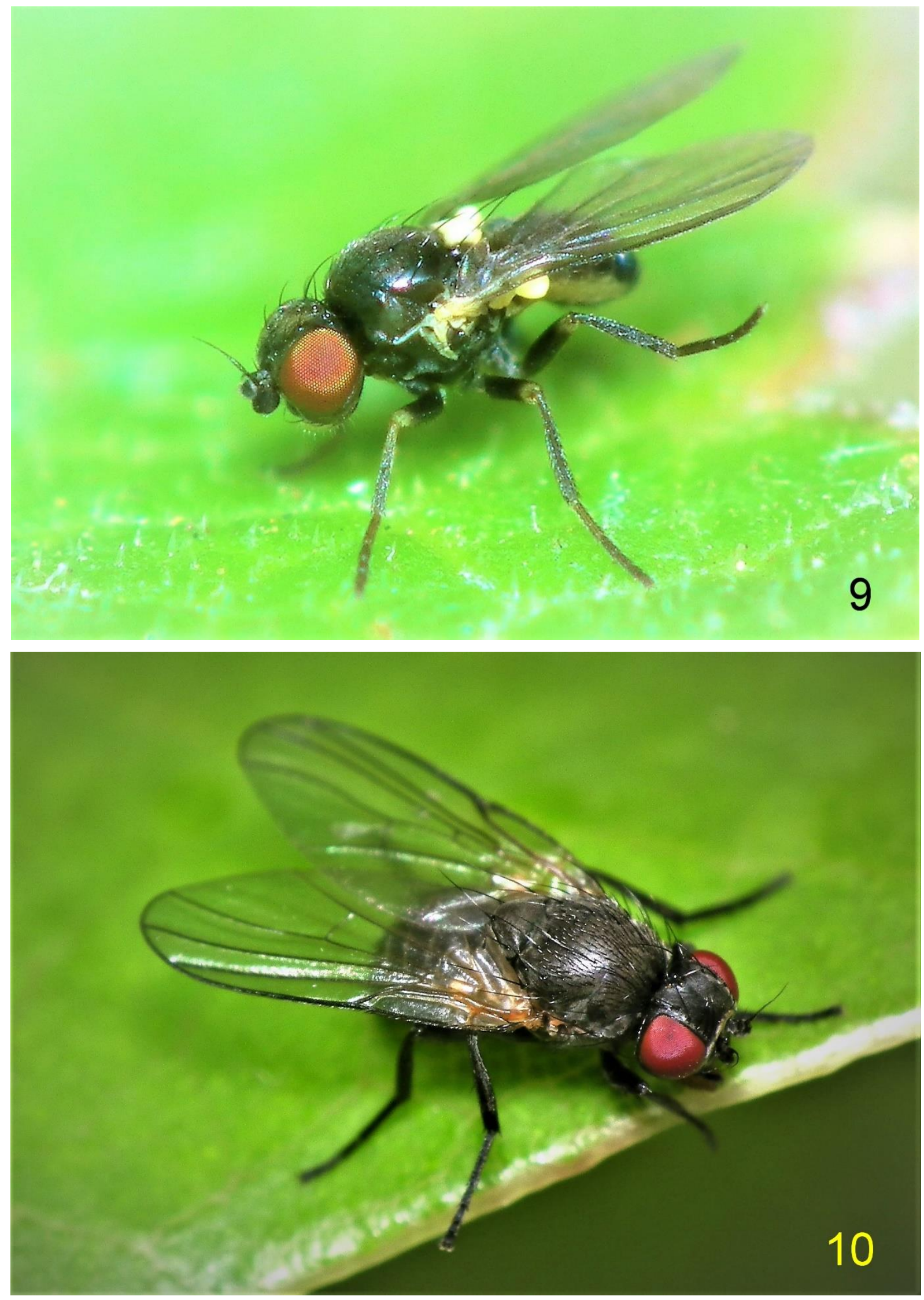

Figs 9-10: Agromyzidae species. 9 - Metopomyza scutellata (Fallén) male, dorsolaterally; 10 - Phytobia cambii (Hendel), male, dorsally: Note the silvery lunule, typically for many tropical Phytobia spp. Photo by R. Andrade. 


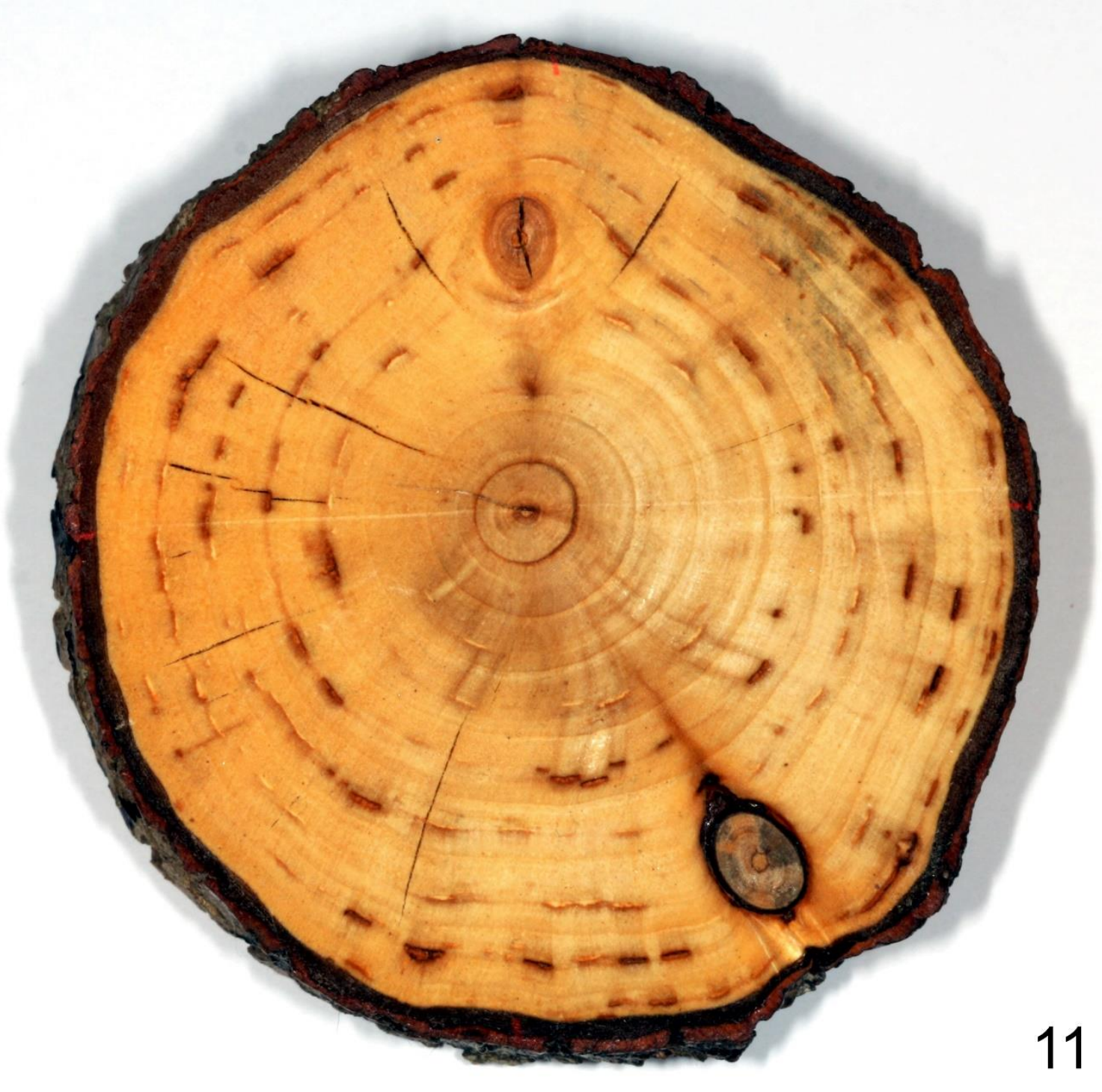

Fig. 11: Phytobia cambii (Hendel), larval pith flecks or medullary spots in a basal cross section of a young willow tree (Salix spec., Bielefeld, Germany). Diameter of trunk $73 \mathrm{~mm}$. During the first three years the tree is still too young to serve for larval development. Note the osmotic effect of some flecks on the central year rings. Photo by M. von Tschirnhaus.

Phytobia cambii (Hendel, 1931) (Figs 10, 11)

Material examined: Portugal: [5b] 10, 9.iii.2017.

Distribution: Species widespread in Europe and recorded from Austria, Belgium, Czech Republic, Denmark, Finland, France, Germany, Great Britain, Hungary, Ireland, Latvia, Lithuania, Netherlands, Poland, Romania (Paşcovici 1975), Russia (North and Central European Territories, East Siberia), Slovakia (PAPP 2009) and Sweden, also recorded from Japan. First record from Portugal.

Biology: Host plants are Populus deltoides, P. euramericana, P. nigra, P. tremula, P. trichocarpa and Salix alba, S. caprea, S. cordata, S. fragilis, S. purpurea, S. triandra, S. viminalis (MARTINEZ et al. 1986).

Note. Specimens reared from Alnus glutinosa and Betula spp. (Betulaceae) by M. Martinez and M. von Tschirnhaus are in all details identical with reared material from Salicaceae with the result that Dendromyza betulae Kangas, 1935 became a junior synonym of P. cambii (Hen- 
del) (von Tschirnhaus 1992: 480, plate 13). Two further genera with larval attack and belonging in the Betulaceae, Carpinus and Corylus, surely also belong to the host genera of P. cambii. Mines found 21.vi.2008 by M. von Tschirnhaus in the young xylem of Alnus trees in the „Hatila Vadisi Mili Park" mountain forests at $1300 \mathrm{~m}$ a.s.1. near Artvin, East Turkey, add this country to the distribution list above. The earliest description of the larval tracks in living wood (pith flecks, medullary spots, Fig. 11), of any agromyzid and especially of $P$. cambii in poplar and willow trees interprets them as the possible work of a Cerambyx species (Coleoptera) (Rennie \& Wood 1830: 239, re-issued 1838 with identical pagination by Charles Knight, London 1838). It was never cited in 291 books and articles dealing since the year 1840 with the damage of the enigmatic „cambium miners“, firstly clarified as agromyzid larvae by Nielsen (1905).

Phytoliriomyza arctica (Lundbeck, 1901)

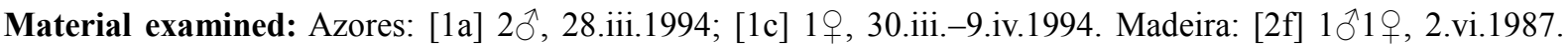
Portugal: [7b] 1ठ, 15.iv.2012; [14a] 1ठ, 12.ix.2013.

Distribution: An almost cosmopolitan species. It has been reported not only from numerous European countries from the Canary Islands to Greenland (as far north as $74^{\circ} 28^{\prime} \mathrm{N}, 20^{\circ} 34^{\prime} \mathrm{W}$, see Wirta et al. 2016) but also from North America, Brazil and Chile. From Portugal hitherto only known from the Azores and Madeira (Spencer 1965a, b), this is a new record from the Portuguese mainland.

Biology: Its host plants are Sonchus spp., probably also other species of Asteraceae.

Note. This species has previously been recorded in both the Azores and Madeira as Phytoliriomyza perpusilla (Meigen, 1830), see Spencer (1963).

Phytoliriomyza dorsata (Siebke, 1863) (Fig. 12)

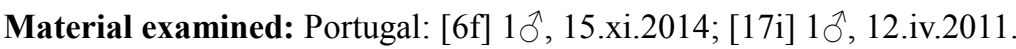

Distribution: Holarctic species known in Europe from Austria, Czech Republik, Denmark, Estonia, Finland, Great Britain, Lithuania, Norway, Poland, Romania, Russia, Slovakia and Sweden (Zlobin 2005). Also recorded from Iran (Shahreki et al. 2012), Japan (Iwasaki 2000), Kuril Islands (Iwasaki 2000), Turkey (Ç1kman \& Civelek 2005) and Yakutia (Nartshuk \& Bagachanova 2010). In North America known from United States (Spencer \& Steyskal 1989). First record from Portugal.

Biology: Host and early stages unknown.

\section{Phytoliriomyza immoderata Spencer, 1963}

Material examined: Portugal: [6g] 5ð, 16.xi.2014; [22c] 10, 25.vi.2013.

Distribution: This species was described from South Africa (Natal) and later recorded in further countries in the Palaearctic Region from Israel (Černý 2009) and Morocco (Černý \& Merz 2006). In Europe recorded from Andorra (Černý 2007a), Greece (Černý 2011a), Sardinia (Černý 2006), Serbia (Černý \& Merz 2006) and Spain (Černý \& Merz 2006). In addition, M. von Tschirnhaus collected it in Italy (Apulia, Spiaggiabella, $25 \mathrm{~km}$ SE' Brindisi, coastal

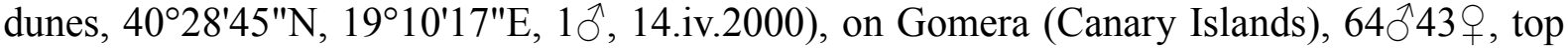
plateau of the volcan Fortaleza, peak $1241 \mathrm{~m}$ a.s.1., 28.iii.1985 and $4{ }^{\lambda} 4$ 우 on the top plateau of the volcan Garajonay, peak $1487 \mathrm{~m}$ a.s.1., 25.iii.1985. Further findings by M. von Tschirnhaus in Spain and Morocco confirm that this species is well established in the Mediterranean realm. First record from the Canary Islands, Peninsular Italy and Portugal.

Biology: Host and early stages unknown. In the Fortaleza example (Gomera) the flies visited the flowering plants of Asphodelus sp. The two mentioned volcanoes should be visited again to find out the host plant among the easily identifiable floral elements of those mountain peaks. 
Phytoliriomyza mikii (Strobl, 1898)

Material examined: Azores: [1a] 19, 28.iii.1994.

Distribution: Species described from Austria and known in Denmark, Finland, Lithuania, Poland, Sweden, also recorded from Yemen (Deeming 2006) and Kuril Islands (Iwasaki 2000). First record from the Azores.

Biology: Host and early stages unknown.

Phytoliriomyza oasis (Becker, 1907)

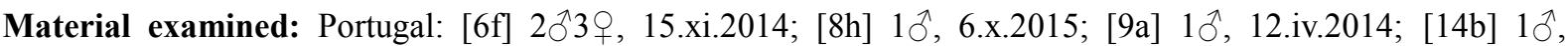
9.viii.2016; [17g] 20, 23.iii.2016.

Distribution: This species was described after a female type from Algeria and later recorded from Greece, Iraq (Spencer 1981), Kyrgyzstan (Černý \& Merz 2006), Lithuania, Morocco, Poland, Spain incl. Canary Islands, Sweden, Turkey (Černý \& Merz 2006) and Uzbekistan (Černý \& Merz 2006). First record from Portugal.

Biology: Host and early stages unknown.

Phytoliriomyza perpusilla (Meigen, 1830)

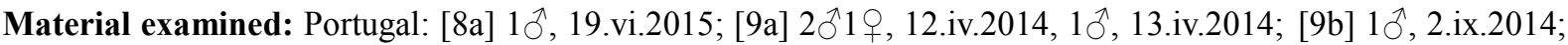

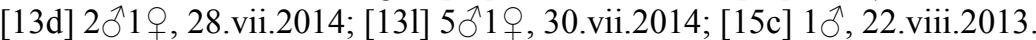

Distribution: This species is known from Palaearctic and Afrotropical regions, in Europe recorded from Austria, Belgium, Bulgaria, Czech Republic, Estonia, Finland, France, Germany, Great Britain, Greece, Hungary, Italy incl. Sardinia (Černý 2006), Lithuania, Netherlands, Poland, Portugal (Černý 2013), Romania (Papp \& Černý 2017), Serbia (Papp \& Černý 2017), Spain incl. Canary Islands, Sweden and Switzerland (Černý 2005b). This species is also known from Tunisia, Turkey, Russia - Yakutia, Cabo Verde Islands, Lesotho, Oman, South Africa and Yemen (Černý \& von Tschirnhaus 2014, Deeming 2006, Nartshuk \& Bagachanova 2010).

Biology: Host plants unconfirmed but are probably species of Compositae, concretely Aster tripolium (Spencer 1976a). The early stages are unknown.

Phytoliriomyza pteridii Spencer, 1973

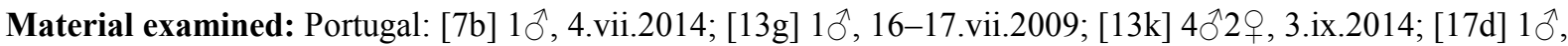
1.vii.2013.

Distribution: It is a rare European species. It was described from England, Scotland, Germany, Montenegro, Slovenia, since that time it has been reported from Andorra (Černý 2007a), Croatia (Černý 2009), France (Černý 2009), Hungary (Papp \& Černý 2017), Ireland, Italy (Černý 2006), Poland, Portugal and Slovakia. M. von Tschirnhaus collected it in large numbers on the small island of Nisiros (Greece) on Pteridium aquilinum and as well on Corfu (Greece) and Mallorca (Spain).

Biology: The larva forms a linear mine at the edge of the frond of Pteridium aquilinum.

\section{Phytoliriomyza scotica Spencer, 1962}

Material examined: Madeira: [2f] 1ㅇ, 2.vi.1987; [2g] 1ㅇ, 6.vi.1987; [2m] 1へ1 1 , 8.vi.1987; [2o] 2ㅇ, 30.v.1987;

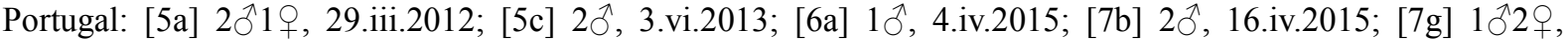

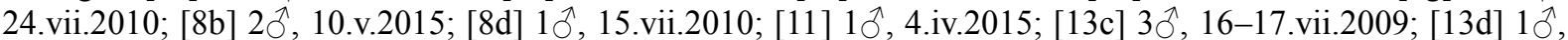

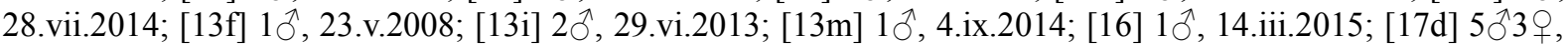
30.viii.2010, 10, 12.v.2011.

Distribution: It was described from Scotland, later recorded from Canary Islands, Czech Republic, France, Germany, Great Britain, Hungary (Papp \& Černý 2017), Portugal incl. Madeira. 

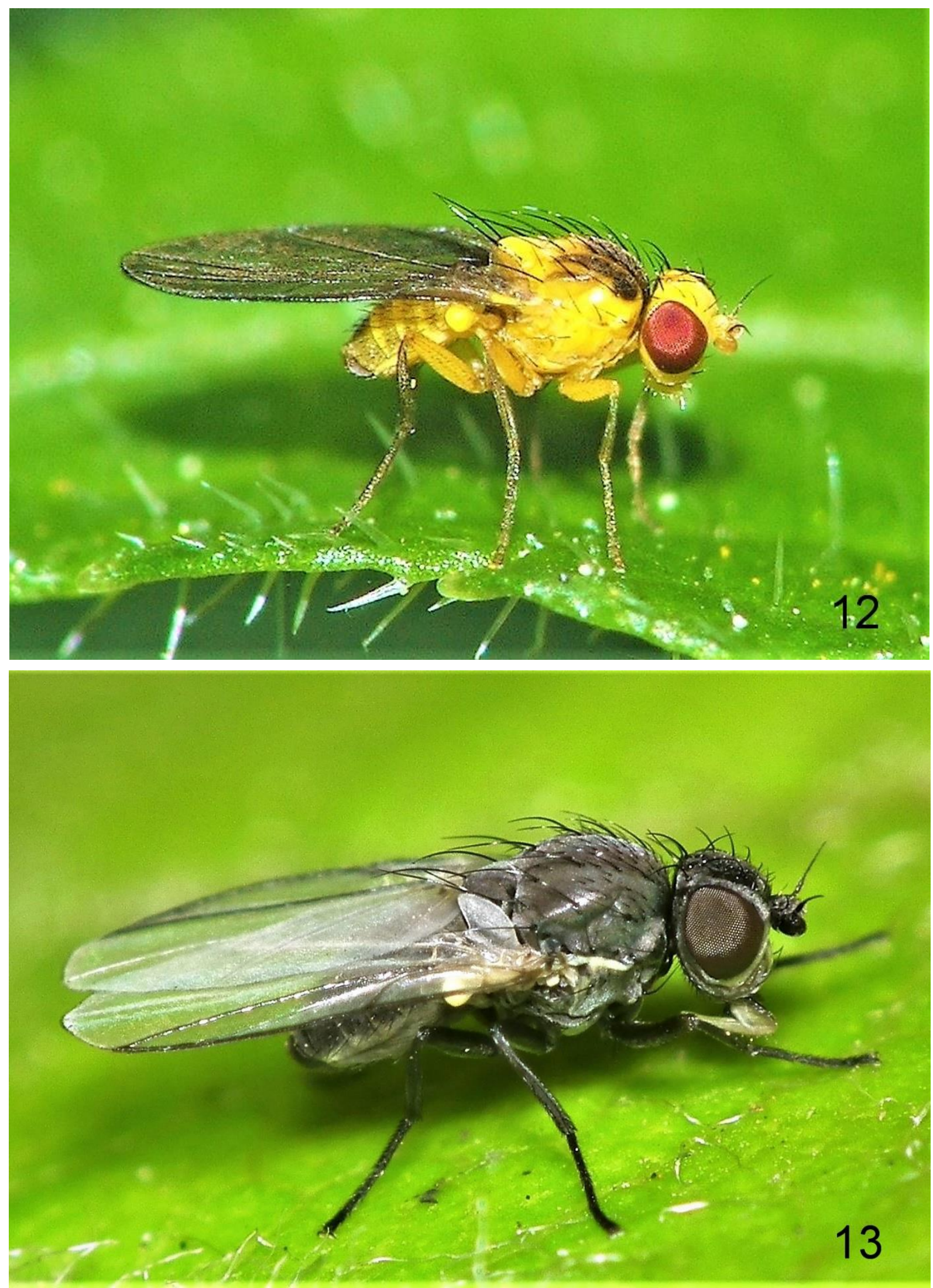

Figs 12-13: Agromyzidae species. 12 - Phytoliriomyza dorsata (Siebke), male, laterally; 13 - Phytomyza albipennis Fallén, male, dorsolaterally. Photo by R. Andrade. 
Biology: On the Canary Islands, certainly feeding on Cotula australis (Spencer 1990; compare von Tschirnhaus 1992). Spencer based his information on unpublished findings of M. von Tschirnhaus: Gomera, 8 samples in the W, NW, N and centrum of the island, 3693436 , 21.iii..-31.iii.1985, swept and aspirated from Cotula australis (Sieb.) Hook, a plant identified later by the British Museum (Natural History). It occurs also in Portugal, on Madeira and the Canary Islands being a neophyt from Australia. But Spencer (1990) on page 261 erroneously named P. scotica ,P. pilosella“. This failure has the reason that M. von Tschirnhaus proposed him to synonymize Phytoliriomyza pilosella Spencer, 1973 from Florida, Costa Rica and Puerto Rico with $P$. scotica. But on p. 301 he postponed the formal synonymization.

Phytomyza albipennis Fallén, 1823 (Fig. 13)

Material examined: Portugal: [17e] $1 \overbrace{}^{\Uparrow} 2$ ㅇ, 3.v.2017.

Distribution: Palaearctic species known from Andorra (Černý 2007a), Austria, Belgium, Bulgaria (Černý \& Merz 2006), Denmark, Croatia, Czech Republic, Estonia, Finland, France, Germany, Great Britain, Greece (Černý 2011a), Hungary, Italy, Lithuania, Netherlands, Norway (Andersen \& Jonassen 1994), Poland, Russia, Slovakia, Spain incl. Canary Islands, Sweden, Switzerland (Černý 2005b), former Yugoslavia, Turkey (Civelek et al. 2007), North Korea (Černý 2007b). First record from Portugal.

Biology: Unknown but larva almost certainly an internal feeder in Ranunculaceae (Spencer 1976a).

Phytomyza cineracea Hendel, 1920

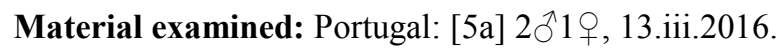

Distribution: Palaearctic species recorded from the Czech Republic, France (Černý 2013), Germany, Great Britain, Hungary, Iceland, Slovakia (Vála \& Černý 2009), Japan and recently recorded from Wrangel Island (Nartshuk \& Khruleva 2011). First record from Portugal.

Biology: Host and early stages unknown.

Phytomyza clematidis Kaltenbach, 1859

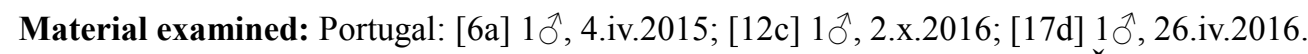

Distribution: West Palaearctic species known from Andorra (Černý 2007a), Austria, Czech Republic, Cyprus (Černý \& Vála 2006), France incl. Corsica, Germany, Great Britain, Greece (Černý \& Merz 2006), Hungary, Israel, Italy (Černý 2006), Lithuania, Maltese Islands, Netherlands, Slovakia, Spain incl. Balearic and Canary Islands, Switzerland and Turkey. First record from Portugal.

Biology: The larva forms a short linear leaf mine on host plants Clematis cirrhosa, C. vitalba, Ranunculus acris, $R$. auricomus, $R$. lanuginosus and $R$. lingua.

Phytomyza conyzae Hendel, 1920

Material examined: Portugal: [12b] 3̂, 29-30.ix.2010.

Distribution: This species is widespread in West Palaearctic and India, in Europe recorded from Albania, Austria, Bulgaria, Czech Republic, Dalmatia (Spasić \& Spencer 1992), Denmark, France incl. Corsica, Germany, Great Britain, Greece, Ireland, Italy incl. Sardinia and Sicily, Lithuania, Maltese Islands, Montenegro (Spasić 1996), Netherlands, Poland, Portugal, Romania, Spain incl. Balearic Islands, Sweden, also recorded from Cyprus (Černý \& Vála 2006), Egypt (Černý 2009), Israel, Morocco and Turkey (Civelek 2002).

Biology: The larva forms leaf mine on host plants namely Anaphalis, Arnica, Asteriscus, Buphthalmum, Dittrichia, Inula, Pallenis, Pulicaria and Telekia. 
Phytomyza evanescens Hendel, 1920

Material examined: Portugal: [5a] 1ठ, 29.iii.2012.

Distribution: Holarctic species known in Europe from Andorra (Černý 2007a), Austria, Belarus, Belgium (Scheirs et al. 1995), Czech Republic, Denmark, Estonia, Faroe Isl., Finland, France, Germany, Hungary, Iceland, Italy incl. Sicily, Lithuania, Netherlands, Norway (Andersen \& Jonassen 1994), Poland, Russia, Slovakia, Spain, Sweden, Switzerland (Černý $2005 b$ ) and former Yugoslavia. Also recorded from Kuril Islands, Asian Russia (Zlobin 1994b), Tajikistan, from North America known in Canada and United States. First record from Portugal. Biology: The larva is feeding as an internal stem-borer of Ranunculus acris and R. lanuginosus.

Phytomyza fallaciosa Brischke, 1880

Material examined: Portugal: [8c] 2ð1 1 , 10.v.2015.

Distribution: Holarctic species known in Europe from Albania (Černý \& Merz 2006), Andorra (Černý 2007a), Austria, Czech Republic, Denmark, Estonia, Faroe Isl., Finland, France, Germany, Great Britain, Greece (Černý 2011a), Iceland, Ireland, Italy, Lithuania, Montenegro (Spasić 1996), Norway, Poland, Romania, Russia, Slovakia, Switzerland (Černý 2005b) and recorded also from North Korea (Černý 2007b) and Turkey (Mart et al. 2005). First record from Portugal.

Biology: The larva forms a linear leaf mine on Ranunculus acris, $R$. auricomus, $R$. breyninus, $R$. lingua and $R$. repens.

\section{Phytomyza gymnostoma Loew, 1858}

Material examined: Portugal: [9a] 10, 12.iv.2014.

Distribution: West Palaearctic species known from Austria, Bosnia and Herzegovina (Đurić \& Hrnčić 2015), Czech Republic, Croatia, Denmark, Finland, France, Germany, Great Britain (Smith et al. 2007), Greece (Simoglou et al. 2008), Hungary, Italy incl. Sicily, Lithuania, Morocco (Mouna 1998), Netherlands, Poland, Romania (Coman \& Roşca 2011), Serbia (Spasić 1994), Slovakia, Slovenia, Spain, Sweden, Switzerland (Černý 2005b), Turkey, Turkmenistan and Ukraine. First record from Portugal.

Biology: The larva forms a mine on its host plants Allium cepa and A. porrum, often hidden inside the bulb of the onion or the compressed porrum leaves.

Note. Already von Tschirnhaus (1994: 523) pointed out in detail that in southern France an undescribed very similar species occurs sympatrically with $P$. gymnostoma (Châine des Alpilles, NNE Mouriès, $43^{\circ} 42^{\prime} \mathrm{N}, 4^{\circ} 54^{\prime} \mathrm{E}, 8{ }^{\top} 6$ ㅇ, 30.iii.1980; olive orchard N Pelissane, $4 \mathrm{~km} \mathrm{E}$ Salon-de-Provence, $5 \hat{\jmath}$, 1.iv.1980). It was collected in natural dry biotopes with wild Allium species. It has thicker yellowish palpi and different male genitalia. The type material of the two junior synonyms of P. gymnostoma (Phytomyza algecirasensis Strobl, 1906, a justified emendation of algeciracensis Strobl, 1906 by Arias Encobet (1912: 69, 238) and reconditioned by Morge (1978: 168), and Agromyza phytomyzina Hering, 1933) has not yet been investigated. The correct determinations of $P$. gymnostoma in the rapidly increasing number of publications on the dispersing Allium pest (140 papers are in the collection of M. von Tschirnhaus, the vast number of internet articles not considered) one day all will become doubtful after the taxonomy of the two sibling species will be clarified.

Phytomyza pastinacae Hendel, 1923

Material examined: Portugal: [17g] 10, 25.v.2013.

Distribution: Holarctic species, in Europe known from Austria, Belgium, Bulgaria, Czech Republic, France, Germany, Great Britain, Greece (Černý 2011a), Ireland, Latvia, Lithuania, Montenegro (Spasić 1996), Netherlands, Poland, Portugal, Russia, Slovakia, also known from United States. 
Biology: The larva forms leaf mine on Angelica, Cicuta, Conium, Heraclerum, Levisticum and Pastinaca.

Phytomyza plantaginis Robineau-Desvoidy, 1851 (Fig. 14)

Material examined: Azores: [1b] 3q, 29.iii.1994; [1n] 2̧̂, 4-5.iv.1994; [1s] 1q, 9.iv,1994; [1t] 1ㅇ, 9.iv.1994.

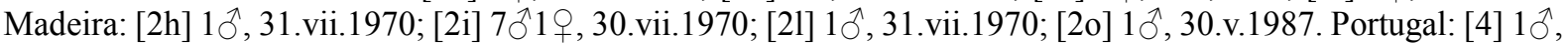

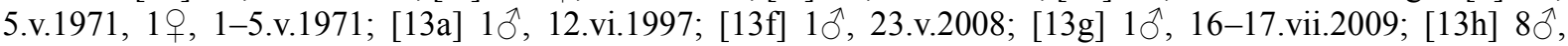
23.v.2008

Distribution: Species known from Holarctic, Neotropical, Oriental and Australian regions. In Europe recorded from Portugal to Russia and from Italy to Finland (Černý \& Merz 2006, Černý \& Vála 2006, Černý 2007a). In Portugal hitherto only known from the Azores (Spencer 1965: 109) and Portuguese mainland (Černý 2013: 286), this is the first record from Madeira.

Biology: The larva forms a narrow, white linear mine on Plantago spp., particularly P. lanceo$l a t a$ and P. major (while the very similar P. griffithsi Spencer, 1963 hitherto has only been reared from $P$. media).

Note. It is of interest that in New Zealand and Australia never males have been collected (Spencer 1976b, 1977). As well, von Tschirnhaus collected only females in Australia and in South America. From the South American continent, the species is not yet reported (Martinez \& Étienne 2002). But von Tschirnhaus collected many samples, all exclusively containing high numbers of females in Chile and Argentina. Two selected examples as first records for those countries: Chile, 38 38'26"S,

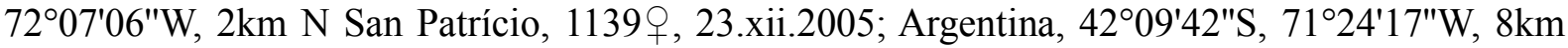
NNW Epuyén, 77, 28.i.2008. P. plantaginis follows the globally invasive "waybread" or "food steps of the white man" (Plantago major) until the passes of the high Andes and the far south of the continents. Parthenogenesis of this species and of Phytomyza crassiseta Zetterstedt, 1860 were reported first by Hering (1926) and Frick (1951) and was confirmed on the base of chromosome studies for P. crassiseta by Block (1969). Thus, the dispersion of males to the Azores and Madeira surely has taken place from Europe or the African continent. Collecting P. plantaginis on five further Macaronesian islands by von Tschirnhaus revealed both, males and females.

Phytomyza ranunculi (Schrank, 1803)

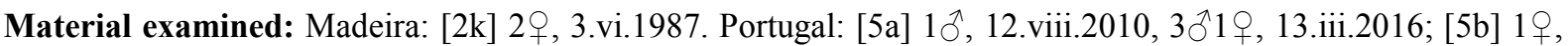
31.v.2017; [6a] 10, 4.iv.2015; [6g] 10, 16.xi.2014; [7b] 1q, 17.iv.2015; [7e] 10, 2.vi.2015; [8c] 2o, 16.v.2015;

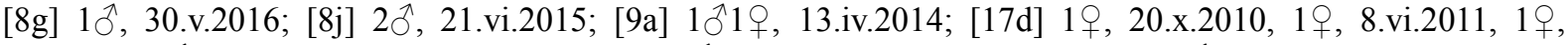

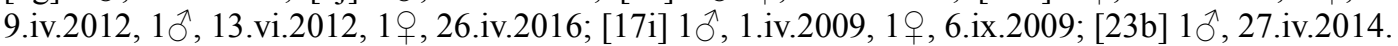

Distribution: Species known from Holarctic Afrotropic (Tanzania: Kilimanjaro) and Oriental regions, widespread throughout Europe.

Biology: The larva form leaf mines on Ficaria, Myosurus and Ranunculus.

Phytomyza ranunculivora Hering, 1932

Material examined: Portugal: [5a] 1ิे, 12.viii.2010.

Distribution: European species recorded from Austria, Balearic Islands, Belarus, Bulgaria, Czech Republic, Denmark, Estonia, Finland, France, Germany, Great Britain, Hungary (Papp 2004), Italy, Lithuania, Poland, Montenegro (Spasić 1996), Norway, Slovakia, Sweden and Switzerland (Černý \& Merz 2006). First record from Portugal.

Biology: The larva forms leaf mine on Ranunculus.

Note. Pakalniškis (1997) retained P. linguae Lundqvist, 1947 as a separate species. M. von Tschirnhaus thoroughly compared material (partly reared from Ranunculus lingua) from Denmark, Germany and the Austrian Alps. He did not find differences in the male genitalia or puparia. May be that the puparium of $P$. ranunculivora figured by Pakalniškis belongs to one of the further species developing on Ranunculus. In as far P. linguae is retained here as a junior synonym. 
Phytomyza rufipes Meigen, 1830 (Fig. 15)

Material examined: Azores: 1ㅇ, 4-5.iv.1994. Madeira: [2d] 1ㅇ, 3.i.1986. Portugal: [5a] 1ð̊, 13.iii.2016.

Distribution: Species known from the Holarctic and Neotropical (Argentina) regions. In Europe it is known from more than thirty countries, from Great Britain to Russia and from Spain (Canary Islands) to Finland and Norway. Also recorded in Canada and United States. From Portugal hitherto only known from Madeira (Becker 1908: 203), this is the first record from the Azores and the Portuguese mainland.

Biology: The larvae forming leaf mines exclusively on Brassicaceae, common on Brassica spp., less frequently on other genera namely Alliaria, Conringia, Diplotaxis, Sinapis, Moricandia, Peltaria, Raphanus, Rorippa and Sisymbrium.

Phytomyza sedi Kaltenbach, 1869

Material examined: Portugal: [19] 10^, 15.iv.2011.

Distribution: A European species described from Germany and hitherto recorded from Andorra (Černý 2007a), Czech Republic (Černý \& Heřman 2015), France, Great Britain (Gibbs 2007), Spain, Sweden (Zlobin 2005), Switzerland (Černý 2005b) and former Yugoslavia. First record from Portugal.

Biology: The larva forms brownish lower surface blotch mine on Sedum album and S. rupestre. Note. The types of $P$. catalaunica Spencer, 1960 had been studied by von Tschirnhaus (1994: $526)$ with the result that the latter name became a junior synonym of $P$. sedi.

Phytomyza spondylii Robineau-Desvoidy, 1851

Material examined: Portugal: [17f] 1§, 14.vi.2013.

Distribution: This is a Holarctic species, widespread and common in Europe namely recorded from Belgium, Bulgaria, Czech Republic, Denmark, Finland, France, Germany, Hungary, Ireland, Italy, Lithuania, Netherlands, Norway, Poland, Portugal, Romania, Spain, Sweden, Switzerland, also known from Canada and United States incl. Alaska.

Biology: The larva forms leaf mine on Heracleum, Levisticum and Pastinaca.

Phytomyza tetrasticha Hendel 1927

Material examined: Portugal: [5a] 2へ, 28.xi.2010, 1ð, 15.xii.2010; [13g] 3ð, 16-17.vii.2009.

Distribution: Palaearctic species in Europe recorded from Belgium, Bulgaria, Czech Republic, Denmark, France incl. Corsica, Germany, Great Britain, Greece (Černý 2011a), Ireland, Italy, Lithuania, Poland, Portugal (Černý 2009) incl. Azores, Slovakia, Spain incl. Canary Islands, Sweden, Switzerland (Černý \& Merz 2007). Also known from Iraq (Spencer 1981), Japan (Iwasaki 1997) and Turkey (Civelek 2003).

Biology: The larva form leaf mine on Mentha.

Phytomyza wahlgreni Rydén, 1944

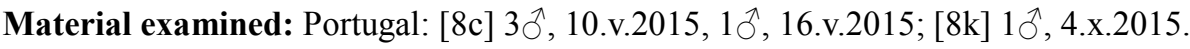

Distribution: Holarctic species described from Sweden, in Europe recorded from Austria, Belarus, Czech Republic, Denmark, Estonia, Faroe Isl., Finland, France, Germany, Great Britain, Ireland, Italy, Latvia (Karpa 2008), Montenegro (Spasić 1996), Norway, Poland, Russia, Slovakia and Sweden. Species known also from China, Kuril Islands (Iwasaki 2000), Morocco (Černý \& Merz 2006), Turkey (Çıkman \& Sasakawa 2010), Uzbekistan (Černý \& Merz 2006) and in North America known from the United States. First record from Portugal.

Biology: The larva feeds in the midrib of Taraxacum officinale.

Note. Females of $P$. wahlgreni are very difficult to distinguish from $P$. rhabdophora Griffiths, 1964 with which it occurs together on Taraxacum and Leontodon (von Tschirnhaus 1969). Constant helpful differentiation features may be mentioned here: Orbits without black edges 
along eye margin and outside the two upper orbital setae; along the yellow hind edges of the tergites there is not a sharp exact border against the anterior black part of the tergite as in rhabdophora, black and yellow are flowing together; the upper yellow edge of the anepisternum is wider in wahlgreni, half-moon shaped with the convex side ventrally and the straight side touching the notopleuron.

Pseudonapomyza atra (Meigen, 1830)

Material examined: Portugal: [6g] 1우 16.xi.2014; [8f] 1ㅇ, 21.vi.2015.

Distribution: Holarctic species known in Europe from Andorra (Černý 2007a), Austria, Belarus, Belgium, Bulgaria, Croatia (Černý 2009), Czech Republic, Denmark, Estonia, Finland, France incl. Corsica (Černý \& Merz 2006), Germany, Great Britain, Greece (Černý \& Merz 2006), Croatia (Černý 2009), Dalmatia (Spasić \& Spencer 1992), Hungary, Italy incl. Sardinia (Černý 2006), Latvia, Lithuania, Maltese Islands (Černý 2005a), Netherlands, Norway (Andersen \& Jonassen 1994), Poland, Portugal incl. Azores and Madeira Islands (Černý \& Merz 2006), Romania, Russia, Slovakia, Spain incl. Canary Islands, Sweden, Switzerland (Černý 2005b), Ukraine and former Yugoslavia. Recorded also from Cape Verde Islands, Cyprus (Černý \& Vála 2006), Egypt, India, Iran, Israel (Černý 2009), Kazakhstan, Kyrgyzstan, Mongolia, Tajikistan, Tunisia (Černý 2009), Turkey, Turkmenistan, Uzbekistan, Yakutia (Nartshuk \& Bagachanova 2010), and known in Canada, United States (Boucher 2004).

Biology: The larva forms leaf mine in leaves of many Poaceae, especially in Agropyron, Apera, Avena, Hordeum, Lolium, Phalaris, Poa, Secale and Triticum.

Pseudonapomyza europaea Spencer, 1973

Material examined: Portugal: [7b] 1ð̊, 28.iv.2017.

Distribution: Species originally known only from European locations and later recorded also from Iran (Ranji et al. 2015), Japan (Černý 2005c), Canada and the United States (Boucher 2004), Turkey (Černý 2005c). In Europe known from Andorra (Černý 2007a), Austria, Belgium, Bulgaria (Černý \& Merz 2006), Czech Republic, Denmark (Petersen \& von Tschirnhaus 2001), Estonia, Finland (Černý \& Merz 2006), France, Germany, Great Britain, Greece (Černý 2011a), Hungary, Italy, Lithuania, Macedonia, Norway (Andersen \& Jonassen 1994), Poland, Romania, Serbia, Slovakia, Slovenia, Spain, Sweden (Zlobin 2005), Switzerland and Ukraine. First record from Portugal.

Biology: Host plants are certainly Poaceae, Greiler (1994) reported Dactylis glomerata as a host plant for P. europaea. In Canada (Quebec) specimens of P. europaea were collected in the same series as specimens of P. atra (Boucher 2004).

\section{Pseudonapomyza hispanica Spencer, 1973}

Material examined: Madeira: [2a] 6 4 우, 22.vii.1995.

Distribution: Species described from Spain, later confirmed from Cyprus, Egypt, Gambia, Greece, Israel, Nigeria, Sierra Leone, Tanzania, Turkey, Yemen and Zambia (Černý \& von Tschirnhaus 2014). M. von Tschirnhaus collected it in Spain, too, and on the islands of Crete and Corfu (Greece). Gil-Ortiz et al. (2010b) added Austria, France, Italy and Madeira but all without documented collecting data. First record with collecting data for Madeira.

Biology: Confirmed host plants are the Poaceae Echinochloa crus-galli (Deeming 2006) and Sorghum halepense. 

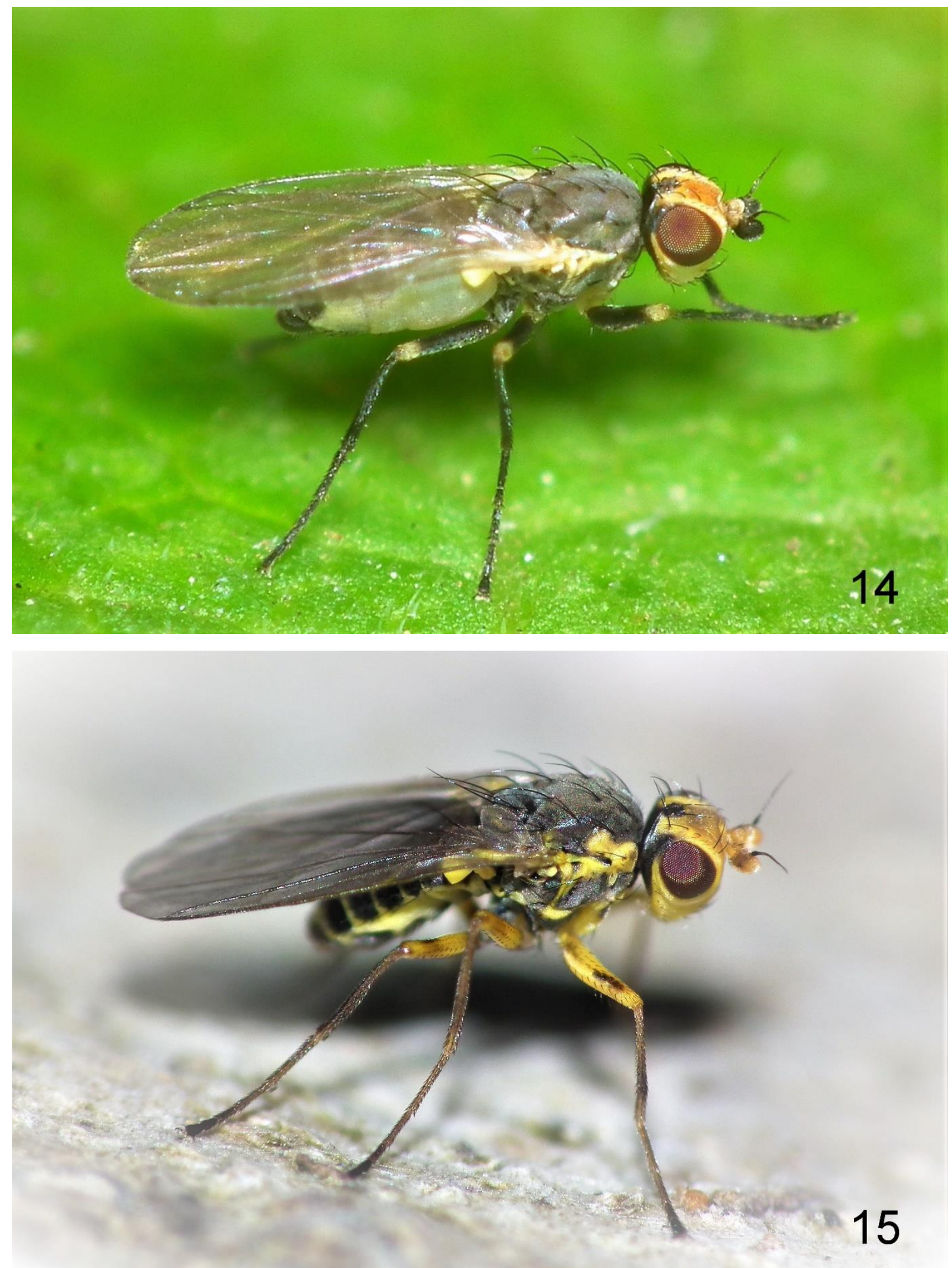

Figs 14-15: Agromyzidae species. 14 - Phytomyza plantaginis Robineau-Desvoidy, male, dorsolaterally; 15 - Phytomyza rufipes Meigen, male, dorsolaterally. Photo by R. Andrade. 
Pseudonapomyza insularis Zlobin, 1993

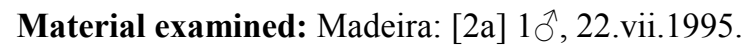

Distribution: Described from Tenerife (Canary Islands) and the Afrotropical Cape Verde Islands, later recorded from Botswana, Gambia, Kenya, Sierra Leone and Zambia (Černý \& Zlobin 2008). No further findings. First record for Madeira.

Biology: Host plants surely are Poaceae, as in all species of the P. atra-group.

Pseudonapomyza pallidinervis Zlobin, 2003

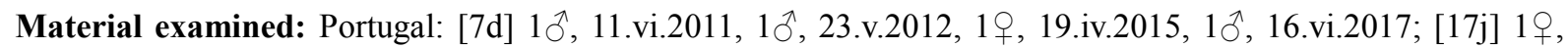
12.iv.2009.

Distribution: Species known from Russia (European part), East Siberia, Kazakhstan and Mongolia. First records from Portugal and Western Europe.

Biology: Host and early stages unknown.

Pseudonapomyza spinosa Spencer, 1973

Material examined: Madeira, Porto Santo Island: [3a] 2ð, 9.vi.1987; [3b] 10Љ12ᄋ, 10.vi.1987. Portugal: [7d]

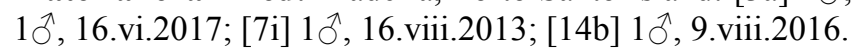

Distribution: This species is recorded from Afrotropical, Palaearctic and Oriental Regions (Černý \& von Tschirnhaus 2014). In Europe it is known from Greece, Spain incl. Canary Islands and in Portugal to date it is known only from Vila Nova de Milfontes (Černý 2013). First record for Porto Santo and the Madeira archipelago.

Biology: Confirmed host plant genera are the Poaceae Brachiaria, Eleusine, Hordeum, Triticum and Zea mays.

\section{Discussion}

The new enlarged catalogue of the Portuguese Agromyzidae presented here indicates that the local fauna of this family on the Azores, Madeira and the Portuguese mainland is much richer than formerly known. A total of 142 species of Agromyzidae are recorded from Portugal, 64 species are new to the Portuguese mainland, 8 species represent the first records for Madeira and Porto Santo, and 5 species represent the first records for the Azores.

Altogether 76 species of Agromyzidae were previously known to occur in Portugal (Bella et al. 2013, Černý 2009, 2013, Černý \& Merz 2006, Gil-Ortiz et al. 2011, Martinez \& Báez 2002). Our records increase the number of Agromyzidae of Portugal to 142 by adding 66 hitherto unrecorded species. Compared with other European countries (e.g. Andorra 92 species, Spain 280 species, France 385 species, Great Britain 398 species) numerous additional species are expected to be discovered during field work in unstudied areas using appropriate collecting methods: Malaise traps, pan traps, sweeping and aspirating or rearing flies from infested plants.

A short comparison of March/April sweep net samples may throw some light on the confirmed poor agromyzid fauna of the Azores: Collecting 20 samples from 28.iii.-9.iv.1994 on the largest Azores island São Miguel $\left(747 \mathrm{~km}^{2}\right)$, M. von Tschirnhaus focused on obtaining Agromyzidae and Chloropidae with the result of eleven agromyzid (and six chloropid) species only. Collecting 24 samples during 18-29.iii.1985 on Gomera (Canary Islands) resulted in 30 species, in 15 samples from 30.iii.-3.iv.1985 on Tenerife 15 species were identified, 18 samples from 26.iii.-3.iv.1986 on Mallorca produced 35 species, and in 22 samples collected 1527.iii.1987 on Crete (Greece) 36 agromyzid species were found. Compared with the Atlantic islands the low diversity may have three reasons: São Miguel is dominated by cattle pastures and agriculture with a low plant diversity, winter and spring bring much more precipitation, far off in the ocean and under permanent wind exposure the arrival of founder species and their population establishment is less probable. 

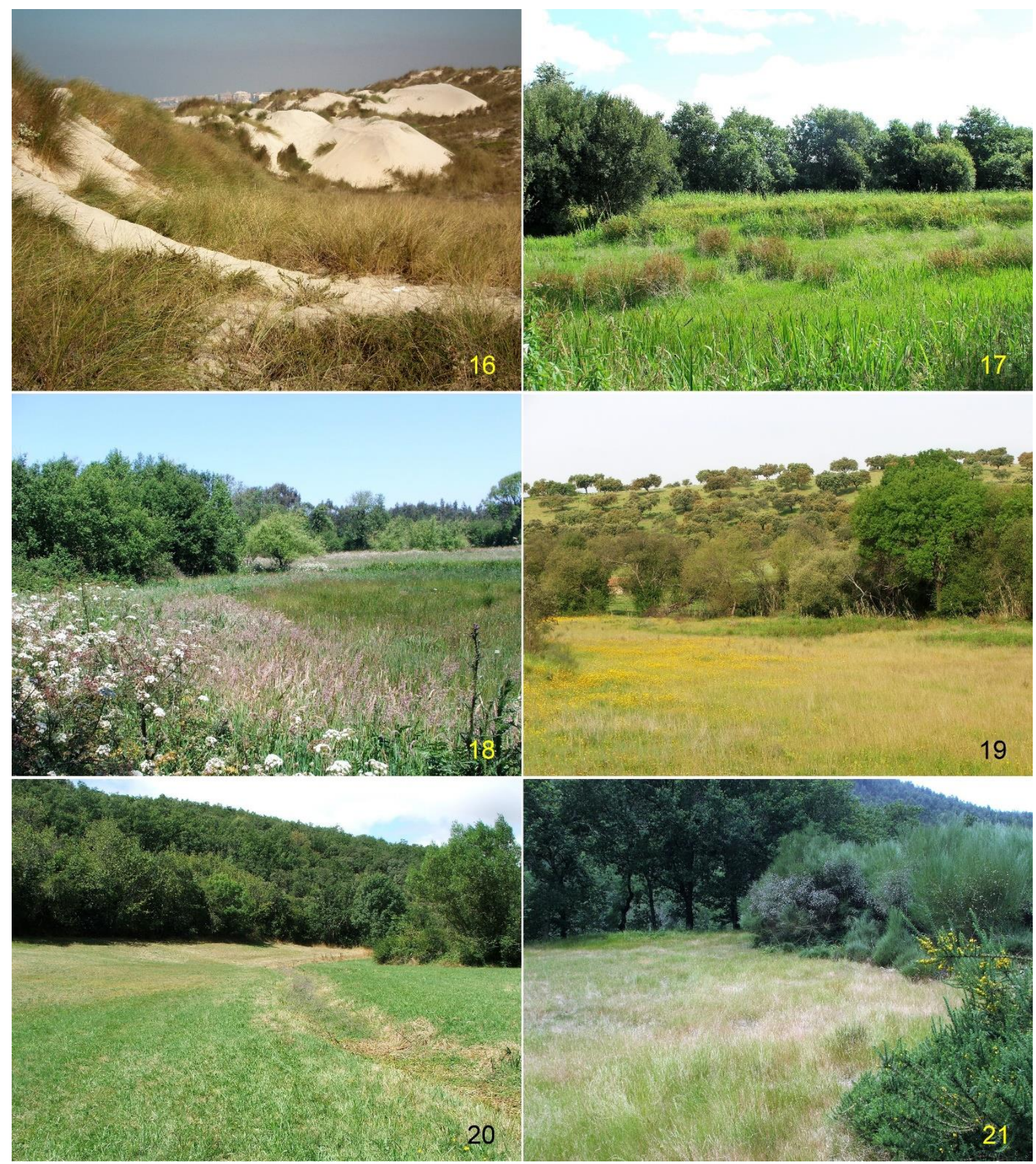

Figs 16-21: Habitats of Agromyzidae. 16 - habitat of Pseudonapomyza pallidinervis Zlobin and $P$. spinosa Spencer, Apúlia e Fão (Esposende); 17 - habitat of Cerodontha (Cerodontha) fulvipes (Meigen), C. (Dizygomyza) luctuosa (Meigen) and Liriomyza orbona (Meigen), Canelas e Fermelã (Estarreja); 18 - habitat of Liriomyza latigenis (Hendel) and Metopomyza scutellata (Fallén), Mindelo (Vila do Conde); 19 - habitat of Agromyza hiemalis Becker, Hexomyza sarothamni (Hendel), Melanagromyza pubescens Hendel, Phytoliriomyza oasis (Becker), Monforte da Beira (Castelo Branco); 20 - habitat of Cerodontha (Butomomyza) mellita Spencer, Hexomyza sarothamni (Hendel), Phytomyza wahlgreni Rydén, Espinhosela (Bragança); 21 - habitat of Cerodontha (Icteromyza) rozkosnyi Černý, Phytomyza albipennis Fallén, Valongo (Valongo). Photo by R. Andrade. 
For the applied entomology and as a serious warning for staffs employed for fulfilling the European quarantine laws here we document the first transatlantic arrival of Nemorimyza maculosa as a neozoon in the Old World. In both Americas it attacks many vegetable plants and cut flowers belonging in plant genera of the Asteraceae and also in the Solanaceae. The papers of Ota \& Nishida (1966) or Stegmaier (1967) are helpful as startpoints to study this species. Several further articles already deal with the parasitoids, competitors and other antagonistic organisms of this leaf miner.

We include new or additional information on several host plant genera of the treated Agromyzidae: Allium (Alliaceae), Alnus and Betula (Betulaceae), Argyranthemum and Cotula (Asteraceae), Digitalis and Plantago (Plantaginaceae), Festuca and Phragmites (Poaceae), Galium (Rubiaceae), Juncus (Juncaceae), Lamium (Lamiaceae), Ranunculus (Ranunculaceae), and Salix (Salicaceae). The unknown host plant of Phytoliriomyza immoderata is assumed to grow on the peaks of two extinct volcanoes on Gomera, being a worthwile aim for a further search.

\section{Updated checklist of the Agromyzidae of Portugal}

( $\mathrm{FE}=$ Fauna europaea, $\mathrm{P}=$ Portuguese mainland 122 spp., $\mathrm{A}=$ Azores 23 spp., $\mathrm{M}=$ Madeira 33 spp., nA: new for the Azores fauna, nM: new for the Madeira fauna, nP: new for the Portuguese mainland fauna)

\section{Agromyzidae Fallén, 1810 SUBFAMILY AGROMYZINAE}

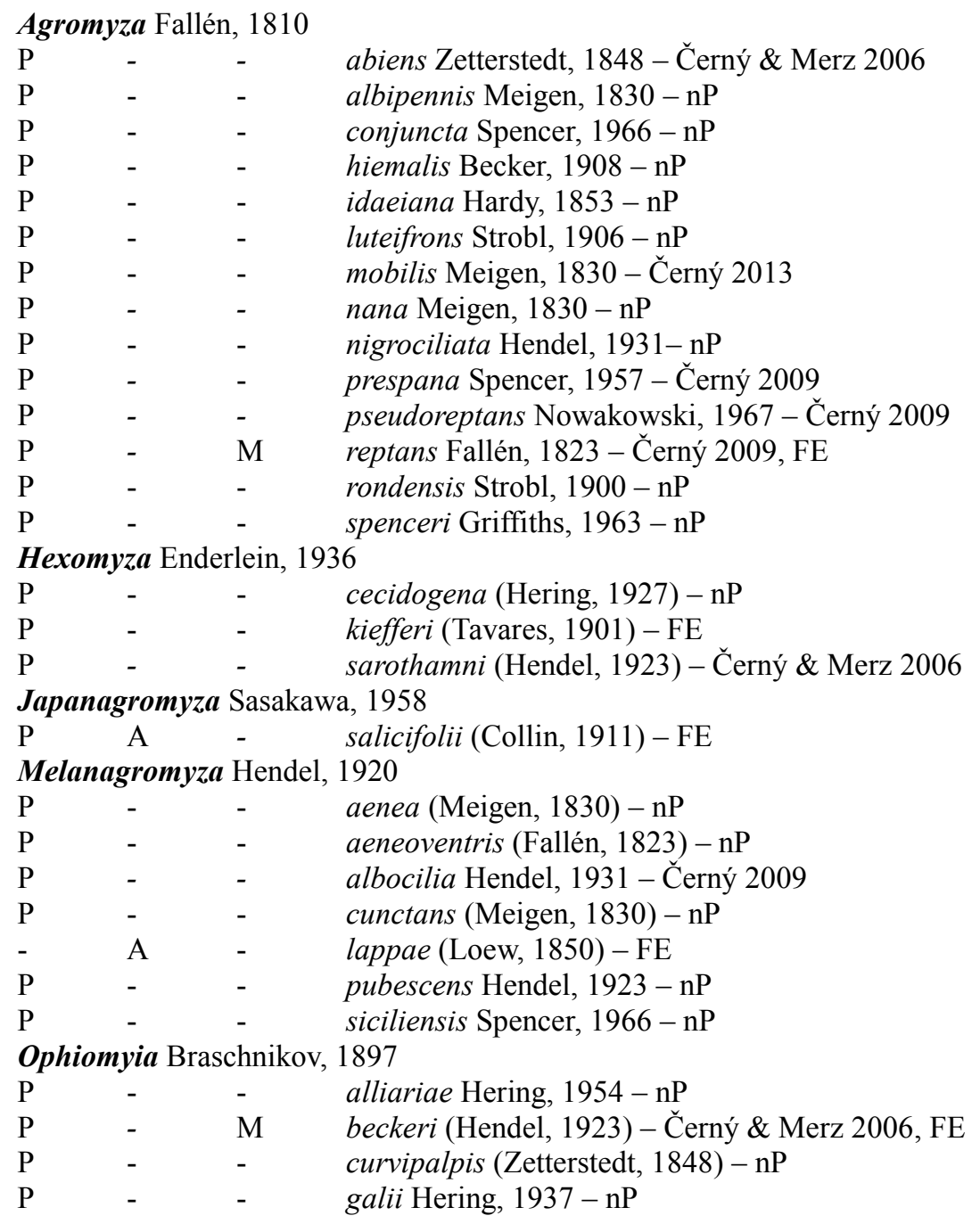


heracleivora Spencer, 1957 - Černý 2013

heringi Starý, 1930 - $\mathrm{nP}$

labiatarum Hering, $1937-\mathrm{nP}$

melandryi de Meijere, 1924 - nP

moravica Černý, $1994-\mathrm{nP}$

orbiculata (Hendel, 1931) - Černý 2013

pulicaria (Meigen, 1830)- Černý 2013

vimmeri Černý, 1994 - nP

\section{Subfamily Phytomyzinae}

Amauromyza Hendel, 1931

subgenus Cephalomyza Hendel, 1931$$
\begin{aligned}
& \mathrm{P} \\
& \mathrm{P} \\
& \mathrm{P}
\end{aligned}
$$$$
\text { - } \quad \text { flavifrons (Meigen, 1830) }-\mathrm{nP}
$$$$
\mathrm{P} \quad-\quad-\quad-\quad \text { luteiceps (Hendel, 1920) - nP }
$$$$
\text { P } \quad \text { - } \quad \text { - } \quad \text { monfalconensis (Strobl, 1909) - Černý } 2009
$$

Aulagromyza Enderlein, 1936

$$
\begin{array}{llll}
\mathrm{P} & - & - & \text { discrepans (van der Wulp, 1871) - Černý } 2009 \\
\mathrm{P} & - & - & \text { orphana }(\text { Hendel, 1920) }-\mathrm{nP} \\
\mathrm{P} & - & - & \text { trivittata (Loew, 1873) - Černý } 2013
\end{array}
$$

Cerodontha Rondani, 1861 subgenus Butomomyza Nowakowski, 1967

$P$

$\mathrm{P}$ subgenus Cerodontha Rondani, 1861

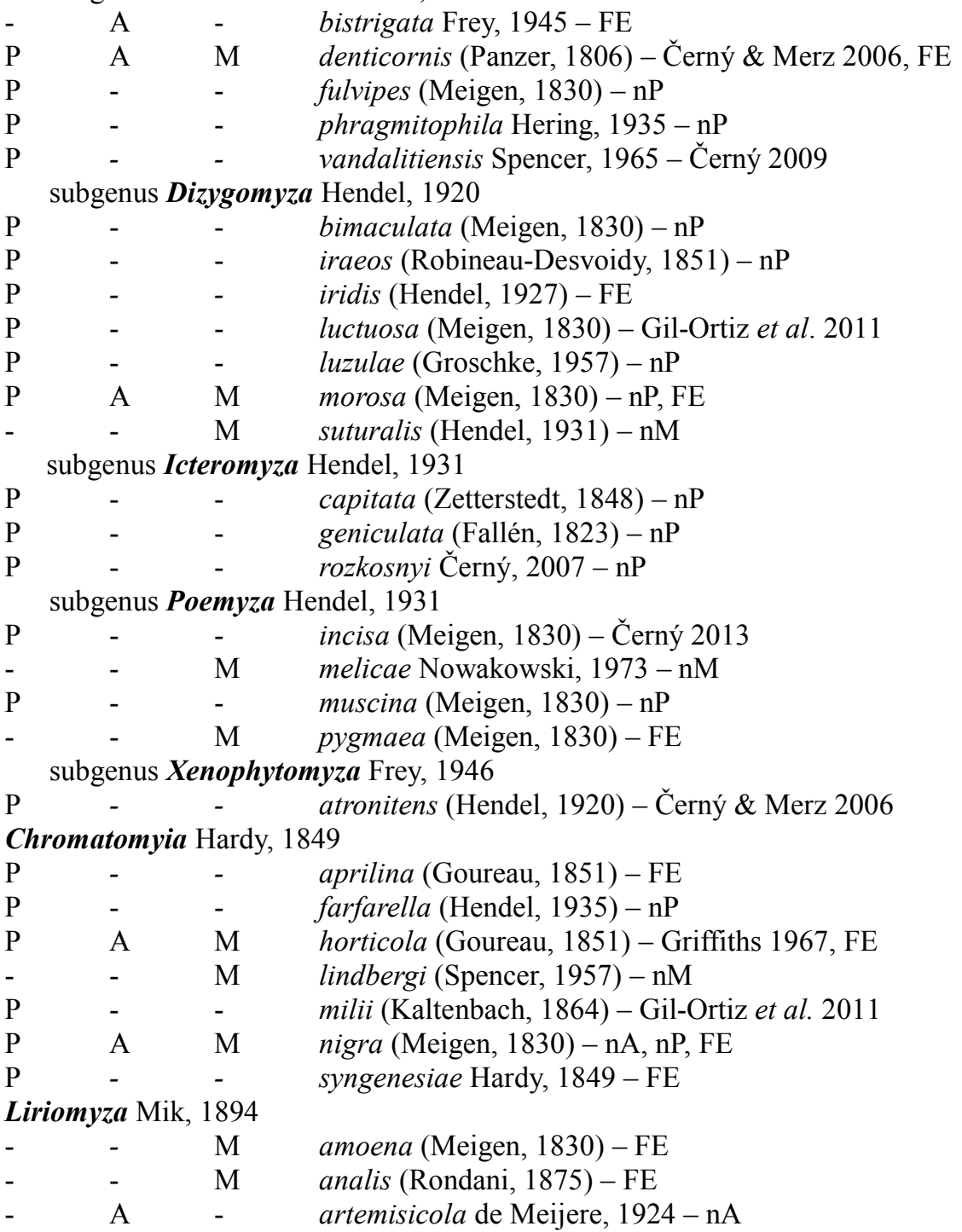

angulata (Loew, 1869) - nP

mellita Spencer, 1971 - nP 


$\begin{array}{lll}\mathrm{P} & - & - \\ \mathrm{P} & \mathrm{A} & - \\ \mathrm{P} & - & - \\ \mathrm{P} & - & - \\ - & - & \mathrm{M} \\ \mathrm{P} & - & - \\ \mathrm{P} & - & \mathrm{M} \\ \mathrm{P} & - & - \\ \mathrm{P} & - & - \\ - & \mathrm{A} & - \\ \mathrm{P} & - & \mathrm{M} \\ \mathrm{P} & - & - \\ \mathrm{P} & - & - \\ \mathrm{P} & - & - \\ \mathrm{P} & - & \mathrm{M} \\ \mathrm{P} & - & - \\ \mathrm{P} & - & - \\ \mathrm{P} & \mathrm{A} & -\end{array}$

brassicae (Riley, 1884) - Černý \& Merz 2006

bryoniae (Kaltenbach, 1858) - FE

cicerina (Rondani, 1875) - FE

congesta (Becker, 1903) - Černý 2013

M euphorbiana Hendel, 1931 - FE

flaveola (Fallén, 1823) - Černý 2013

M huidobrensis (Blanchard, 1926) - FE

- infuscata Hering, 1926 - nP

latigenis (Hendel, 1920) - nP

nigrifrons Hendel, 1920 - FE

$\mathrm{M} \quad$ orbona (Meigen, 1830) $-\mathrm{nP}$

pedestris Hendel, 1931 - nP

- ptarmicae de Meijere, 1925 - Gil-Ortiz et al. 2011

richteri Hering, 1927 - Gil-Ortiz et al. 2011

M strigata (Meigen, 1830)- $\mathrm{P}=$ Gil-Ortiz et al. 2011

taraxaci Hering, 1927 - Černý 2009

trifolii (Burgess in Comstock, 1880)

Metopomyza Enderlein, 1936

$\mathrm{P} \quad$ - $\quad$ - $\quad$ scutellata (Fallén, 1823) - nP

Napomyza Westwood, 1840

$\begin{array}{lll}\mathrm{P} & \mathrm{A} & - \\ \mathrm{P} & \mathrm{A} & \mathrm{M} \\ \mathrm{P} & - & - \\ \mathrm{P} & \mathrm{A} & -\end{array}$

Nemorimyza Frey, 1946

Phytobia Lioy, 1864

$\mathrm{P}$

Phytoliriomyza Hendel, 1931

bellidis Griffiths, 1967 - nP, FE

lateralis (Fallén, 1823) - Černý \& Merz 2006, FE

merita Zlobin, 1993 - nP

scrophulariae Spencer, 1966 - Černý 2013, nA

maculosa (Malloch, 1913) - nM

cambii (Hendel, 1931) - nP

\begin{tabular}{|c|c|c|c|}
\hline $\mathrm{P}$ & A & M & arctica (Lundbeck, 1901) - nP, FE \\
\hline $\mathrm{P}$ & - & - & dorsata (Siebke, 1863) - nP \\
\hline $\mathrm{P}$ & - & - & immoderata Spencer, $1963-\mathrm{nP}$ \\
\hline $\mathrm{P}$ & - & - & jacarandae Steyskal \& Spencer, 1978 - B \\
\hline - & A & - & mikii (Strobl, 1898) - nA \\
\hline $\mathrm{P}$ & - & - & oasis (Becker, 1907) - nP \\
\hline $\mathrm{P}$ & - & M & pectoralis Becker, $1908-\mathrm{P}=$ Černý 2013 \\
\hline $\mathrm{P}$ & - & - & perpusilla (Meigen, 1830) - Černý 2013 \\
\hline $\mathrm{P}$ & - & - & pteridii Spencer, 1973 - FE \\
\hline $\mathrm{P}$ & - & M & scotica Spencer, $1962-\mathrm{FE}$ \\
\hline
\end{tabular}

Phytomyza Fallén, 1810

$\begin{array}{lll}- & - & \mathrm{M} \\ \mathrm{P} & - & - \\ \mathrm{P} & - & - \\ \mathrm{P} & - & - \\ \mathrm{P} & - & - \\ \mathrm{P} & - & - \\ \mathrm{P} & - & - \\ \mathrm{P} & - & - \\ \mathrm{P} & - & - \\ - & - & \mathrm{M} \\ \mathrm{P} & - & - \\ \mathrm{P} & - & - \\ \mathrm{P} & \mathrm{A} & \mathrm{M} \\ - & - & \mathrm{M} \\ \mathrm{P} & - & - \\ \mathrm{P} & \mathrm{A} & \mathrm{M} \\ \mathrm{P} & \mathrm{A} & \mathrm{M} \\ \mathrm{P} & - & - \\ \mathrm{P} & \mathrm{A} & \mathrm{M}\end{array}$

affinis Fallén, 1823 - FE

albipennis Fallén, $1823-\mathrm{nP}$

bellidina Hendel, 1934 - FE

cineracea Hendel, 1920 - nP

clematidis Kaltenbach, 1859 - nP

conyzae Hendel, 1920 - FE

crassiseta Zetterstedt, 1860 - Černý 2009

evanescens Hendel, 1920 - nP

fallaciosa Brischke, $1880-\mathrm{nP}$

flavicornis Fallén, 1823 - FE

gymnostoma Loew, 1858 - nP

medicaginis Hering, 1925 - Černý 2009

obscura Hendel, 1920 - Černý \& Merz 2006, FE

obscurella Fallén, 1823 - FE

pastinacae Hendel, 1923 - FE

plantaginis Robineau-Desvoidy, 1851 - Černý \& Merz 2006, nM, FE

ranunculi (Schrank, 1803) - P = Černý 2013, FE

ranunculivora Hering, $1932-\mathrm{nP}$

rufipes Meigen, $1830-\mathrm{nA}, \mathrm{nP}, \mathrm{FE}$ 


\begin{tabular}{|c|c|c|c|}
\hline $\mathrm{P}$ & - & - & sedi Kaltenbach, $1869-\mathrm{nP}$ \\
\hline $\mathrm{P}$ & - & - & smyrnii Spencer, 1954 - FE \\
\hline $\mathrm{P}$ & - & - & spondylii Robineau-Desvoidy, $1851-\mathrm{FE}$ \\
\hline- & A & M & tenella Meigen, $1830-\mathrm{FE}$ \\
\hline $\mathrm{P}$ & A & - & tetrasticha Hendel, 1927 - Černý 2009 \\
\hline $\mathrm{P}$ & - & - & wahlgreni Rydén, 1944 - nP \\
\hline \multicolumn{4}{|c|}{ Pseudonapomyza Hendel, 1920} \\
\hline $\mathrm{P}$ & A & M & atra (Meigen, 1830) - Černý \& Merz 2006, FE \\
\hline $\mathrm{P}$ & - & - & europaea Spencer, $1973-\mathrm{nP}$ \\
\hline - & - & M & hispanica Spencer, $1973-\mathrm{nM}$ \\
\hline - & - & $\mathrm{M}$ & insularis Zlobin, $1993-\mathrm{nM}$ \\
\hline $\mathrm{P}$ & - & - & pallidinervis Zlobin, $2003-\mathrm{nP}$ \\
\hline $\mathrm{P}$ & - & M & spinosa Spencer, 1973 - Černý 2013, nM \\
\hline $\mathrm{P}$ & - & - & vota Spencer, 1973 - Černý \& Merz 2006 \\
\hline
\end{tabular}

Acknowledgements: Our sincere thanks go to Pedro Andrade (Vila do Conde, Portugal), Miroslav Barták (Praha, Czech Republic), Werner Barkemeier (Flensburg, Germany), Bohuslav Mocek (Hradec Králové, Czech Republic) and Gerd Weigmann (Berlin) for a friendly provision or loan of valuable material for this study.

\section{References}

Andersen A. (2012): On the Agromyzidae (Diptera) in Norway, Part 1. - Norwegian Journal of Entomology 59: 5-30.

Andersen A. \& Jonassen T. (1994): Faunal records of Agromyzidae (Diptera) from Norway. - Fauna norvegica, Ser. B 41: 59-64.

Arias Encobet J. (1912): Datos para el conocimiento de la distribución geográfica de los Dípteros de España. Memorias de la Real Sociedad española de Historia natural 7(2): 61-246.

Becker T. (1908): Dipteren der Insel Madeira. - Mitteilungen aus dem zoologischen Museum in Berlin 4(1): 181 206.

Beiger M. (1979): Materials to the knowledge of mining insects of Bulgaria. - Polskie Pismo entomologiczne 49: 485-534. (In Polish, Engl. summary).

Bell H., Wakefield M., Macarthur R., Stein J., Collins D., Hart, A., Roques A., Augustin S., Yart A., Pere C., Schrader G., Wendt C., Battisti A., Faccoli M., Marini L. \& Toffolo E.P. (2014): A Review of the Literature Relevant to the Monitoring of Regulated Plant Health Pests in Europe. - Appendix C to the final report on: Plant health surveys for the EU territory: an analysis of data quality and methodologies and the resulting uncertainties for pest risk assessment (PERSEUS) CFP/EFSA/PLH/2010/01. (Supporting Publications 2014: EN-676: 212 pp.); 673 pp., efsa (European Food Safety Authority), Parma, Italy.

Bella S. (2013): New alien insect pests to Portugal on urban ornamental plants and additional data on recently introduced species. - Annales de la Société entomologique de France 49(4): 374-382.

Benavent-Corai J., Martinez M. \& Peydró J.R. (2005): Catalogue of the hostsplants of the world Agromyzidae (Diptera): Part 1: List of Agromyzidae species and their hosts-plants. Part II: List of hosts [sic!]plants and Agromyzidae associated. - Bollettino di Zoologia agraria e di Bachicoltura, Università degli Studi di Milano, Ser. II 37(Suppl.): 1-97.

Bland K.P. (1983): Further records of Scottish agromyzid flies (Diptera: Agromyzidae). - Entomologist's Record and Journal of Variation 95(3-4): 77-79.

Block K. (1969): Chromosomal variation in Agromyzidae. II. Phytomyza crassiseta Zetterstedt - a parthenogenetic species. - Hereditas 62(3): 357-381.

Boucher S. (2004): The New World fauna of the genus Pseudonapomyza (Diptera: Agromyzidae). - The Canadian Entomologist 136(6): 781-791.

- (2012): Revision of the Canadian species of Amauromyza Hendel (Diptera: Agromyzidae). - The Canadian Entomologist 144: 733-757.

Buhr H. (1941): Dipteren-, insbesondere Agromyziden-Minen aus Südeuropa. - Stettiner entomologische Zeitung 102: 73-119.

CABI/EPPO (1999): Nemorimyza maculosa (Malloch), Diptera: Agromyzidae. - Distribution Maps of Plant Pests. Compiled by CAB International in association with EPPO 593: 1-2. 
Ç1kman E. \& Civelek H.S. (2005): Contributions to the leafminer fauna (Diptera: Agromyzidae) from Turkey, with four new records. - Phytoparasitica 33(4): 391-396.

Çıkman E. \& Sasakawa M. (2006): Two new records for the Turkish Agromyzidae (Diptera) fauna. - Türkiye Entomoloji Dergisi 30(4): 255-260.

Civelek H.S. (2002): New records of Agromyzidae (Diptera) from Western Turkey. - Insecta Mundi 16(1-3): 4955.

Civelek H.S., Çıkman E. \& Dursun O. (2009): Revised checklist of Turkish Agromyzidae (Diptera) fauna of Turkey. - Turkish Journal of Entomology 33(3): 349-358.

Civelek H.S., Tonguc A., Ozgul O. \& Dursun O. (2007): Contributions to the Turkish Agromyzidae Fauna from Anatolian Part of Turkey, with fifteen New Records (Insecta: Diptera). - Mitteilungen des internationalen entomologischen Vereins e.V. 32(3/4): 151-160.

Coman M. \& Roşca I. (2011): Researches regarding morphological aspects of Napomyza gymnostoma Loew. Scientific Papers, UASVM (University of Agronomic Sciences and Veterinary Medicine of Bucharest) Scientific Papers - Series A, Agronomy 54: 360-365.

Commission of the European Communities (2002): Commission Directive 2002/36/EC of 29 April 2002, amending certain Annexes to Council Directive 2000/29/EC on protective measures against the introduction into the Community of organisms harmful to plants or plant products and against their spread within the Community. - Official Journal of the European Communities (Series L) 116: 16-26.

Černý M. (2005a): Amauromyza (Amauromyza) maltensis sp. n. (Diptera: Agromyzidae) with an account of agromyzid mining flies from the Republic of Malta. - Folia heyrovskyana 12(2-3): 85-104.

- (2005b): Additional notes on the fauna of Agromyzidae (Diptera) in Switzerland. - Revue suisse de Zoologie 112(4): 771-805.

- (2005c): A new species of Pseudonapomyza from Egypt, with notes on distribution of some other Palaearctic species of the genus (Diptera: Agromyzidae). In: Kubík Š. \& Barták M. (eds): Dipterologica bohemoslovaca 11. - Folia Facultatis Scientiarum Naturalium Universitatis Masarykianae Brunensis - Biologia 109 (2004): 95-100.

- (2006): Additional records of Agromyzidae (Diptera) from Italy (pp. 19-32). In: Kinkorová J. (ed): Dipterologica bohemoslovaca 13. - Acta Universitatis Carolinae biologica 50: 1-158.

- (2007a): New faunistic records of Agromyzidae Fallén (Diptera) from Andorra including description of three new species. - Boletín Sociedad entomológica aragonesa 41: 43-51.

- (2007b): Description of eight new species of Agromyzidae (Diptera) from North Korea, including new records. - Studia dipterologica 14(1): 209-229.

- (2008): Agromyzidae (p. 328). In: Borges P.A.V., Abreu C., Aguiar A.M.F., Carvalho P., Jardim R., Melo I., Oliveira P., Sérgio C., Serrano A.R.M. \& Vieira P. (eds.): A list of the terrestrial fungi, flora and fauna of Madeira and Selvagens archipelagos, 438 pp. Direcçao Regional do Ambiente da Madeira and Universidade dos Açores, Funchal and Angra do Heroísmo.

- (2009): New faunistic data on the Agromyzidae (Diptera) from the West Palaearctic Region. - Klapalekiana 45: 9-21.

- (2010): Diptera - Agromyzidae (p. 223). In: Borges P.A.V., Costa A., Cunha R., Gabriel R., Gonçalves V., Martins A.F., Melo I., Parente M., Raposeiro P., Rodrigues P., Santos R.S., Silva L., Vieira P. \& Vieira V. (eds.) A list of the terrestrial and marine biota from the Azores. Princípia, Cascais, $432 \mathrm{pp}$.

- (2011a): Agromyzidae (Diptera) in the vicinity of the Kerkini Lake with descriptions of eight new species from Greece. - Acta entomologica Musei nationalis Pragae 51(1): 299-347.

- (2011b): A review of the species of Cerodontha Rondani (Diptera: Agromyzidae) of Israel, with a new species of the subgenus Poemyza Hendel, 1931. - Israel Journal of Entomology 40 (2010): 117-143.

- (2012): The fauna of Agromyzidae (Diptera) in the Gemer region (Central Slovakia), with descriptions of three new species from Slovakia. - Časopis Slezského Muzea Opava (A), 61: 49-76.

- (2013): Additional records of Agromyzidae (Diptera) from the West Palaearctic Region. - Časopis Slezského Muzea Opava (A), 62: 281-288.

Černý M. \& Heřman P. (2015): Vrtalkovití (Diptera: Agromyzidae) Českého krasu (Leaf-miner flies (Diptera: Agromyzidae) of the Bohemian Karst (central Bohemia, Czech Republic)). - Západočeské entomologické listy 6: 50-65. Online: http://www.zpcse.cz/entolisty/entolisty.html, 12-10-2015.

Černý M. \& Merz B. (2006): New records of Agromyzidae (Diptera) from Palaearctic Region. -Mitteilungen der schweizerischen entomologischen Gesellschaft 79: 77-106.

- (2007): New records of Agromyzidae (Diptera) from the West Palaearctic Region, with an updated checklist for Switzerland. - Mitteilungen der schweizerischen entomologischen Gesellschaft 80: 107-121.

Černý M. \& von Tschirnhaus M. (2014): New records of Agromyzidae (Diptera) from the Afrotropical Region, with a checklist. - Acta Musei Silesiae, Scientiae naturales 63: 159-176.

Černý M. \& Vála M. (2006): New records of Agromyzidae (Diptera) from Cyprus (Pp. 33-42). In: Kinkorová J. (ed): Dipterologica bohemoslovaca 13. - Acta Universitatis Carolinae biologica 50: 1-158. 
Černý M. \& Zlobin V.V. (2008): Pseudonapomyza zambiana Černý, sp. nov. and new records of Pseudonapomyza from Afrotropical region (Diptera: Agromyzidae). - Folia heyrovskyana, Series A 16(3): 8390.

Deeming J.C. (2006): Agromyzidae (Diptera: Cyclorrhapha) from the Arabian Peninsula. - Fauna of Arabia 21: $395-423$

Dempewolf M. (2001): Larvalmorphologie und Phylogenie der Agromyzidae (Diptera). - Dissertation, Fakultät für Biologie, Universität Bielefeld (Germany) [unpublished]. Online at: http://pub.uni-bielefeld.de/publication/ 2305691 .

Đurić Z. \& Hrnčić S. (2015): Napomyza gymnostoma Loew. (Diptera, Agromyzidae) in Banja Luka Region (Republic of Srpska, Bosnia and Herzegovina). - Agroznanje (= Agroknowledge Journal) 15(4) (2014): 383392.

Dursun O., Civelek H.S., Barták M., Kubík Š., Yildirim E.M. \& Černý M. (2015): Contributions to leafminer (Diptera: Agromyzidae) fauna and new records of plant pests and weeds in Turkey. - Türkiye Entomoloji Dergisi (= Turkish Journal of Entomology) 39(2): 159-169.

Erfurth P. \& Plescher A. (1982): Zum Auftreten bakterieller, pilzlicher und tierischer Schaderreger an Heilund Gewürzpflanzen. - Nachrichtenblatt für den Pflanzenschutz in der DDR 37(1): 18-22.

Fahringer J. (1937): Opuscula braconologica. Band IV, Palaearktische Region, Band III, Lieferung 4-6 (Bogen 17-33) (des Gesamtwerkes Lief. 29-31). Fritz Wagner, Wien. Pp. 257-520, I-IX.

Franz H. (1989): Die Nordost-Alpen im Spiegel ihrer Landtierwelt. Eine Gebietsmonographie, umfassend: Fauna, Faunengeschichte, Lebensgemeinschaften und Beeinflussung der Tierwelt durch den Menschen. Universitätsverlag Wagner, Innsbruck. Band VI/2 Diptera Cyclorapha [sic!], 445 pp.

Frey R. (1945): Tiergeographische Studien über die Dipterenfauna der Azoren. I. Verzeichnis der bisher von den Azoren bekannten Dipteren. - Commentationes biologicae 8(10) (1944): 1-114, Tafel I-IV.

- (1949): Die Dipterenfauna der Insel Madeira (Unter Mitwirkung von H. Schmitz, R. Storå und L. Tiensuu). Commentationes biologicae 8(16): 1-47.

Frick K.E. (1951): Parthenogenetic reproduction in Phytomyza plantaginis R.-D., the second reported case in the family Agromyzidae (Diptera). - Science 114(2970): 576.

Gibbs D. (2006): The British species of Cerodontha Rondani,1861 subgenus Cerodontha (Diptera, Agromyzidae), including two species new to the British list. - Dipterists Digest (Second Series) 13(1): 59-64.

Gil-Ortiz R., Martinez M. \& Jiménez-Peydró R. (2010a): New species records of Agromyzidae (Diptera) from Spain. - Journal of entomological Science 45(2): 91-105.

Gil-Ortiz R., Martinez M., Falcó-Gari J.V. \& Jiménez-Peydró R. (2010b): Lista comentada de las especies de Agromyzidae (Diptera) citadas para Andalucía. - Boletin de la Asociación española de Entomologia 34(3-4): 307-321.

Gil-Ortiz R, Falcó-Garí J.V. \& Martinez M. (2011): New species records of Agromyzidae (Diptera) from Portugal. - Bolletim da Sociedade portuguesa de Entomologia 222(VIII-8): 161-169.

Godinho M., Goncalves A., Leite L., Anunciada L. \& Mexia A. (1994). Leafminers (Liriomyza spp.) problems in greenhouses in Portugal: evolution and present situation. - IOBC-WPRS Bulletin 17(5): 199-205.

Greiler H. (1994): Insektengesellschaften auf selbstbegrünten und eingesäten Ackerbrachen. Pp. 1-136 in W. Nentwig, H.-M. Poehling (Eds), Agrarökologie 11. Bern: P. Haupt.

Griffiths G.C.D. (1967): Revision of the Phytomyza syngenesiae group (Diptera, Agromyzidae), including species hitherto known as „Phytomyza atricornis Meigen“. - Stuttgarter Beiträge zur Naturkunde 177: 1-28.

- (1974): Studies on boreal Agromyzidae (Diptera). V. On the genus Chromatomyia Hardy, with revision of Caprifoliaceae-mining species. - Quaestiones entomologicae 10(1): 35-69.

- (1980): Studies on boreal Agromyzidae (Diptera). XIV. Chromatomyia miners on Monocotyledones. Entomologica scandinavica Supplement 13: 1-61.

Guglya Y.A. (2011): A study of the fauna of leaf-miner flies of subfamily Agromyzinae (Diptera: Agromyzidae) of Ukraine. Report 1. 28 new species for the fauna of Ukraine - The Kharkov entomological Society Gazette 19(2): 61-66. In Russian.

- (2012): A study of the fauna of leaf-miner flies of subfamily Agromyzinae (Diptera: Agromyzidae) of Ukraine. Report 2. 15 new species for the fauna of Ukraine. The first record of Melanagromyza provecta (de Meijere, 1910) for Europe - The Kharkov entomological Society Gazette 20(1): 56-62. In Russian.

- (2016): A study of the fauna of leaf-miner flies of the subfamily Agromyzinae (Diptera: Agromyzidae) of Ukraine. Report 3. Eleven new species for the fauna of Ukraine. - The Kharkov entomological Society Gazette 23(2), 2015: 29-38.

Hendel F. (1931-36). 59. Agromyzidae. In: Lindner E. (ed.): Die Fliegen der Palaearktischen Region. Schweizerbart'sche Verlagsbuchhandlung, Stuttgart, 6(2): 570 pp. Stuttgart.

Hering M. (1926): Nachgewiesene parthenogenetische Fortpflanzung bei einer blattminierenden acalyptraten Muscide. (Dipt.). - Zoologischer Anzeiger 68(11-12): 283-287. 
Iwasaki A. (1997): Notes on Phytomyza Leaf-miners (Diptera, Agromyzidae) on Lamiaceae in Japan. - Japanese Journal of Entomology 65(3): 500-501.

- (2000): Agromyzidae (Insecta: Diptera) of Kuril Islands. - Natural History Research, Special Issue 7: 141-162.

Kahanpää J. (2014): Checklist of the leaf-mining flies (Diptera, Agromyzidae) of Finland. In: Kahanpää J. \& Salmela J. (eds) Checklist of the Diptera of Finland. ZooKeys 441: 291-303. doi: 10.3897/zookeys.441.7586.

Karpa A. (2008). Catalogue of Latvian Flies (Diptera: Brachycera). - Latvijas entomologs 46: 4-43.

Lonsdale O. (2017): The Liriomyza (Diptera: Schizophora: Agromyzidae) of Canada \& Alaska. - Zootaxa 4234(1): 1-156.

Mart C., Tursun A.Ö. \& Civelek H.S. (2005): Contributions to the Agromyzidae (Diptera) Fauna of Turkey.Turkish Journal of Zoology 29(4): 357-359.

Martinez M. (2011): Fauna Europaea: Agromyzidae. In: Beuk P. \& Pape T. (2017) Fauna Europaea: Diptera, Flies. Fauna Europaea version 2017.06, http://fauna-eu.org. Hosted by: Museum für Naturkunde in Berlin Leibniz Institute for Evolution and Biodiversity Science.

Martinez M. \& Báez M. (2002): Agromyzidae: 138-142. In: Carles-Tolrá M. \& Andersen H. (coord.). Catálogo de los Diptera de España, Portugal y Andorra (Insecta). Monografias S.E.A. (Sociedad Entomológica Aragonesa), Vol. 8, Zaragoza 2002: 1-323.

Martinez M. \& Etienne J., (2002): Deux remarquables espèces nouvelles d'Agromyzidae (Diptera) des Antilles françaises. - Revue française d'Entomologie 24 (3): 143-150.

Martinez M., Gumez J.-L. \& Munnier P. (1986): Un ravageur mal connu: la mouche mineuse du cambium des peupliers. - Bulletin du Centre de Populiculture du Hainaut 1(1 er trimestre): 26-35.

Morge G. (1978): Diptera Collectionis P. Gabriel Strobl - XII (Verzeichnis der Dipteren-Arten der Kollektion STROBL nach dessen Insekten-Hauptkatalog: "Catalog des naturhistorischen Cabinets von Admont. I.", p. 669-741). - Beiträge zur Entomologie 28(1): 69-168.

Mouna M[ohamed] (1998): [Biodiversité des] Invertébrés terrestres. - Étude Nationale sur la Biodiversité Nationale. Deuxième Rapport nationale sur la Biodiversité du Maroc. Ministère de l'Environnement-PNUE (= Programme des Nations Unies pour l'environnement), Rabat, IV + 125 pp.

Nartshuk E.P. \& Bagachanova A.K. (2010): Leaf-miners flies (Diptera, Agromyzidae) of Yakutia (Russia). Euroasian entomological Journal 9(3): 525-534.

Nartshuk E.P. \& Khruleva O.A. (2011): Plant-feeding Dipterans (Diptera, Chloropidae, Agromyzidae) from Wrangel Island (The Chukchi Sea). - Zoologicheskij Zhurnal 90(9): 1135-1140. (In Russian, Engl summ.; English translation in Entomological Review 91(7) 2011: 849-854).

Nartshuk E.P. \& von Tschirnhaus M. (2017): Leafminer flies (Diptera: Agromyzidae) of the fauna of Russia and adjacent countries: The genus Agromyza Fallén. - Studia dipterologica 22(2) 2015: 215-232.

Neczypor W. (1962): Phytomyza (Napomyza) lateralis Fallén, ein neuer Schädling an Digitalis lanata Ehrh. und Digitalis pupurea L. - Pharmazie 17: 780-782.

Nowakowski J.T. (1973). Monographie der europäischen Arten der Gattung Cerodontha Rond. - Annales zoologici (Warszawa), 31(1): 1-327.

Ostrauskas H., Pakalniškis S. \& Taluntytė L. (2005): Dipterous miners collected in greenhouse areas in Lithuania. - Ekologija 2: 22-28.

Ota A.K. \& Nishida T. (1966): A biological study of Phytobia (Amauromyza) maculosa (Diptera: Agromyzidae). - Annals of the entomological Society of America 59(5): 902-911.

Pakalniskiš S.A. (1997): The Lithuanian Agromyzidae (Diptera). Descriptions of 4 new species and other notes. (Pp. 17-34). In: Skirkevičius A. \& Jonaitis V. (eds): Lietuvos entomologų darbai. Lietuvos entomologu draugijos 30-mečiui, 1996 (= Research of Lithuanian Entomologist[s]. To the Thirty Years of Lithuanian Entomological Society, 1996). Lithuanian entomological Society, Institute of Ecology, Vilnius. 287 pp.

Papp L. (1984): Family Agromyzidae (Pp. 263-343). In: Soós Á. \& Papp L. (eds): Catalogue of Palaearctic Diptera Vol. 9. Akadémiai Kiadó, Budapest. 1-460.

- (2004): Twenty species of Diptera new to Hungary. - Folia entomologica hungarica 65: 135-144.

- (2009): Additions to the Diptera fauna of Hungary. - Folia entomologica hungarica 70: 225-242.

Papp L. \& Černý M. (2015): Agromyzidae (Diptera) of Hungary. Volume 1. Agromyzinae. Pars Ltd, Nagykovácsi, Hungary 2015: 416 pp.

- (2016): Agromyzidae (Diptera) of Hungary. Volume 2. Phytomyzinae I. Pars Ltd, Nagykovácsi, Hungary 2016 : $385 \mathrm{pp}$.

- (2017): Agromyzidae (Diptera) of Hungary. Volume 3. Phytomyzinae II. Pars Ltd, Nagykovácsi, Hungary 2017 : $427 \mathrm{pp}$.

Paşcovici V.D. (1975): Two new serious pests in osier-willow stands in the Iasi subregion of Romania: Phytobia cambii Hend. and Aphrophora salicina Goeze. - Revista Padurilor - Industria lemnului, Celuloza şi Hîrtie, Silvicultura şi Exploatarea Padurilor 90(1): 40-42. [In Romanian].

Petersen F.T. \& von Tschirnhaus M. (2001): Agromyzidae (Pp. 179-182). In: Petersen F.T. \& Meier R. (eds). A Preliminary list of the Diptera of Denmark. - Steenstrupia 26(2): 1-276. 
Ranji H., Karimpour Y. \& Dousti A. (2015): A checklist of the Iranian Agromyzid leaf-miner flies with 11 new records. - Journal of entomological Society of Iran 35(1): 45-55.

Rennie, J[ames] [author not named in the book, attributed to J. Rennie in "Checklist of American imprints"] (1830): The Library of Entertaining Knowledge. - Insect Architecture. Volume I. [Chapter XII. Leaf-mining Caterpillars, pp. 233-238; Bark-mining Caterpillars, pp. 239-240]. - Published under the Superintendendence of the Society for the Diffusion of Useful Knowledge. Lilly \& Wait, Boston and 19 further listed American publishers. xii +420 pp. [Second identical edition by Charles Knight, London; Longman, Rees, Orme, Brown, and Green, London; Oliver \& Boyd, Edinburgh; T. Atkinson \& Co. Glasgow; Wakeman, Dublin; Willmer, Liverpool, and Bines \& Co. Leeds].

Sanabria de Arévalo I. (1994): Insectos minadores (Diptera: Agromyzidae) de la Sabana de Bogotá (Cundinamarca, Colombia). - Revista colombiana de Entomología 20(2): 61-100.

Sasakawa M. (1986): Chinese Agromyzidae (Diptera) in institute of zoology, Academia Sinica. Entomotaxonomia 8(3): 163-171.

- (1996): Oriental Agromyzidae (Diptera) in Bishop Museum, Part 2. - Scientific Reports of Kyoto prefectural University, Human Environment and Agriculture 48: 7-37.

- (2005): Notes on the Japanese Agromyzidae (Diptera). 5. Japanese species of the genus Cerodontha Rondani, with the description of five new species. - Scientific Reports of Kyoto prefectural University, Human Environment and Agiculture 57: 47-64.

- (2006): Agromyzidae (Diptera) from Hong Kong. - Acta Entomologica Sinica 49(5): 835-842.

- (2008): Agromyzidae (Insecta: Diptera) from the Alishan Mountains, Taiwan, with Descriptions of Five New Species. - Species Diversity 13: 133-148.

Saleh M., Rassoul A. \& Al-Saffar H.H. (2013): Survey of the genus Liriomyza Mik. [sic!] (Diptera: Agromyzidae) of Iraq. - Advances in Bioresearch 4(3): 92-94.

Scheirs J., Bruyn L. \& von Tschirnhaus M. (1995): Agromyzidae (Diptera) of the nature reserve "Hobokense polder": faunistics and life-history aspects. - Bulletin et Annales de la Société royale belge de Entomologie 131(2): 191-205.

Shahreki Z., Rakhshani E. \& Sasakawa M. (2012): A Contribution to the agromyzid leaf miners (Diptera: Agromyzidae) of Iran. - Biologica nyssana 3(1): 31-36.

Simoglou K.B., Roditakis E., Martinez M. \& Roditakis N.E. (2008): First record of Phytomyza gymnostoma Loew (Diptera: Agromyzidae) a leaf mining pest of leeks in Greece. - EPPO Bulletin 38(3): $507-$ 509.

Smith R.M., Baker R.H.A., Malumphy C.P., Hockland S., Hammon R.P., Ostojá-Starzewski J.C. \& Collins D.W. (2007): Recent non-native invertebrate plant pest establishments in Great Britain: origins, pathways, and trends. - Agricultural and Forest Entomology 9(4): 307-326.

Spasić R. (1991): The leaf miners (Agromyzidae, Diptera) of wheat in Serbia. - Zaštita bilja (= Plant Protection), Beograd 42(4), 198: 313-323.

Spasić R. (1996): Agromyzidae (Insecta, Diptera). The fauna of Durmitor, 5. Agromyzidae (Insecta, Diptera). The Montenegrin Academy of Sciences and Arts. Special Editions 32, Section of Natural Sciences 18, Podgorica: 107-135. (in 1-180).

Spasić R. \& Spencer K.A. (1992): Agromyzidae (Diptera) u zbirci hrvatskog prirodoslovnog muzeja u Zagrebu (= Agromyzidae (Diptera) in the collection of the Croatian Natural History Museum, Zagreb). - Glasnik Priroidnja Glasnik Priroidnjackog Muzeja u Beogradukog Muzeja u Beogradu. (Bulletin of natural History Museum in Belgrade) 47: 139-143. [In Serbocroatian].

Spencer K.A. (1954): Agromyzidae (Dipt.) in Portugal, including a description of a new species. Entomologist's monthly Magazine 90: 219-221.

- (1965a): The genus Phytoliriomyza Hendel (Agromyzidae, Diptera): a clarification of the four European species, with a list of eight other species now known in the genus. - Annals and Magazine of natural History 13(7): 657-663.

- (1965b): Agromyzidae (Diptera) from the Azores and Madeira. - Boletim do Museum Municipal do Funchal 19(85): 104-110.

- (1976a): The Agromyzidae (Diptera) of Fennoscandia and Denmark. Fauna Entomologica Scandinavica, Vol. 5 Part 1 (1-304), Part 2 (305-606). Scandinavian Science Press Ltd., Klampenborg.

- (1976b): The Agromyzidae of New Zealand (Insecta: Diptera). - Journal of the Royal Society of New Zealand 6(2): 153-211.

- (1976c): Beiträge zur Kenntnis der Fauna Afghanistans. (Agromyzidae, Diptera). - Acta Musei Moraviae Brno 61: 171-173.

- (1977): A revision of the Australian Agromyzidae (Diptera). - Western Australian Museum Perth. Special Publication 8: 3-255.

- (1981): Agromyzidae (Diptera) in Iraq. - Entomologist's Gazette 32(3): 177-180. 
- (1990): Host Specialization in the World Agromyzidae (Diptera). Series entomologica. Kluwer Academic Publishers (Dordrecht, Boston, London) 45: i-xiii, 1-444.

Spencer K.A. \& Steyskal G.C. (1986): Manual of the Agromyzidae (Diptera) of the United States.- United States Department of Agriculture, Agriculture Handbook 638: vi + 478 pp.

Stegmaier C.E. (1967): Some new host plant records and parasites of Phytobia (Amauromyza) maculosa in Florida (Diptera: Agromyzidae). - Florida Entomologist 50(2): 99-101.

Strakhova I.S., Yefremova Z.A., von Tschirnhaus M. \& Yegorenkova E.N. (2013): Комплекс Паразитоидов (Нуmenoptera, Eulophidae) минирующих мух агромизид (Diptera, Agromyzidae) в Среднем Поволжье. (Parasitoid complex (Hymenoptera, Eulophidae) of mining flies (Diptera, Agromyzidae) in the middle Volga river basin). - Zoologicheskij zhurnal 92(5): 553-561. (In Russian, English summary; English translation in Entomological Review 93(7) 2013: 865-873).

Suh S.J. \& Kwon Y.J. (1998): Classification of the Genus Agromyza Fallén from Korea (Diptera: Agromyzidae). - Korean Journal of Entomology 28(4): 295-299.

Süss L. (1999): Su alcuni Agromizidi recentemente raccolti in Italia. - Bollettino di Zoologia agraria e di Bachicoltura, Ser. II, 31(2): 127-137.

- (2003): Ulteriori reperti di Ditteri Agromyzidi in Italia. [New records of leaf miners (Diptera Agromyzidae) in Italy]. - Bollettino di Zoologia agraria e di Bachicoltura, Ser. II, 35: 177-180.

Thuneberg E. (1960): Finnische Entomologische Gesellschaft. Referat. Monatsversammtung 3.XII.1959. Coleoptera, Diptera, Homoptera: Neu für die Fauna des Landes. - Annales entomologici fennici 26(4): (291), 293, (300), 301. (In Finish and German).

Vála M. \& Černý M. (2009): Agromyzidae. Pp. 221-235. In: Roháček J. \& Ševčík J. (eds): Diptera of the Pol'ana Protected Landscape Area - Biosphere Reserve (Central Slovakia). SNC SR, Administration of the PLA - BR Pol'ana, Zvolen, 340 pp.

van Achterberg C. (2014): Notes on the checklist of Braconidae (Hymenoptera) from Switzerland. Mitteilungen der schweizerischen entomologischen Gesellschaft 58: 191-213.

von Tschirnhaus M. (1969): Zur Kenntnis der Variabilität, Eidonomie und Verwandtschaft bemerkenswerter Agromyzidae (Diptera). - Senckenbergiana biologica 50(3/4): 143-157.

- (1981): Die Halm- und Minierfliegen im Grenzbereich Land-Meer der Nordsee. Eine ökologische Studie mit Beschreibung von zwei neuen Arten und neuen Fang- und Konservierungsmethoden (Diptera: Chloropidae et Agromyzidae). - Spixiana Supplement 6: 1-405, Taf. 1-11.

- (1991): New results on the ecology, morphology, and systematics of Agromyzidae (Diptera). - Pp. 285-313 in: Weismann L., Országh I. \& Pont A.C. (eds): Proceedings of the 2nd international Congress of Dipterology held in Bratislava, Czechoslovakia, August 27 - September 1, 1990. - 368 pp.; VEDA, Publishing House of the Slovak Academy of Sciences, Bratislava \& SPB Academic Publishing, The Hague.

- (1994): Minierfliegen (Diptera: Agromyzidae) aus Malaise-Fallen in spezifischen Pflanzengesellschaften: Ein Weinberg der Ahr-Eifel in Entwicklung zu einem Felsenbirnen-Gebüsch (Cotoneastro-Amelanchieretum). Beiträge zur Landespflege in Rheinland-Pfalz 16 (1993): 481-534.

Wirta H., Várkonyi G., Rasmussen C., Kaartinen R., Schmidt N.M., Hebert P.D.N., Barták M., Blagoev G., Disney H., Ertl S., Gjelstrup P., Gwiazdowicz D.J., Ilmonen J., Jakovlev J., Jaschhof M., Kahanpää J., Kankaanpää T., Krogh P.H., Labbee R., Lettner C., Maw E., Michelsen V., Nielsen S.A., Nielsen T.R., Paasivirta L., Pedersen S., Pohjoismäki J., Salmela J., Vilkamaa P., Väre H., von Tschirnhaus M. \& Roslin T. (2016): Establishing a community-wide DNA barcode library as a new tool for arctic research. - Molecular Ecology Resources 16: 809-822.

Woodroffe G.E. \& Southgate, B.J. (1952): Dacnusa didas Nixon (Hym., Braconidae) and Syntomopus thoracicus Walk. (Hym., Pteromalidae) bred from Napomyza lateralis (Fall.) (Dipt., Agromyzidae). Entomologist's monthly Magazine 88: 46.

Zlobin V.V. (1979): Mining flies of the genus Cerodontha Rond. (Diptera, Agromyzidae) from the USSR. I. Sugenus Cerodontha s. str. - Entomologičeskoe obozrenie, 57(4): 873-882. (In Russ.)

- (1994a): Review of mining flies of the genus Napomyza Westwood (Diptera: Agromyzidae). IV. Palaearctic species of lateralis-group. - Dipterological Research 5(1): 39-78.

- (1994b): Review of mining flies of the genus Napomyza Westwood (Diptera: Agromyzidae). V. Phytomyza species currently placed in the genus Napomyza Westwood. - Dipterological Research 5(4): 289-311.

- (1995): Review of mining flies of the genus Metopomyza Enderlein (Diptera: Agromyzidae). - International Journal of dipterological Research 6(2): 143-168.

- (2001): Review of mining flies of the genus Napomyza Westwood (Diptera: Agromyzidae). VI. First record of Napomyza species from Oriental region. - International Journal of dipterological Research 12(1): 43-47.

- (2003a): Review of mining flies of the genus Liriomyza Mik (Diptera: Agromyzidae). I. The Palaearctic flaveolagroup species. - International Journal of dipterological Research 13(3) 2002: 145-178. 
- (2003b): Contribution to the knowledge of the genus Pseudonapomyza Hendel (Diptera: Agromyzidae), with descriptions of twenty four Old World species. - International Journal of dipterological Research 13(4): 205245.

- (2005): A revised check list of Swedish Agromyzidae (Diptera). - International Journal of dipterological Research 16(3): 167-181.

Authors' addresses: Miloš Černý, CZ-763 63 Halenkovice 1, Czech Republic.

E-mail: cerny.milos@centrum.cz

Rui Andrade, Rua Calouste Gulbenkian 237 4H3, 4050-145 Porto, Portugal.

E-mail: ruiamandrade@yahoo.com

Ana Rita Gonçalves, Computational Biology \& Population Genomics Group, cE3c Centre for Ecology, Evolution and Environmental Changes, Departamento de Biologia Animal, Universidade de Lisboa, Portugal.

E-mail: anagoncalvesm@gmail.com

Michael von Tschirnhaus, Fakultät Biologie, Universität Bielefeld, Postfach 100131 , 33501 Bielefeld, Germany.

E-mail: m.tschirnhaus@uni-bielefeld.de 